\title{
UNHA COMO BIOMARCADOR DE EXPOSIÇÃO SUBCRÔNICA AO FLÚOR A PARTIR DO DENTIFRÍCIO FLUORETADO EM CRIANÇAS DE 2 - 3 ANOS
}

MARIA HELOÍSA CORRÊA RODRIGUES

Dissertação apresentada à
Faculdade de Odontologia de
Bauru, da Universidade de São
Paulo, como parte dos requisitos
para obtenção do título de Mestre
em Odontologia, área de Saúde
Coletiva

(Edição Revisada) 


\section{UNHA COMO BIOMARCADOR DE EXPOSIÇÃO SUBCRÔNICA AO FLÚOR A PARTIR DO DENTIFRÍCIO FLUORETADO EM CRIANÇAS DE 2 - 3 ANOS}

MARIA HELOÍSA CORRÊA RODRIGUES

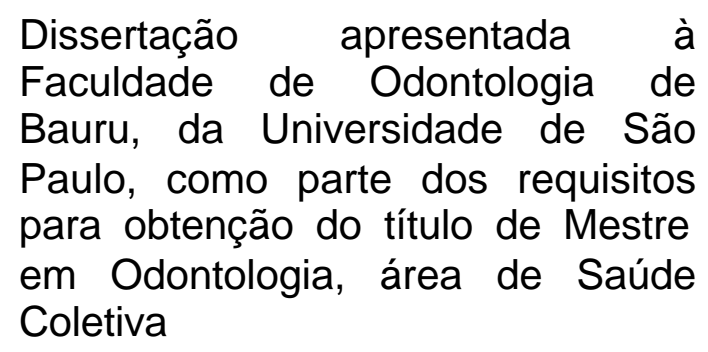

(Edição Revisada)

Orientadora: Prof ${ }^{a}$ Dra. Marília Afonso Rabelo Buzalaf 


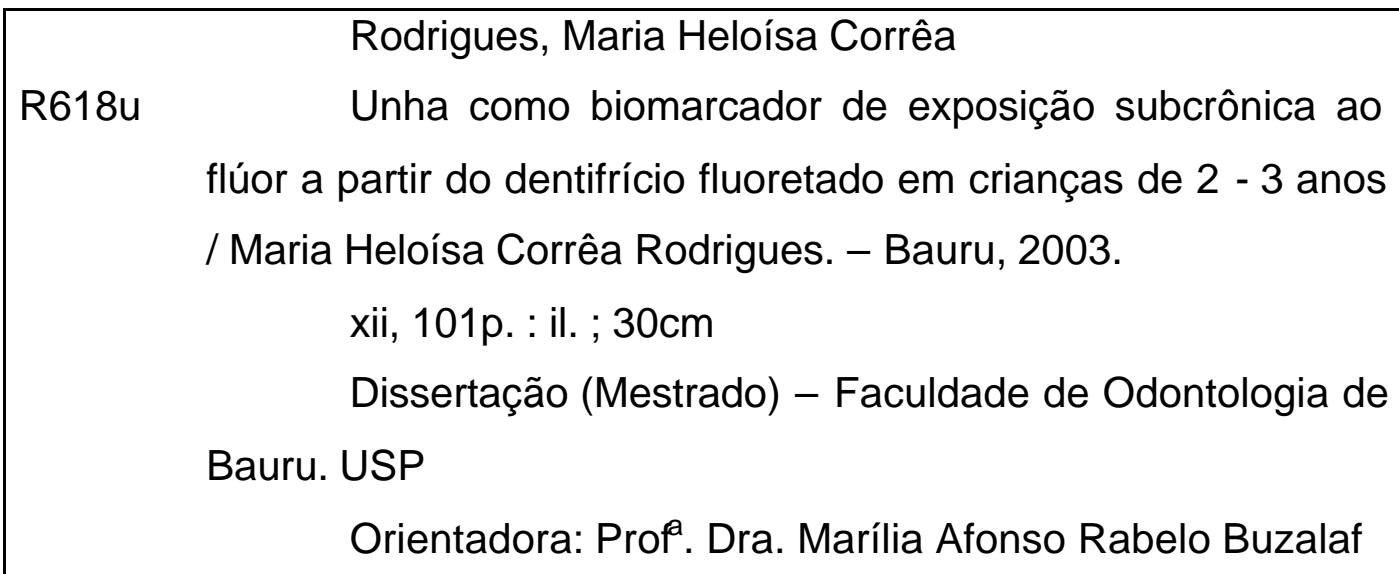

Autorizo, exclusivamente para fins acadêmicos e
científicos, a reprodução total ou parcial desta dissertação, por
processos fotocopiadores e/ou meios eletrônicos.
Assinatura do autor (a): Maria Heloísa Corrêa Rodrigues
Data: 7 de maio de 2003




\section{MARIA HELOÍSA CORRÊA RODRIGUES}

14 de fevereiro de 1975

$1993-1996$

1997

$1998-1999$

Associações
Nascimento - Presidente Prudente - SP

Curso de Odontologia - Universidade do Sagrado Coração - Bauru - SP

Curso de Aperfeiçoamento em Odontologia Preventiva, ministrado na PREV

Curso de Especialização em Odontologia em Saúde Coletiva - Faculdade de Odontologia de Bauru - Universidade de São Paulo

CROSP - Conselho Regional de Odontologia de São Paulo

APCD - Associação Paulista dos CirurgiõesDentistas

SBPqO - Sociedade Brasileira de Pesquisa Odontológica 


\begin{abstract}
A Deus,
Pois sem Ele nada seria possível.

Possibilitando força e saúde para mais uma conquista, nesta passagem, que é a vida.
\end{abstract}

Aos meus pais, Mariano e Risoleta,

Por fazerem parte de minha vida e pela oportunidade de continuar me aperfeiçoando em minha carreira profissional.

Ao meu namorado Julio Cesar,

Por nas horas de maiores dificuldades transformá-las em alegres.

Às minhas irmãs, Maria Cecília e Maria Cristina

pelo apoio, mesmo longe.

Dedico este trabalho. 


\title{
AGRADECIMENTO ESPECIAL
}

\author{
À Prof ${ }^{a}$ Dr $^{\text {a }}$ Marília Afonso Rabelo Buzalaf, pois a conclusão deste \\ trabalho teria sido inatingível sem seu apoio, palavras de coragem, \\ orientação valiosa e constante. E principalmente pela oportunidade de \\ compartilhar de seus conhecimentos e ter o privilégio de sua convivência e \\ amizade.
}




\section{AGRADECIMENTOS}

Ao Prof. Dr. José Roberto de Magalhães Bastos, pelo incentivo, conhecimentos partilhados e a oportunidade dada de estar sempre me aperfeiçoando.

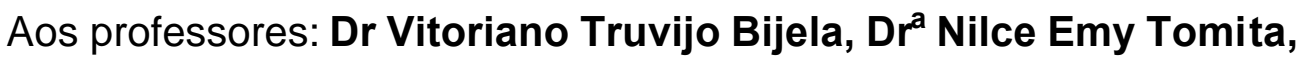
Ms Arsênio Sales Peres e Ms Silvia Helena Sales Peres, professores do Departamento de Odontopediatria, Ortodontia e Saúde Coletiva, meus sinceros agradecimentos.

Ao Prof. Dr. José Roberto Pereira Lauris, pela realização das análises estatísticas e pelos conhecimentos transmitidos.

Aos amigos de turma: Flávia, José Mauro, Patrícia, Rosana, Selma e Soraia

"Nenhum caminho é longo demais quando um amigo nos acompanha" 
Ao Prof. Dr. José Mauro Granjeiro, professor do Departamento de Bioquímica, meu muito obrigada.

Aos pais e crianças participantes deste estudo, pela fundamental e efetiva colaboração.

Aos funcionários Silvia, Marta, Helena, Rosa e Cleide do Departamento de Odontopediatria, Ortodontia e Saúde Coletiva, pela boa vontade e simpatia.

Aos alunos de graduação, pós-graduação e funcionários do Departamento de Bioquímica, Thelma, Ovídio, Gilmar e Pâmela, pela colaboração.

À Tatiana Furlani pela valiosa colaboração no processo analítico deste estudo.

À Faculdade de Odontologia de Bauru, na pessoa de sua Excelentíssima Diretora, $\operatorname{Prof}^{\mathrm{a}} \mathrm{Dr}^{\mathrm{a}}$ Maria Fidela de Lima Navarro. 


\section{SUMÁRIO}

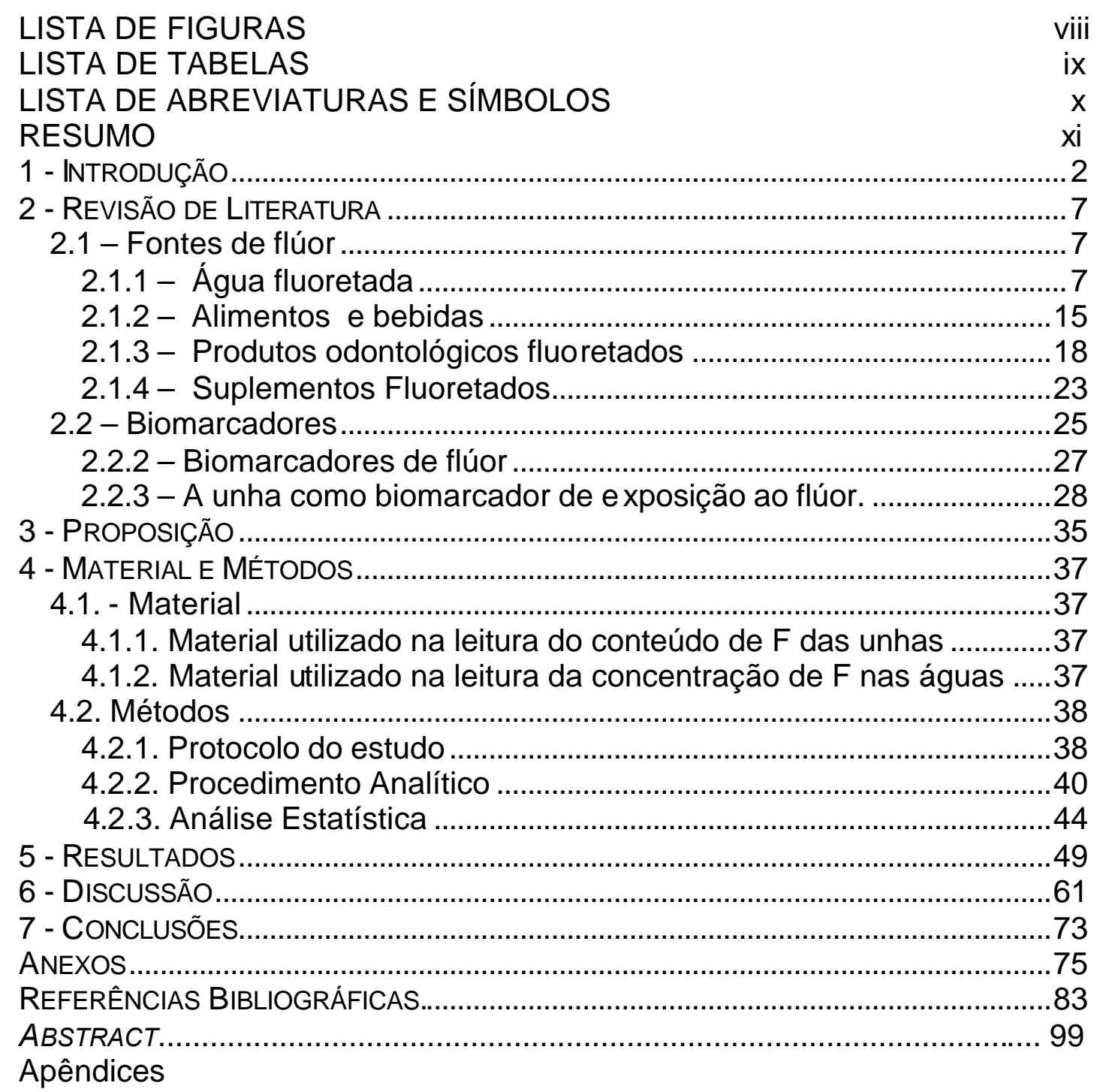




\section{LISTA DE FIGURAS}

FIGURA 1 - Corte sagital esquemático de unha em um dedo da mão.

FIGURA 2 - Placa de Petri vaselinada. Adição das amostras de unhas com $2 \mathrm{~mL}$ de água deionizada.

FIGURA 3 - $\quad$ Adição de $50 \mu \mathrm{L}$ de $\mathrm{NaOH} 0,05 \mathrm{M}$ na tampa da placa de Petri distrubuídos em 3 gotas...

FIGURA 4 - Fechamento das placas e adição de $2 \mathrm{~mL}$ HMDS.

FIGURA 5 - Vedamento imediato do orifício com vaselina e parafilme.

FIGURA 6 - $\quad$ As gotas de $\mathrm{NaOH}$ foram combinadas numa única gota, tamponada com $25 \mu \mathrm{L}$ de ácido acético e o volume total foi ajustado para $75 \mu \mathrm{L}$ com água deionizada.

FIGURA 7 - A leitura foi feita com eletrodo Orion 9409 e um micro eletrodo calomelano de referência.

FIGURA 8 - $\quad$ Concentração de $F(\mu \mathrm{g} / \mathrm{g})$ nas unhas das mãos e dos pés ao longo do tempo. Foi usado dentifrício placebo entre 29/11 e 27/12, dentifrício fluoretado (1500 ppm F) entre 28/12 e 24/01 e dentifrício placebo entre 25/01 e $21 / 02$, quando as crianças retomaram ao seu dentifrício habitual.

FIFURA 9 - Concentração média de $\mathrm{F}$ (ppm) na água de abastecimento das residências dos voluntários.

FIGURA 10 - Correlação entre a concentração de $F(\mu \mathrm{g} / \mathrm{g})$ nas unhas das mãos e dos pés. 


\section{LISTA DE TABELAS}

TABELA 1 - Concentração de íon flúor segundo a média das temperaturas anuais

TABELA 2 - Dosagem de suplemento fluoretado recomendada por dia em mg

TABELA 3 - Concentração média ( $(\mathrm{DP})$ de $F(\mu \mathrm{g} / \mathrm{g})$ nas amostras de unhas das mãos por datas e voluntários.

TABELA 4 - Concentração média ( $($ DP) de $F \mu \mathrm{g} / \mathrm{g}$ ) nas amostras de unhas dos pés por datas e voluntários.

TABELA 5 - Concentração média $( \pm D P)$ de $F \mu(\mu / g)$ nas amostras das unhas das mãos e dos pés, nas diferentes coletas..

TABELA 6 - Concentração média de $F$ (ppm) na água de 56 abastecimento das residências dos voluntários.

TABELA 7 - Hábitos de escovação das crianças antes do início do 58 experimento. 


\section{LISTA DE ABREVIATURAS E SÍMBOLOS}

$\begin{array}{ll}\text { CDTA } & \text { ácido ciclo-hexano diamino tetra acético } \\ \mathrm{DP} & \text { desvio padrão } \\ \mathrm{F} & \text { Flúor } \\ \mathrm{HCl} & \text { ácido clorhídrico } \\ \mathrm{HF} & \text { ácido fluorídrico } \\ \mathrm{HMDS} & \text { hexametil-disilazano ou hexametil-disiloxano } \\ \mathrm{M} & \text { molar (mol/L) } \\ \mu \mathrm{g} & \text { Micrograma } \\ \mathrm{mL} & \text { Mililitro } \\ \mathrm{mg} & \text { Miligrama } \\ \mathrm{mV} & \text { Milivoltagem } \\ \mathrm{NaOH} & \text { hidróxido de sódio } \\ \mathrm{NaF} & \text { fluoreto de sódio } \\ \mathrm{OH} & \text { ĺon hidroxila } \\ \mathrm{r} & \text { Coeficiente de correlação } \\ \mathrm{p} & \text { nível de significância } \\ \mathrm{ppm} & \text { partes por milhão } \\ \mathrm{TISAB} & \text { "total ionic exchange adjustment buffer" }\end{array}$




\section{RESUMO}

O objetivo deste estudo foi avaliar o uso das unhas das mãos e dos pés como biomarcadores de exposição subcrônica ao flúor $(F)$ a partir do dentifrício fluoretado em crianças de 2-3 anos de idade. Dez crianças utilizaram dentifrício placebo (sem F) durante 28 dias, dentifrício fluoretado (Sorriso,1570 ppm) por mais 28 dias e dentifrício placebo por mais 28 dias, quando retornaram ao seu dentifrício usual. A escovação foi realizada 3 vezes/dia com uma quantidade de dentifrício do tamanho de uma ervilha. As unhas foram cortadas a cada duas semanas, durante o período experimental e por mais 22 semanas. A concentração de $F$ das unhas foi analisada com 0 eletrodo íon específico (Orion 9409) após difusão facilitada por HMDS. Os dados foram analisados por análise de variância a dois critérios e teste de Tukey $(p<0,05)$. Não houve diferença estatisticamente significante entre a concentração de $F$ nas unhas das mãos e dos pés. As médias nas concentrações de $F( \pm D P)$ nas 4 primeiras semanas e nas últimas 6 semanas foram 2,709 $( \pm 0,971)$ e 2,698 $( \pm 1,167) \mu \mathrm{g} / \mathrm{g}$, nas unhas das mãos e dos pés, respectivamente. $O$ pico na concentração de $F$ ocorreu na 112 dias depois do início do uso do dentifrício fluoretado e foi 10,051 $( \pm 3,328)$ e 9,186 $( \pm 3,862) \mu \mathrm{g} / \mathrm{g}$ para unhas das mãos e dos pés, respectivamente. Isto indicou que o $\mathrm{F}$ entra nas unhas através da extremidade de crescimento. Um pequeno, mas significativo na concentração de $\mathrm{F}$ nas unhas ocorreu 28 dias após de iniciado o uso de dentifrício fluoretado $(7,251 \pm 5,682$ e 5,612 $\pm 4,627$ $\mu \mathrm{g} / \mathrm{g}$, para unhas das mãos e dos pés, respectivamente). Isto sugere que o $\mathrm{F}$ 
também entra através do leito da unha. Os resultados indicam que as unhas das mãos e dos pés são biomarcadores apropriados de exposição subcrônica ao F a partir do dentifrício fluoretado em crianças jovens. 
INTRODUCÃO 


\section{1- INTRODUÇÃO}

O F é o $13^{\circ}$ elemento mais encontrado na superfície da terra e sua utilização tem possibilitado um declínio na prevalência de cárie dentária, resultando numa melhora significativa na saúde bucal da população, tanto dos países industrializados como também dos países em desenvolvimento. Porém, tem-se notado que simultaneamente a esse declínio da cárie dentária, a prevalência de fluorose dentária tem aumentado em comunidades fluoretadas e não fluoretadas (LEVERETT ${ }^{55}$, 1986; JACKSON et al. ${ }^{52}$, 1999; TSUTSUI et al. ${ }^{96}, 2000$; TABARI et al. ${ }^{91}$, 2000).

A fluorose dentária é um defeito do esmalte resultante da exposição à ingestão crônica excessiva de $\mathrm{F}$ durante o período de formação dos dentes (SZPUNAR; BURT $^{90}, 1988 ;$ PENDRYS; KATZ ${ }^{73}$, 1989). O grau de manifestação da fluorose depende da dose total de F ingerida, do tempo de duração da exposição e também da resposta individual de cada um. A resposta individual se refere à massa corpórea, fatores nutricionais, taxa de crescimento ósseo, alteração da atividade renal e homeostasia de cálcio (DENBESTEN $\left.{ }^{30}, 1994\right)$. Entretanto, o fator de risco mais importante para a ocorrência e grau da fluorose dentária é a quantidade total de fluoreto consumida de todas as fontes durante o período crítico de desenvolvimento dos dentes (DENBESTEN ${ }^{31}$, 1999; FOMON; EKSTRAND; ZIEGLER ${ }^{40}$, 2000; MASCARENHAS $\left.{ }^{61}, 2000\right)$. 
ISHII; SUCKLING ${ }^{51}$ (1991) relataram que o período crítico de exposição para toda a dentição permanente é entre 11 meses e 7 anos de idade. A ingestão excessiva de $\mathrm{F}$ por crianças acima de 7 anos não causará fluorose dentária. Entretanto, a faixa de maior risco para a ocorrência de fluorose dentária nos incisivos centrais superiores permanentes, dentes com grande comprometimento estético, é de 15 a 24 meses de idade para os meninos e de 21 a 30 meses para meninas (EVANS; DARVELL ${ }^{37}, 1995$ ).

OPHAUG; SINGER; HARLAND ${ }^{69}$ (1980) afirmaram que a ingestão diária de $\mathrm{F}$ entre 0,05 e $0,07 \mathrm{mg} / \mathrm{kg}$ peso corporal/dia "é geralmente considerado ótima". FORSMAN ${ }^{41}$ (1977) relatou que a fluorose dentária ocorre provavelmente quando a ingestão de $\mathrm{F}$ por crianças excede 0,1 $\mathrm{mg} / \mathrm{kg}$ peso corporal/dia. No entanto, trabalhos realizados no Quênia mostraram fluorose dentária com ingestão média de $\mathrm{F}$ tão baixa quanto 0,04 $\mathrm{mg} / \mathrm{kg}$ peso corporal/dia (BAELUM et al. ${ }^{4}$, 1987). Também FEJERSKOV; BAELUM; RICHARDS ${ }^{38}$ (1996) consideraram que a fluorose dentária poderia ocorrer com doses muito mais baixas que as relatadas até então, observando alterações com doses em torno de $0,02 \mathrm{mg}$ de $\mathrm{F} / \mathrm{kg}$ peso corporal/dia. Deste modo, pode-se afirmar que a dose "ótima" de ingestão de F adequada para a prevenção de cárie dentária e a não ocorrência de fluorose dentária clinicamente inaceitável ainda não é precisamente conhecida (GUHA-CHOWDHURY; DRUMMOND; SMILLIE $\left.{ }^{44}, 1996\right)$.

Sendo a fluorose considerada um efeito sistêmico em resposta à ingestão total de $\mathrm{F}$ e à sua absorção, todas as fontes que contribuem para a 
ingestão total deste íon devem ser consideradas. Atualmente as maiores fontes de ingestão de $\mathrm{F}$ para indivíduos acima de 1 ano de idade são alimentos e bebidas, água de beber e produtos odontológicos fluoretados (BURT $^{9}$, 1992; WHITFORD ${ }^{101}$, 1994; FOMON; EKSTRAND ${ }^{39}, 1999 ;$ FOMON; EKSTRAND; ZIEGLER ${ }^{40}$, 2000; MASCARENHAS ${ }^{61}, \quad 2000$; BUZALAF; CURY; WHITFORD $\left.{ }^{10}, 2001\right)$.

Os dentifrícios, que são os produtos odontológicos mais freqüentemente usados, contêm uma concentração de $F$ variando entre 500 e 1500 ppm. Desde que o dentifrício fluoretado foi introduzido no mercado, a prevalência e a severidade da cárie dentária tem declinado enquanto a prevalência da fluorose dentária tem aumentado (WARREN; LEVY ${ }^{99}$, 1999). Enquanto o declínio da cárie pode ser largamente atribuído ao uso difundido do dentifrício fluoretado, como também às outras fontes de $\mathrm{F}$ (LEVERETT ${ }^{55}$, 1986; JACKSON et al. ${ }^{52}$, 1999; TABARI et al. $\left.{ }^{91}, 2000\right)$, estudos recentes têm atribuído o aumento da prevalência da fluorose dentária ao uso precoce do dentifrício fluoretado (EVANS; STAMM ${ }^{36}$, 1991; MASCARENHAS; BURT², 1998; WARREN; LEVY99 , 1999; PEREIRA et al. $^{78}$, 2000; RIORDAN $^{83}$, 2002; BUZALAF et al. $\left.{ }^{16}, 2002\right)$

Devido ao aumento da prevalência da fluorose dentária, a investigação dos biomarcadores de exposição ao $\mathrm{F}$ que sejam de fácil coleta e análise deve ser intensificada (CLARKSON $\left.{ }^{21}, 2000\right)$. A coleta das unhas é simples e não-invasiva, e há muitos estudos sugerindo o uso das unhas como biomarcadores de exposição ao $\mathrm{F}$ em animais (BUZALAF et al. ${ }^{15}$, 
2002) e humanos (SCHAMSCHULA et al. ${ }^{86}$, 1985; MACHOY ${ }^{58}, 1989$; CZARNOWSKI et al. ${ }^{27}, 1996$; WHITFORD et al. $\left.{ }^{103}, 1999\right)$. Tanto as unhas das mãos como as unhas dos pés têm sido usadas para este objetivo, mas a literatura é contraditória quando compara os níveis de $\mathrm{F}$ presentes nas unhas das mãos com aqueles presentes nas unhas dos pés MACHOY ${ }^{58}$, 1989; WHITFORD et al. ${ }^{103}, 1999$ ). Além disso, não há um estudo longitudinal enfocando o uso das unhas como biomarcadores de exposição subcrônica ao $\mathrm{F}$ a partir do dentifrício fluoretado. 
REVISÃO DE LITERATURA 


\section{2 - REVISÃO DE LITERATURA}

É extremamente importante ressaltar que investigações recentes e revisões de literatura têm confirmado a segurança do $\mathrm{F}$ com relação à saúde humana, quando usado conforme recomendado para o controle da cárie. Entretanto, sabe-se há muito que a característica clínica mais precoce da exposição à ingestão crônica excessiva de $\mathrm{F}$ por crianças pequenas é a fluorose dentária, que, por sinal, aumentou desde a última metade do século passado (Clark $\left.{ }^{20}, 1994\right)$.

Este aumento na incidência e severidade da fluorose dentária tem sido atribuído à ingestão excessiva de $\mathrm{F}$ na fase de desenvolvimento dos dentes, em suas mais variadas fontes: água fluoretada, alimentos e bebidas, ingestão inadvertida de dentifrício fluoretado e o inapropriado uso de suplementos dietéticos.

\section{1 - FONTES DE FLÚOR}

\subsection{1 - Água fluoretada}

Em 1901, Jonh Macauley Eager escreveu um relato que foi depois conhecido como a primeira documentação científica no que diz respeito à fluorose dentária $\left(\mathrm{EAGER}^{32}\right.$, 1901). Ele escreveu detalhadamente sobre uma descoloração marrom nos dentes, chamada "denti di chiaie", baseado em 
observações de emigrantes italianos no porto de Nápoles. A causa de tais descolorações foi atribuída provavelmente à água de beber.

Em 1911, McKay ${ }^{66}$ (1933) descreveu a presença de dentes com o esmalte mosqueado em crianças residentes na zona urbana de Colorado Springs, nos Estados Unidos, fato que não ocorria nas que habitavam a zona rural. Mais tarde, em 1916, McKay juntamente, com Black, observaram que as pessoas que residiam na área urbana provida pela água de abastecimento de Colorado Springs e que estavam, naquele momento, no período de formação dentária, apresentavam o manchamento, caracterizando assim uma distrofia endêmica do esmalte dentário. Porém, os indivíduos da área rural desprovida de abastecimento de água não apresentavam os sinais do mosqueamento, sugerindo existir uma relação direta entre a defeito estrutural no esmalte e a presença de alguma substância na água. Também naquele momento, os autores verificaram que as crianças moradoras em áreas que apresentavam o esmalte mosqueado tinham uma prevalência menor de cárie dentária quando comparadas com aquelas residentes em locais desprovidos pelo abastecimento e que não tinham os mesmos sinais de mosqueamento do esmalte.

Em 1942, Dean realizou um relevante estudo conhecido como o "Estudo das 21 cidades", que procurou responder qual a concentração de F na água provocava o mosqueamento dentário, ao mesmo tempo em que buscou descobrir concentrações capazes de uma ação preventiva e eficaz na redução da cárie dentária. Os resultados deste estudo mostraram uma 
redução de 50\% na experiência de cárie dentária em concentrações de 0,6 ppm quando comparada com a concentração de 0,2 ppm, e uma redução de mais de $60 \%$ em concentrações de 1,2 ppm, salientando a possibilidade de controle da cárie por meio da fluoretação controlada e de níveis adequados da água de abastecimento. Neste estudo foi determinado que o $\mathrm{F}$ presente na água em concentrações em torno de 1 ppm promovia a máxima redução no índice CPOD sem, no entanto, provocar o aparecimento de manchas antiestéticas e que, quando o nível de F na água excedia a 1,5 ppm, não ocorria queda significativa no índice CPOD, porém havia um aumento na ocorrência e na severidade da fluorose (DEAN $\left.{ }^{28}, 1950\right)$.

No entanto, os primeiros estudos controlados da fluoretação artificial datam de 1945. O "momento da verdade na história da fluoretação das águas”, conforme descrito por Frank McClure (McCLURE $\left.{ }^{63} 1970\right)$, teve início em 25 de janeiro de 1945, quando Grand Rapids, Michigan, Estados Unidos da América, tornourse a primeira cidade do mundo a ajustar sua concentração de $\mathrm{F}$ na água visando à promoção da saúde dentária. Logo depois, a fluoretação foi implantada em outras cidades dos EUA e mais tarde em outros países.

No Brasil, a primeira cidade a fluoretar artificialmente suas água foi Baixo Guandu, no Espírito Santo, em 1953 (VIEGAS ${ }^{97}$, 1987). No entanto,

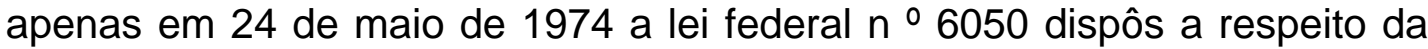
fluoretação da água em sistemas públicos de abastecimento ${ }^{8}$, sendo

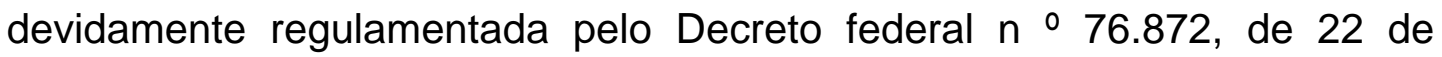


dezembro de 1975. A Portaria do Ministério da Saúde nํ 635/Bsb, de 26 de dezembro de 1975, aprovou e determinou normas e padrões a serem seguidos para a correta fluoretação das águas dos sistemas de abastecimento, desde a concentração de íon F a ser utilizada de acordo com a média das temperaturas máximas anuais de cada região (TABELA 1), até os compostos fluoretados recomendados. Ainda constituem a legislação pertinente, as portarias do Ministério da Saúde $n$ ํ 3.313, de janeiro de 1998, e $\mathrm{n}{ }^{0} 1.469$, de dezembro de 2000 , que estabelecem os procedimentos e as responsabilidades relativas ao controle e à vigilância da qualidade da água para o consumo humano.

VIEGAS $^{97}$, em 1987, ressalta que a fluoretação das águas de abastecimento público é um método adequado, eficiente, seguro, prático e perene. Sendo uma medida ideal de saúde pública para a prevenção da cárie dentária em países onde existam serviços de abastecimento de água. 
Tabela 1. Concentração de íon $F$ recomendada na água de beber em relação à temperatura média da cidade.

\begin{tabular}{cccc}
\hline $\begin{array}{c}\text { Médias das temperaturas } \\
\text { máximas diárias }\left({ }^{\circ} \mathrm{C}\right)\end{array}$ & $\begin{array}{c}\text { Limites recomendados para a concentração } \\
\text { de íon flúor em mg/L } \\
\text { Mínimo }\end{array}$ & Máximo & Ótimo \\
\hline $\mathbf{1 0 - 1 2 , 1}$ & 0,9 & 1,7 & 1,2 \\
$\mathbf{1 2 , 2 - 1 4 , 6}$ & 0,8 & 1,5 & 1,1 \\
$\mathbf{1 4 , 7 - 1 7 , 7}$ & 0,8 & 1,3 & 1,0 \\
$\mathbf{1 7 , 8 - 2 1 , 4}$ & 0,7 & 1,2 & 0,9 \\
$\mathbf{2 1 , 5 - 2 6 , 3}$ & 0,7 & 1,0 & 0,8 \\
$\mathbf{2 6 , 8 - 3 2 , 5}$ & 0,6 & 0,8 & 0,7 \\
\hline
\end{tabular}

Muitos trabalhos têm sido realizados relacionando a água fluoretada com a ocorrência da fluorose dentária. Em 1995, CARMO et al..$^{19}$ realizaram um estudo que relacionou a prevalência de fluorose dentária em áreas com diferentes concentrações de $\mathrm{F}$ na água de consumo. Crianças de 610 escolares na idade de 10-14 anos foram avaliados para o índice de Dean e T-F para a fluorose dentária de três cidades brasileiras, Piracicaba $(0,7$ ppm F), Iracemápolis (0,2 ppm F) e Pereiras (6,4 ppm F). Foram encontradas prevalências de 2,0\%, 20,4\% e 58,8\%, utilizando-se o índice T-F, e de 4,5\%, 20,8\% e 58,8\%, com o índice de Dean, nas cidades de Iracemápolis, Piracicaba e Pereiras respectivamente.

Por outro lado, MALTZ e FARIAS ${ }^{59}$ (1998) também avaliaram a prevalência de fluorose dentária em escolares de cidades brasileiras com e 
sem água de consumo artificialmente fluoretada, no ano de 1987, isto é, anteriormente ao uso disseminado de dentifrício fluoretado. Nas cidades sem água de abastecimento fluoretada a prevalência de fluorose dentária foi praticamente inexistente. Nas duas cidades com água de consumo fluoretada, a prevalência e severidade da fluorose foram bastante baixas, sugerindo que somente o consumo de água artificialmente fluoretada, nas concentrações utilizadas $(0,45-0,96$ ppm F e 0,318-0,721 ppm F), não causa alta prevalência de fluorose dentária.

Numa revisão sistemática acerca da fluoretação da água, McDONAGH et al. ${ }^{64}$ (2000), após análise de 214 estudos, observaram que a fluoretação da água estava associada com um aumento na proporção de crianças livres de cáries e uma redução no número de dentes afetados por cárie. Os autores encontraram ainda um aumento dose-dependente na fluorose dentária, sendo que com um nível de $\mathrm{F}$ de 1 ppm, estimou-se que $12,5 \%$ das pessoas expostas teriam fluorose dentária considerada preocupante do ponto de vista estético. Não foram encontradas evidências claras de outros possíveis efeitos colaterais. Os autores reforçaram a idéia de que qualquer decisão acerca da fluoretação das águas deve considerar não apenas a relação risco (fluorose dentária) - benefício (redução da cárie dentária), mas também aspectos éticos, ambientais, ecológicos, financeiros e legais.

Em Toronto, Canadá, no outono de 1999 a concentração de F na água de abastecimento foi reduzida em 2 estágios (de 1,2 ppm para 1,0 ppm 
e então para $0,8 \mathrm{ppm}$ ). Num levantamento realizado durante o ano escolar de 1999-2000, encontrou-se uma prevalência de fluorose moderada (TSIF $\geq$ 2) em $14 \%$ das crianças de 7 anos de idade e de 12,3\% em crianças de 13 anos. Os autores acreditam que esta prevalência deva cair conforme a redução na concentração de $\mathrm{F}$ na água de abastecimento começar a fazer efeito (LEAKE et al. ${ }^{54}$, 2002).

Em Bauru-SP, BUZALAF et al. ${ }^{14}$ (2002) monitoraram a qualidade da fluoretação da água de abastecimento público em diversos pontos de distribuição. O conteúdo de $\mathrm{F}$ variou de 0,01 a 9,35 ppm. Diante dos resultados os autores recomendaram uma maior vigilância e monitoramento da água da cidade de Bauru.

Em anos recentes, tem havido um aumento no consumo de água mineral no Brasil, bem como em outros países. O conteúdo de $\mathrm{F}$ presente em 104 marcas de água mineral comercialmente disponíveis no Brasil foi analisado por VILLENA; BORGES; CURY ${ }^{98}$ (1996). Os valores encontrados variaram de 0 a 4,4 ppm, mas a grande maioria teve conteúdo de $\mathrm{F}$ abaixo de $0,1 \mathrm{ppm}$.

Em 2001, BASTOS et al. ${ }^{5}$ avaliaram a concentração de $\mathrm{F}$ existente nas fontes naturais e nas águas minerais das cidades de Águas de Lindóia, Lindóia e Serra Negra, região chamada de "Circuito das Águas". Todas as amostras apresentavam concentrações de $F$ abaixo dos limites considerados preventivos de cárie, variando de 0 a 0,46 ppm. Os autores ressaltam a necessidade de divulgação destes dados para que a população 
e os profissionais de saúde sejam alertados para tal fato, uma vez que tem ocorrido o aumento do consumo dessas águas minerais, que são vendidas em todo o território nacional. Além disso, a população da região, consome a água proveniente das fontes naturais, não sendo beneficiada pelo $F$ presente na água de abastecimento público.

GREC et al. ${ }^{43}$ (2003), verificaram a porcentagem da população da cidade de Bauru que consumia água mineral, as marcas consumidas e sua concentração de F especificada no rótulo e a verificada na análise. De 1000 residências visitadas, em $312(31,2 \%)$ consumia-se água mineral e em 688 $(68,8 \%)$ não. Sendo assim, cerca de $29,72 \%$ da população da cidade consome água mineral e 70,28\% não. Em algumas marcas de água mineral, a concentração de $\mathrm{F}$ especificada nos rótulos não foi à mesma encontrada nas análises de F. Segundo os autores os resultados deste estudo reforçam a importância e a necessidade de um controle bastante rigoroso, por parte da vigilância sanitária, na concentração de F nestas águas.

A água fluoretada provavelmente tem um impacto maior na prevalência da fluorose indiretamente, por ser usada na industrialização de leites em pó e outros alimentos e bebidas infantis $\left(B U R T^{9}, 1992\right)$, além de ser utilizada para reconstituir fórmulas infantis. BUZALAF et al. ${ }^{11}$ (2001) realizaram um estudo que avaliou o conteúdo de $F$ em 10 amostras de fórmulas infantis disponíveis no mercado. As amostras foram preparadas com água deionizada, água mineral $(0,02$ a 0,69 ppm) e água fluoretada (0,9 ppm). Quando as fórmulas foram reconstituídas com água deionizada, 
somente a amostra da fórmula à base de soja apresentou uma concentração de $\mathrm{F}$ mais elevada $(0,75 \mathrm{ppm})$. Segundo os autores este achado é coerente com a literatura em relação a produtos à base de soja. Ao utilizarem a água mineral como diluente da fórmula, apenas uma marca comercial de água mineral (Ibirá) apresentou alto teor de F. Mas, a água de abastecimento, o diluente mais utilizado no Brasil, especialmente pela população mais carente, tornourse uma questão preocupante. Todas as marcas de fórmulas, quando reconstituídas com água fluoretada, excederam a ingestão diária ótima de $\mathrm{F}$ recomendada e quase todas poderiam fornecer uma ingestão diária de F acima dos limiares sugeridos para a fluorose em crianças jovens.

\subsection{2 - Alimentos e bebidas}

A maioria dos alimentos tem concentração de $F$ menor que 0,5 ppm (TAVES $\left.{ }^{93}, 1983\right)$, com exceção dos produtos à base de frutos do mar e frango, que podem conter altos níveis de F, sendo que a inclusão de ossos, pele e conchas nestes produtos durante o processo de industrialização contribui muito para estes valores elevados. Os produtos à base de frango podem conter de 0,6 a 10,5 ppm de F (LEVY; KIRITSY; WARREN ${ }^{56}$, 1995; HEILMAN et al. $^{46}$, 1997). Entretanto, TRAUTNER; SIEBERT ${ }^{95}$ (1986) observaram uma reduzida biodisponibilidade do $\mathrm{F}$ para a maioria dos produtos à base de carnes e peixes, provavelmente devido ao alto conteúdo de cálcio destes alimentos. 
As bebidas incluem refrigerantes, sucos de frutas e chás, entre outras. As concentrações de $\mathrm{F}$ nas bebidas refletem aquelas encontradas na água usada para o seu preparo (HEILMAN et al. ${ }^{47}$, 1999). Em geral, variam de 0,1 a 1,4 ppm, exceto para os chás, que podem conter até 7 ppm de $\mathrm{F}\left(\mathrm{CUR} \mathrm{Y}^{25}\right.$, 1981; CLOVIS; HARGREAVES ${ }^{22}$, 1988; PANG; PHILIPPS; BAWDEN¹1, 1992). HEINTZE; BASTOS ${ }^{48}$ (1996) avaliaram a concentração de $F$ de diversas bebidas encontradas no mercado brasileiro como: refrigerantes de vários sabores, sucos, leite, chás. Os resultados indicaram que todas as bebidas, com exceção do chá preto (1,60ppm) e uma água mineral com gás (2,6 ppm), apresentaram concentrações de $\mathrm{F}$ abaixo de 1 ppm, a maioria abaixo de 0,4 ppm.

O conteúdo de $F$ de várias marcas comerciais de chás e sucos encontradas no mercado brasileiro foi avaliado por BUZALAF et al. ${ }^{12}$ (2002), como também foi relacionado com o risco de fluorose dentária. Foram avaliados os seguintes produtos: chá preto para infusão $(n=12)$, chá industrializado pronto para o consumo $(n=15)$, suco em pó $(n=10)$, suco em pó contendo chá $(n=3)$ e suco pronto para o consumo $(n=4)$. Todas as amostras de chá preto para infusão e sucos em pó contendo chá, e duas amostras de chás industrializados pronto para o consumo apresentaram concentração de $F$ mais alta do que $0,7 \mu \mathrm{g} / \mathrm{mL}$. De qualquer modo, se as amostras dos outros produtos fossem reconstituídas com água fluoretada poderiam ser importantes contribuintes para a ingestão total diária de $\mathrm{F}$. Assim, os autores concluíram que o consumo de alguns produtos analisados 
por crianças na idade de risco para a fluorose dentária deveria ser evitado. E a concentração de F destes produtos deveria ser informada em seus rótulos.

BUZALAF et al. ${ }^{17}$ (2003) analisaram a concentração de F em diversas marcas de chocolates e bolachas de chocolate encontradas no mercado nacional, visto que o chocolate e as bolachas de chocolate são bastante apreciados pelas crianças e que alguns dos alimentos analisados podem ser importantes contribuintes para a ingestão diária total de F. Neste caso foi observado em uma marca de bolacha (Danyt's) uma maior concentração de F, considerando que em apenas 3 unidades podem fornecer $40 \%$ da ingestão diária máxima de $\mathrm{F}$ recomendada $(0,07 \mathrm{mg} / \mathrm{Kg}$ peso corporal) para uma criança de 2 anos de idade $(12 \mathrm{Kg}$ ), quando consumidas uma única vez por dia.

Em um recente estudo realizado por BUZALAF et al. ${ }^{13}$ (2002) com o objetivo de avaliar o conteúdo de $\mathrm{F}$ em produtos comumente utilizados por bebês e crianças jovens, foi encontrada na maioria dos produtos baixa concentração de F, exceto em dois cereais (Mucilon e Neston) que tiveram concentração média de $\mathrm{F}$ de 2,430 $\mu \mathrm{g} / \mathrm{g}$ e 6,160 $\mu \mathrm{g} / \mathrm{g}$, respectivamente, e um achocolatado (Toddynho) que teve uma concentração média de F de 1,180 ppm. Surpreendentemente, os produtos que tiveram concentrações de $\mathrm{F}$ mais altas (Mucilon e Neston) foram fabricados em áreas não fluoretadas. Isto significa que a fonte de $\mathrm{F}$ destes produtos não é a água. Com base nos resultados, os autores concluíram que alguns alimentos e bebidas infantis podem ser importantes contribuintes para a ingestão diária total de F e que 
apenas uma porção de Neston (30g em $200 \mathrm{~mL}$ de leite) ou um frasco do Toddynho $(200 \mathrm{~mL})$ correspondem, isoladamente, a $30 \%$ da dose diária máxima de $\mathrm{F}$ para crianças de 2 anos. $\mathrm{O}$ consumo por crianças em idade de risco para a fluorose dentária tem que ser controlado. Os autores também ressaltam que os rótulos dos produtos deveriam fornecer informações sobre seus conteúdos de F.

\subsection{3 - Produtos odontológicos fluoretados}

Os produtos odontológicos fluoretados têm concentrações de F variando entre 230 ppm nas soluções para bochecho até 23000 ppm nos vernizes fluoretados. Os dentifrícios, que são os produtos odontológicos mais freqüentemente usados, contêm uma concentração de $F$ variando de 500 e 1500 ppm, tanto na forma de fluoreto de sódio quanto na forma de monofluorfosfato de sódio (WHITFORD $\left.{ }^{101}, 1994\right)$.

Em 1954, MUHLER et al. ${ }^{68}$ publicaram 0 primeiro relato da capacidade de um dentifrício fluoretado em reduzir a incidência de cárie dentária em crianças. Seguindo-se à confirmação destes resultados, em 1964 foi aceito o primeiro dentifrício fluoretado pelo Conselho de Terapêutica Dentária da American Dental Association. A partir de então houve a disseminação do uso de dentifrícios fluoretados, sendo que em 1980, todos os dentifrícios vendidos nos EUA continham F. 
No Brasil, a portaria $n^{0} 22^{7}$, de 20 de dezembro de 1989 estabeleceu normas que regulamentam a incorporação de $\mathrm{F}$ nos dentifrícios (sem obrigatoriedade), estabelecendo uma concentração mínima de 1000 e máxima de 1500 ppm de F solúvel no momento da fabricação, um mínimo de 600 ppm de F solúvel após um ano desta data e um mínimo de 450 ppm de $\mathrm{F}$ pelo restante do prazo de validade. No entanto, uma nova portaria $\mathrm{n}^{0} 71$ de 29 de maio de 1996, não especifica que o $\mathrm{F}$ deve se apresentar na forma solúvel no dentifrício.

A efetividade dos dentifrícios fluoretados na redução da incidência de cárie dentária tem sido extensivamente documentada em uma infinidade de pesquisas clínicas publicadas e em muitas outras não publicadas, as quais foram revisadas em várias ocasiões na década de 80 (MELLBERG; RIPA ${ }^{67}$, 1983; BIESWANGER; STOOKEY์, 1989). É claro que fica difícil documentar isto precisamente devido ao uso disseminado da água fluoretada e de outras fontes de consumo do F. No entanto, não pode ser considerada uma simples coincidência o fato de o primeiro relato de declínio de cárie dentária numa comunidade não fluoretada dos EUA (ZACHERL; LONG ${ }^{104}$, 1979) ter ocorrido alguns anos após cerca de $90 \%$ das crianças escolares terem começado a usar dentifrícios fluoretados. Uma evidência ainda mais forte da importância dos dentifrícios fluoretados como medida de saúde pública foi trazida por estudos na Inglaterra, onde menos que $10 \%$ da população ingere água fluoretada. Nesses estudos o declínio na prevalência de cáries coincidiu com o aumento do uso de dentifrícios fluoretados (ANDLAW; 
BURCHELL; TUCKER ${ }^{2}$, 1982; ALLEN; ASHLEY; NAYLOR ${ }^{1}, 1983$; MANSBRIDGE; BROWN $\left.{ }^{60}, 1985\right)$.

Vários estudos têm investigado o possível impacto do uso de dentifrício fluoretado no desenvolvimento da fluorose dentária. Muitos estudos sugerem uma relação entre o uso dos dentifrícios fluoretados por crianças jovens e o desenvolvimento de fluorose dentária (PENDRYS; KATZ $^{72}$, 1989; PENDRYS; KATZ; MORSE ${ }^{77}$, 1996; PENDRYS; KATZ ${ }^{73}$, 1998; MASCARENHAS; BURT $T^{62}$, 1998; WARREN; LEVY ${ }^{99}$, 1999; BUZALAF et al. $\left.{ }^{16}, 2002\right)$. Além do uso precoce de dentifrício fluoretado, outras variáveis na escovação têm sido relacionadas com o aumento de fluorose dentária, como: quantidade de dentifrício usado, freqüência de escovação e quantidade de dentifrício ingerida (RIORDAN; BANKS ${ }^{84}$, 1991; EVANS; STAMM ${ }^{36}$ 1991). De todas estas variáveis de uso de dentifrício fluoretado, o uso antes da idade de 2 anos é a mais associada com fluorose dentária. 0 risco de desenvolver fluorose dentária a partir do uso de dentifrício fluoretado antes de 2 anos varia desde um leve aumento até um aumento de 11 vezes. As razões para esta ampla variação são as múltiplas fontes de $\mathrm{F}$ e os diferentes índices de fluorose dentária empregados nos diferentes estudos (MASCARENHAS ${ }^{61}, 2000$ ). Um estudo onde somente o dentifrício fluoretado era a fonte de $\mathrm{F}$ mostrou uma associação entre o seu uso precoce e fluorose dentária (MASCARENHAS; BURT $\left.{ }^{62}, 1998\right)$.

Também a concentração de $\mathrm{F}$ presente no dentifrício é um fator a ser considerado. O estudo de HOLT et al. ${ }^{49}$ (1994), que avaliou o risco de 
fluorose dentária em crianças que tinham participado previamente de uma pesquisa clínica, envolvendo o efeito preventivo de cáries e o uso de dentifrícios com baixa concentração de $F(550$ ppm) na idade entre 2 e 5 anos, mostrou que as crianças que tinham usado este dentifrício tinham uma probabilidade significantemente menor de desenvolver fluorose dentária.

Segundo PESSAN; SILVA; BUZALAF ${ }^{79}$ (2003) a ingestão de F através da escovação é de $0,034 \mathrm{mg} / \mathrm{Kg}$ peso para crianças de $4-5$ anos e 0,041 mg/Kg para crianças de 6-7 anos de idade.

Em um estudo realizado por LIMA; CURY $^{57}$ (2001) com crianças de 20-30 meses de idade residentes em áreas com água fluoretada mostrou que as mesmas ingeriam em média $0,09 \mathrm{mg} \mathrm{F} / \mathrm{Kg} / \mathrm{dia}$, tendo a dieta contribuído com 45\%, e o dentifrício com 55\%, deste modo excedendo a dose limite de 0,07 mg F/Kg/dia. Os autores sugerem três alternativas para esta dose ser reduzida:

$\checkmark$ Redução da concentração ótima de F na água de abastecimento de 0,7 para 0,3-0,4 ppm;

$\checkmark$ Utilização de dentifrício contendo 600 ppm de F solúvel;

$\checkmark$ Utilização de, no máximo, 0,3 g de dentifrício por escovação.

Do ponto de vista de risco e benefício do uso do $F$, segundo os autores, a terceira possibilidade seria, a princípio, a mais viável. Na condição deste estudo, se as crianças utilizassem 0,3 g de dentifrício por escovação, 
seriam submetidas a uma dose segura para a fluorose dentária, considerando o limiar de 0,05 a 0,07 mg F/Kg/dia.

No entanto, segundo RICHARDS; BANTING ${ }^{80}$ (1996) a quantidade média de dentifrício aplicado na escova por crianças menores que 6 anos é 0,55 g por escovação. Em média, 48\% desta quantidade é ingerida por crianças de 2-3 anos, $42 \%$ por crianças de 4 anos e 34\% por crianças de 5 anos (ERICSSON; FORSMAN ${ }^{34}$, 1969; HARGREAVES; INGRAM; WAGG ${ }^{45}$, 1972; RICHARDS; BANTING ${ }^{80}$, 1996). Assim, a quantidade de dentifrício usada na escova tende a aumentar com a idade, enquanto a quantidade ingerida tende a diminuir (LEVY; KIRITSY; WARREN $\left.{ }^{56}, 1995\right)$.

Para que seja reduzido o risco de desenvolvimento de fluorose dental, dentifrícios sem F ou então com concentrações mais baixas, em torno de 500 ppm, deveriam ser recomendados para crianças muito pequenas ou préescolares, ou então o dentifrício contendo níveis acima de 1000 ppm só deveria ser usado sob a supervisão dos pais, os quais devem colocar o dentifrício na escova (apenas uma porção do tamanho de uma ervilha) e supervisionar a escovação para assegurar que a criança está expectorando e lavando a boca após a escovação (WARREN; LEVY99, 1999; MASCARENHAS ${ }^{61}, 2000 ;$ TABARI et al. $\left.{ }^{91} 2000\right)$. 


\subsection{4 - Suplementos Fluoretados}

Em um Workshop no Canadá em 1994 (Canadian Workshop Meeting) foi decidido que a suplementação de $F$ não deveria ser recomendada para crianças mais jovens do que 3 anos de idade e que a dosagem para crianças de 3 a 5 anos deveria ser reduzida de $0,5 \mathrm{mg} / \mathrm{dia}$ para $0,25 \mathrm{mg} / \mathrm{dia}$, uma vez que o uso do suplemento fluoretado é identificado como sendo o principal fator de risco para a fluorose dentária.

Os suplementos fluoretados são recomendados para crianças que moram em áreas com deficiência na fluoretação das águas. A dose diária recomendada é baseada na idade da criança e na concentração de $F$ na água de beber (TABELA 2) (SPUZNAR; BURT ${ }^{90}$, 1988; PENDRYZ; MORSE $^{75}$, 1990; PENDRYZ; MORSE $\left.{ }^{76}, 1995\right)$.

Tabela 2. Dosagem de suplemento fluoretado recomendada por dia em $\mathrm{mg}$.

\begin{tabular}{lccc}
\hline \multicolumn{1}{c}{ Idade } & \multicolumn{3}{c}{ Concentração de $\mathrm{F}$ na água beber } \\
\cline { 2 - 4 } & $<\mathbf{0 , 3}$ & $\mathbf{0 , 3 - \mathbf { 0 , 6 }}$ & $>\mathbf{0 , 6}$ \\
\hline Nascimento até $\mathbf{6}$ meses & zero & zero & zero \\
6 meses a 3 anos & 0,25 & zero & zero \\
De $\mathbf{3}$ a $\mathbf{5}$ anos & 0,50 & 0,25 & zero \\
De $\mathbf{6}$ a $\mathbf{1 6}$ anos & 1 & 0,50 & zero \\
\hline
\end{tabular}

LALUMANDIER $^{53}$, em 1992, associou a ocorrência de fluorose dentária em indivíduos residentes em áreas com fluoretação deficiente com a freqüente suplementação e a idade em que as crianças iniciaram a 
escovação dos dentes, enquanto que para os indivíduos que bebiam água fluoretada a fluorose foi associada somente com a idade em que se iniciou a escovação dos dentes com dentifrício fluoretado. $O$ autor sugere que suplementos e escovação dos dentes em idade precoce aumentam o risco para a fluorose dentária.

GUHA-CHOWDHURY; DRUMMOND; SMILLIE ${ }^{44}$ (1996) realizaram um estudo para testar a hipótese de que a quantidade total de $\mathrm{F}$ recebida através da dieta, dentifrício e suplementos fluoretados por crianças residentes em áreas com baixos teores de $\mathrm{F}$ na água, era similar àquela recebida através da dieta e do dentifrício por crianças residentes em áreas fluoretadas. Os autores verificaram que, se algumas crianças da área de baixo teor de $F$ recebessem 0,50 ou até mesmo $0,25 \mathrm{mg} F /$ dia, receberiam uma quantidade total de $\mathrm{F}$ superior às recebidas pelas crianças das áreas fluoretadas. Desta maneira, este estudo suporta a redução das doses de F dos suplementos para diminuir o risco de fluorose nos dentes anteriores permanentes e primeiros molares.

O risco de fluorose dentária em áreas fluoretadas quando há a utilização de suplemento fluoretado é quase 4 vezes mais alto do que em áreas não fluoretadas (RIORDAN, BANKS ${ }^{84}$, 1991; MASCARENHAS ${ }^{61}$, 2000). 


\section{2 - BIOMARCADORES}

Para indicar uma alteração que poderia levar a uma doença clínica (GRANDJEAN ${ }^{42}$, 1995) têm-se os marcadores biológicos ou biomarcadores, os quais são indicadores que sinalizam eventos em sistemas biológicos ou amostras (Committee on Biological Markers of the National Research Council $^{23}$, 1987). O uso de biomarcadores em Epidemiologia não é uma idéia nova $\left(H U L K A^{50}, 1991\right)$, mas foi recentemente que os biomarcadores se tornaram importantes na toxicologia ambiental (CULLEN; REDLICH $\left.{ }^{24}, 1995\right)$. Dependendo dos efeitos biológicos envolvidos, os biomarcadores podem ser úteis no monitoramento do estado de saúde, em determinar a relação doseresposta, bem como em estimar os riscos (DeCAPRIO $\left.{ }^{29}, 1997\right)$.

CAMPOS $^{18}$ (2002) utilizou as unhas para detectar exposição crônica à cocaína. Segundo a autora, amostras de urina são mais utilizadas para se detectar uma exposição recente, como em casos de "doping" e de análise periódica realizada em funcionários de empresas, onde o intuito é verificar se os atletas ou trabalhadores estão atuando sob efeito de drogas. Mas se for preciso verificar exposição crônica à droga, a análise da urina não é eficiente, pois após 72 horas da exposição, torna-se difícil a detecção da cocaína e seus produtos de biotransformação, e é neste contexto que a análise da unha ganha importância. Entretanto, as unhas servem como alternativas para verificar casos de exposição prolongada, como em investigações forenses pós-morte. 
Num simpósio realizado pelo National Institute of Health, em Bethesda, Maryland, EUA, em 1999, foi estabelecida uma agenda internacional de necessidades de pesquisa envolvendo F. Entre os tópicos, estava a avaliação de possíveis biomarcadores, que fossem de fácil coleta e análise, para a exposição ao $\mathrm{F}$ em humanos (CLARKSON $\left.{ }^{21}, 2000\right)$. As vantagens e limitações do plasma, saliva dos ductos e urina como biomarcadores para exposições recentes e do osso e dentina como biomarcadores teciduais para exposições crônicas foram discutidos. Também foi discutido o possível uso das unhas como indicadoras de exposições subcrônicas ao F, e possivelmente exposições crônicas se a ingestão permanecesse relativamente constante.

O Comitê de marcadores biológicos do Conselho Nacional de Pesquisa dos Estados Unidos, em 1987, classificou os biomarcadores em 3 tipos:

Biomarcadores de efeito: pode ser um indicador de um componente endógeno do sistema biológico, uma medida da capacidade funcional do sistema, ou um estado alterado de sistema, que é reconhecido como uma anormalidade ou doença.

Biomarcador de susceptibilidade: é definido como um indicador de que a saúde do sistema é especialmente sensível ao desafio da exposição a um composto xenobiótico (substância originada fora do organismo). 
Biomarcador de exposição: pode ser a identificação de uma substância exógena ao sistema, o produto de interação entre um composto xenobiótico e componentes endógenos, ou outro evento no sistema biológico relacionado à exposição.

\subsection{2 - Biomarcadores de F}

Classificação dos biomarcadores de F de acordo com o Comitê Nacional de Pesquisa dos EUA, 1997:

Biomarcadores de efeito: as fluoroses dentária e esquelética são efeitos colaterais de uma exposição prévia a níveis de $\mathrm{F}$ moderados ou altos. Deste modo, as fluoroses dentárias e esqueléticas são biomarcadores apropriados, uma vez que representam sinais de exposição prévia ao $\mathrm{F}$.

Biomarcadores de susceptibilidade: vários fatores podem afetar 0 modo como os indivíduos respondem a uma mesma dose de F. Como biomarcadores de susceptibilidade ao F temos desnutrição, metabolismo do cálcio e magnésio, condição renal e genética.

Biomarcadores de exposição: Os biomarcadores de exposição podem refletir diferentes períodos de exposição a um evento. Ou seja, os marcadores conhecidos de meia-vida curta ou de curto tempo, indicam uma exposição que ocorreu poucos minutos ou horas atrás, enquanto outros refletem dias, semanas ou muitos meses atrás. Como biomarcadores de meia vida-curta podemos citar o plasma, soro, saliva e urina, que indicam 
exposições recentes ao $F$, enquanto que osso, dentes, cabelo e unhas podem refletir a exposição prévia de semanas ou vários meses, ou seja, indicam a exposição crônica ao F.

A Organização Mundial de Saúde classificou os biomarcadores de exposição ao F de acordo com a cronologia de sua marcação:

$\checkmark$ Marcadores históricos: ossos e dentes, são ferramentas úteis para o monitoramento da exposição crônica ao F.

$\checkmark$ Marcadores contemporâneos: urina, plasma e saliva, podem refletir a exposição aguda ao $\mathrm{F}$.

Marcadores recentes: cabelo e unhas, podem refletir exposições crônicas e subcrônicas ao F.

\subsection{3 - A unha como biomarcador de exposição ao F.}

As unhas são placas curvas queratinizadas, dispostas na superfície dorsal das falanges distais, com função protetora. Apresentam uma parte distal, exposta, o corpo e uma parte proximal oculta, a raiz (matriz). Esta é coberta por um prolongamento ou prega da camada córnea da epiderme. A unha repousa sobre o leito ungueal, que é abundantemente vascularizado e inervado. O crescimento das unhas é contínuo durante a vida, graças a um processo de proliferação e diferenciação de células epiteliais da raiz da unha, que gradualmente se queratinizam para formar a placa córnea (Figura 1), (O’RAHILLY70, 1964). As unhas variam no seu aspecto, forma, tamanho e resistência com a idade, não havendo diferença no que diz respeito ao 
sexo. As unhas da criança são mais finas e menores, e com a idade tornamse mais grossas.

McDONNELL e O'MULLANE ${ }^{65}$ (2001) averiguaram a velocidade de crescimento e o comprimento no qual as unhas poderiam ser cortadas para a análise do conteúdo de $\mathrm{F}$ em crianças de 2 a 3 anos de idade. As médias (variação) obtidas foram 0,7 mm/semana $(0,5-0,9 \mathrm{~mm})$ e 7,5 mm $(6,4-9,2$ $\mathrm{mm})$, respectivamente.

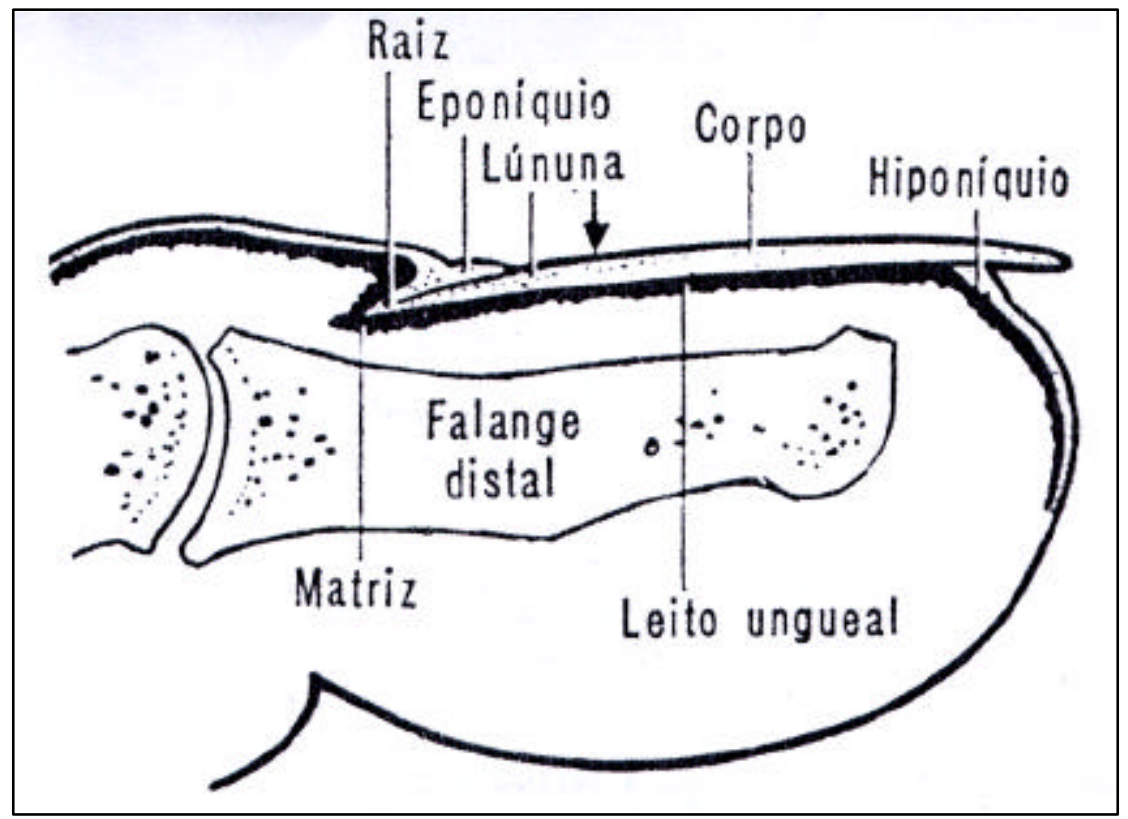

Figura 1. Corte sagital esquemático de unha em um dedo da mão. 
O número de trabalhos existentes na literatura relacionando-se os níveis de $\mathrm{F}$ presente nas unhas como biomarcadores da exposição de $\mathrm{F}$ é reduzido. Vários métodos de preparação e análise, bem como várias concentrações de $\mathrm{F}$ têm sido descritos na literatura. $\mathrm{O}$ uso das unhas como biomarcadores para exposição ao $\mathrm{F}$ tem ainda alguns pontos que necessitam ser mais estudados. Não há muitos relatos na literatura, e alguns são contraditórios.

SCHAMCHULA et al. ${ }^{86}$ (1985) fizeram hidrólise em base forte a alta temperatura e então usaram o eletrodo íon específico para analisar as unhas das mãos de 3 grupos de crianças húngaras, cuja concentração de $F$ na água de beber variava de 0 a $0,11 \mathrm{ppm}$, de 0,5 a $1,1 \mathrm{ppm}$ ou de 1,6 a 3,1 ppm. As concentrações médias de $\mathrm{F}$ encontradas nas unhas das mãos foram $0,79,1,31$ e $2,31 \mathrm{mg} / \mathrm{Kg}$, respectivamente.

$\mathrm{MACHOY}^{58}$ (1989) usou um método de cromatografia gasosa para avaliar se a quantidade variável de $\mathrm{F}$ no meio ambiente é refletida na concentração de $F$ nas unhas das mãos de cinco grupos de crianças polonesas. Um dos grupos vivia numa comunidade sem água fluoretada, mas que possuía uma fábrica que processava "fosforitas e apatitas". A concentração média de $\mathrm{F}$ nas unhas das mãos foi de $12,2 \mathrm{mg} / \mathrm{kg}$. Três grupos residiam em comunidades sem água fluoretada, enquanto que o outro grupo tinha uma concentração de 0,64 ppm na água. A concentração média nas unhas das mãos do último grupo foi de $8,6 \mathrm{mg} / \mathrm{Kg}$, enquanto que dos outros três grupos foi de 2,5, 6,4 e 7,6 mg/Kg. Através destes resultados 
o autor concluiu que as influências ambientais alteram o conteúdo de F nas unhas das crianças. Também neste estudo foram analisadas as unhas das mãos e as dos pés de um único indivíduo, para avaliar as concentrações médias $( \pm D P)$ de $F$, que foram de 3,65 $( \pm 1,02)$ e 3,58 $( \pm 0,55)$ para as unhas das mãos e dos pés, respectivamente.

Em 1990, SCHIMIDT e LEUSCHKE ${ }^{87}$ realizaram um estudo com o objetivo de determinar o conteúdo de $\mathrm{F}$ nas unhas das mãos de indivíduos com e sem exposição crônica ao F. As causas da exposição foram emissões de indústrias como, por exemplo, fábrica de ácido hidrofluorídrico. $\mathrm{O}$ conteúdo de $\mathrm{F}$ das unhas dos dois grupos foi extremamente baixo. As médias para os grupos sem e com exposição ao $F$ foram 0,8 e 2,78 ppm, respectivamente. Neste estudo houve uma larga variação dos resultados que segundo os autores poderia ser explicada pela aderência de partículas de sujeira nas amostras de unhas.

SPATE et al. $^{89}$ (1994) usaram análise por ativação neutra para determinar as concentrações de $\mathrm{F}$ em unhas dos pés obtidas de mulheres residentes em Holden ou Boston, Massachusets, nos EUA onde a água continha 0,09 e 1,0 ppm, respectivamente. As concentrações médias (com as variações) foram de 4,2 (2,4-9,7) e 6,4 (2,7-10,1) mg/Kg.

WHITFORD et al. ${ }^{103}$ (1999) analisaram a concentração de F existente nas unhas com o eletrodo através de difusão facilitada por HMDS. Os autores observaram que a área de superfície das unhas (intactas, cortadas em pequenos pedaços ou pulverizadas), imersão em água deionizada por 6 
horas, imersão em água fluoretada (1 ppm) por 2 horas ou remoção de matéria orgânica das unhas por incineração não causaram alterações no conteúdo de $\mathrm{F}$ analisado. Os autores relataram ainda que o conteúdo de $\mathrm{F}$ presente nas unhas dos pés é aproximadamente a metade daquele presente nas unhas das mãos. Um dos autores do trabalho aumentou a ingestão de $\mathrm{F}$ durante 1 mês e observou um incremento significante na concentração de F das unhas das mãos cerca de 3,5 meses depois. Foram, ainda, dosadas as concentrações de $\mathrm{F}$ presentes nas unhas das mãos de crianças brasileiras que residiam em áreas contendo $0,1,1,6$ ou 2,3 ppm de $\mathrm{F}$ na água, tendo-se encontrado médias de 1,85, 5,28 e 7,52 mg/Kg, respectivamente, o que indica que, à semelhança das concentrações de $F$ na urina, as concentrações de F nas unhas das mãos são boas indicadoras da ingestão de F.

BUZALAF et al. ${ }^{15} 2002$ investigaram as mudanças na concentração de $F$ no plasma e nas unhas de ratos que receberam diferentes concentrações de $\mathrm{F}$ na água de beber. Uma relação direta entre a concentração de $F$ nas unhas e no plasma foi identificada $(r=0,67, p<0,001)$, indicando que as unhas podem ser utilizadas como indicadores de concentração de $\mathrm{F}$ no plasma em ratos submetidos à ingestão crônica de F.

Em 2003, ARSATP realizou um estudo com o objetivo de avaliar a unha como um possível indicador biológico de exposição ao F para prever o risco de fluorose dentária. O trabalho foi composto por dois estudos distintos, ambos envolvendo crianças de 20 a 30 meses de idade. No primeiro estudo, 
a autora verificou a relação entre concentração de $\mathrm{F}$ nas unhas e na água de abastecimento de três cidades paulistas: Cordeirópolis, Piracicaba e Assistência, que possuem $0,03,0,64$ e $1,53 \mu \mathrm{g} / \mathrm{g}$ de $\mathrm{F}$ na água, respectivamente. Os resultados da concentração de $F$ nas unhas das crianças deste estudo foram 1,65, 2,85 e 4,14 $\mu \mathrm{g} / \mathrm{g}$ para Cordeirópolis, Piracicaba e Assistência, respectivamente. Estes resultados sugerem que a unha pode ser um indicador da ingestão de $\mathrm{F}$ através da água de abastecimento. O segundo estudo contou com a participação de 23 crianças de Piracicaba, e verificou se a unha poderia ser indicador biológico para diferenciar a somatória da exposição ao $\mathrm{F}$ pela dieta mais dentifrício fluoretado. Para isto, o estudo foi dividido em duas fases, que duraram cerca de três meses cada. Na primeira (Fase $A=$ dieta-F + dentifrício-F), as crianças estavam expostas normalmente ao $F$, através da alimentação e da escovação com dentifrício fluoretado. Na segunda (Fase $B=\operatorname{dieta-F}$ ), as crianças passaram a escovar os dentes com um dentifrício sem F. As concentrações de $F( \pm D P)$ encontradas nas unhas das crianças foram 2,64 $( \pm 0,91)$ e $2,80( \pm 0,94) \mu \mathrm{g} / \mathrm{g}$ para as fases $\mathrm{A}$ e fase $\mathrm{B}$, respectivamente. Estes resultados indicaram que a concentração de $F$ nas unhas das crianças na faixa etária de risco para a fluorose dentária, expostas à água fluoretada, não parece ser um indicador biológico para diferenciar o efeito somatório da $\begin{array}{lllll}\text { exposição sistêmica } & \text { ao } & F & \text { do } & \text { dentifrício. }\end{array}$ 
PROPOSICÃO 


\section{3 - PROPOSIÇÃo}

Este estudo cruzado longitudinal, realizado com crianças na idade de risco para a fluorose dentária em incisivos superiores (2-3 anos de idade) que utilizaram dentifrício fluoretado, teve como objetivos:

$\checkmark$ Identificar as unhas como possíveis biomarcadores para exposição subcrônica ao F através do dentifrício fluoretado.

$\checkmark$ Verificar o intervalo de tempo em que o F pode ser detectado nas unhas após o início de uso do dentifrício fluoretado.

$\checkmark$ Comparar a concentração de F encontrada nas unhas das mãos com as dos pés. 
MATERIAL E MÉTODOS 


\section{4 - MATERIAL e MÉtodos}

\subsection{MATERIAL}

4.1.1. Material utilizado na leitura do conteúdo de $F$ das unhas

$\checkmark$ Placa de Petri plástica (Falcon, $n^{\circ} 1007$ )

$\checkmark$ Balança de precisão AND $( \pm 0,01 \mathrm{mg})$

$\checkmark$ Mesa agitadora - Nova técnica modelo NT 145

$\checkmark$ Eletrodo flúor-sensível Orion 9409

$\checkmark$ Micro eletrodo de referência calomelano (Accumet, $\mathrm{n}^{\circ}$ de catálogo \# 13-620-79)

$\checkmark$ Vaselina

$\checkmark$ Parafilme

$\checkmark$ Padrão de F contendo 0,1 M F (Orion)

$\checkmark$ Água deionizada

$\checkmark$ HMDS - hexametildisiloxano (Aldrich)

$\checkmark$ Ácido sulfúrico concentrado

$\checkmark \mathrm{NaOH} 0,05 \mathrm{M}$

$\checkmark$ Ácido acético 0,2 M

\subsubsection{Material utilizado na leitura da concentração de $F$ nas} águas

$\checkmark$ Eletrodo flúor sensível Orion 9609

$\checkmark$ Soluções padrão de fluoreto de sódio 100 ppm (Orion) 
$\checkmark$ Água deionizada
$\checkmark \quad$ Tisab (CDTA 0,4\%, pH 5,0)

\subsection{MÉTODOS}

\subsubsection{Protocolo do estudo}

O presente estudo caracterizourse por ser um estudo cruzado longitudinal. Contou com a participação de um único grupo focal, constituído por 10 crianças na faixa etária de 2-3 anos. Todas elas apresentavam um bom estado de saúde bucal e geral e não estavam ingerindo nenhum medicamento.

O experimento constou de três etapas distintas. Na primeira etapa as crianças escovaram os dentes 3 vezes ao dia com dentifrício placebo, que não contém $F$, durante 28 dias

$\mathrm{Na}$ segunda etapa as crianças escovaram os dentes com dentifrício Sorriso (1570 ppm de F, MFP) três vezes ao dia, também por 28 dias. E a terceira e última etapa do experimento foi idêntica à primeira.

A cada etapa as mães recebiam informações de forma verbal e escrita (Anexo 1) a respeito da maneira como a escovação deveria se proceder: a pasta utilizada deveria ser a fornecida para aquela etapa, a quantidade de pasta colocada na escova deveria ser o correspondente ao tamanho de uma ervilha (aproximadamente $0,5 \mathrm{~g}$ ) e a escovação deveria ser 
realizada 3 vezes ao dia, após o café da manhã, após o almoço e antes de dormir, da maneira habitual.

As amostras de unhas foram coletadas pelas mães, desde o início do experimento. Nas datas das coletas as mães eram lembradas através de um telefonema para que não houvesse esquecimento. Foram fornecidos recipientes devidamente lavados com água deionizada e etiquetados com as datas das coletas, como também o tipo de amostra a ser coletada (unhas das mãos ou unhas dos pés). As amostras foram coletadas a cada duas semanas até o final do experimento e então por mais 5 meses adicionais, pois em adultos sabe-se que apenas 3,5 meses após a ingestão de $\mathrm{F}$ é que o seu aumento é detectado nas unhas (WHITFORD et al. $\left.{ }^{103}, 1999\right)$.

A água da residência dos voluntários também foi coletada em recipientes apropriados, durante as três etapas do experimento, nos mesmos dias em que as amostras de unhas eram coletadas.

O projeto foi submetido e aprovado pelo Comitê de Ética em Pesquisa da Faculdade de Odontologia de Bauru (Apêndice 1), atendendo às normas da Resolução 196/96 do Conselho Nacional de Saúde, sendo que os responsáveis pelos voluntários receberam uma carta de informação sobre o estudo (Anexo 2) e assinaram um termo de consentimento livre e esclarecido concordando em participar do experimento (Anexo 3).

A princípio o Projeto de Pesquisa foi intitulado de "Influência de dentifrício fluoretado na concentração de flúor nas unhas de crianças de 2-3 
anos". Em virtude dos resultados obtidos, após a sua conclusão, passou a ser intitulado: "Unha como biomarcador de exposição subcrônica ao flúor a partir de dentifrício fluoretado em crianças de 2-3 anos” (Apêndice 2).

\subsubsection{Procedimento Analítico}

\subsubsection{Unhas}

Os fragmentos das unhas das mãos e dos pés de cada criança, em cada data, foram analisados conjuntamente, sendo que para cada data correspondente houve dois resultados por criança, ou seja, um resultado para as unhas das mãos e outro para as unhas dos pés. Em 3 casos, nos quais a massa das unhas foi superior a $20 \mathrm{mg}$, a análise foi feita em duplicata (Anexos 4 e 5).

Antes da análise, os fragmentos foram limpos com o auxílio de uma escova interdental e também com um pedaço de tecido umedecido com água deionizada. Após este procedimento os fragmentos foram colocados em ultra-som com água deionizada por 10 minutos e secos em estufa a $60^{\circ} \mathrm{C}$ (2 a 3 horas). Finalizados os procedimentos de limpeza e secagem os fragmentos foram pesados (Balança de precisão AND, $\pm 0,01 \mathrm{mg}$ ).

A análise de $F$ foi feita após difusão facilitada por HMDS (hexametildisiloxano), pelo método de Taves $^{92}$ (1968), como modificado por Whitford $^{102}$ (1996). Para tanto, os fragmentos de unha foram colocados em placas de Petri plásticas (Falcon, ñ 1007), juntamente com $2 \mathrm{~mL}$ de água 
deionizada (figura 2). Na tampa destas placas, foram colocados $50 \mu \mathrm{L}$ de $\mathrm{NaOH}$ 0,05 M, distribuídos em 3 gotas (figura 3). As placas foram fechadas, seladas com vaselina, e por um orifício feito previamente na tampa foi colocado o HMDS (Aldrich, 2,0 mL em ácido sulfúrico $3 \mathrm{M}$ ), (figura 4). O orifício foi imediatamente selado com vaselina e parafilme (figura 5). As placas foram colocadas numa mesa agitadora (Nova Técnica, modelo NT 145) em velocidade $2-3$, durante toda a noite (12 a 14 horas). No dia seguinte, as tampas foram removidas, invertidas e as gotas de $\mathrm{NaOH}$ foram combinadas numa única gota. $\mathrm{O} \mathrm{NaOH}$ foi tamponado pela adição de $25 \mu \mathrm{L}$ de ácido acético $0,2 \mathrm{M}$. $\mathrm{O}$ volume total foi então ajustado para $75 \mu \mathrm{L}$ com água deionizada usando uma pipeta (figura 6). A gota, que contém todo o $\mathrm{F}$ das unhas foi analisada com o eletrodo Orion 9409 e um micro-eletrodo de referência calomelano (Accumet, número de catálogo \#13-620-79), ambos acoplados ao potenciômetro Orion EA 940. Durante a leitura, os dois eletrodos foram mantidos unidos através de bandas de borracha e colocados em contato com a gota na parte interna da tampa da placa (figura 7).

O princípio químico do método é baseado na dissociação de moléculas de HMDS na presença de ácido forte numa placa de difusão. O F (das amostras ou soluções-padrão) liga-se ao radical silano, formando um composto volátil, chamado trimetilfluorsilano. Este composto se difunde para o "trap", de natureza alcalina $(\mathrm{NaOH})$, localizado no interior da tampa fixada no fundo da placa de difusão. O F é trocado pelo íon hidroxila. Um novo composto é formado (trimetilsilanol), sendo o F liberado. 


\section{Validação da análise}

A técnica de difusão facilitada por HMDS apresenta as vantagens de separar o F da amostra, eliminando interferentes, e ao mesmo tempo concentrá-la, o que incrementa o limite de detecção do $\mathrm{F}$ pelo eletrodo sensível, que é de $0,02 \mu \mathrm{g} / \mathrm{mL}$, conforme consta no manual do fabricante. Uma vez que nossa amostra tem um volume final de 0,075 mL, após a difusão facilitada por HMDS, permitiu fazer a leitura em amostras com mais de $2,5 \mathrm{mg}$ de unha com concentração de F superior a $3 \mu \mathrm{g} / \mathrm{g}$.

As soluções-padrão (contendo $0,5,1,0,5,0,10,0,50,0 \mathrm{~nm} F$ ) empregadas na realização da curva de calibração foram preparadas por diluição seriada de um estoque-padrão contendo $0,1 \mathrm{M} F$ (Orion) e difundidas em triplicata, em concomitância com as amostras de unha analisadas. Foi feita a primeira leitura antes de se começar a ler as amostras de unhas, a segunda quando a metade das amostras já tinha sido lida e a terceira após o término da leitura das amostras.

As leituras obtidas em milivoltagem (mV), foram convertidas para $\mu \mathrm{g}$ de F, através do Programa Excel (Microsoft). A média das leituras obtidas a partir dos padrões foi inserida na planilha (Anexo 6), e então foi calculada a porcentagem de variação entre a quantidade de $F$ medida e a esperada pelos padrões. Somente curvas de calibração com porcentagem de variação de até $5 \%$ para todos os padrões e $r \geq 0,99$ (linearidade) foram aceitas, contemplando a exatidão do método. 
Além disto, padrões que não sofreram difusão foram preparados usando-se as mesmas soluções ( $\mathrm{NaOH}$ 0,05 $\mathrm{M}$ e ácido acético 0,20 M) que foram usadas para se preparar os padrões e amostras que sofreram difusão. Estes padrões não difundidos foram feitos de modo a ter exatamente a mesma concentração de $F$ que os padrões que sofreram difusão. A comparação das leituras de $\mathrm{mV}$ mostrou que o $\mathrm{F}$ nos padrões difundidos foi completamente captado e analisado.

\subsubsection{2. ÁGUA}

A concentração de $\mathrm{F}$ presente nas amostras de água foi determinada em duplicata, usando o eletrodo Orion 9609 após o tamponamento com um volume idêntico de Tisab, contendo CDTA 0,4\% pH 5,0 (figura 9).

\section{Validação da análise}

A curva de calibração foi realizada com os mesmo cuidados descritos para a validação da análise de $F$ nas unhas. Foram feitas curvas de calibração com 1,0 mL de soluções-padrão contendo $0,1,0,2,0,4,0,8,1,6$ e $3,2 \mu \mathrm{g} \mathrm{F}$.

Em adição, medições de $\mathrm{F}$ em $10 \%$ das amostras foram repetidas para se determinar a repetibilidade das análises. 


\subsubsection{ANÁLISE ESTATÍSTICA}

Os dados foram analisados por Análise de Variância a dois critérios e teste de Tukey $(p<0,05)$. Os dois critérios utilizados foram: tempo e local (unhas das mãos e unhas dos pés). Também foi realizado o teste de correlação entre as unhas das mãos e unhas dos pés. A diferença entre a concentração de $\mathrm{F}$ encontrada na água de abastecimento das residências dos voluntários foi analisada pelo teste não paramétrico de Kruskall-Wallis, uma vez que não houve homogeneidade dos desvios-padrão e da amostra, sendo empregado o teste de Dunn para comparações individuais $(p<0,05)$. 


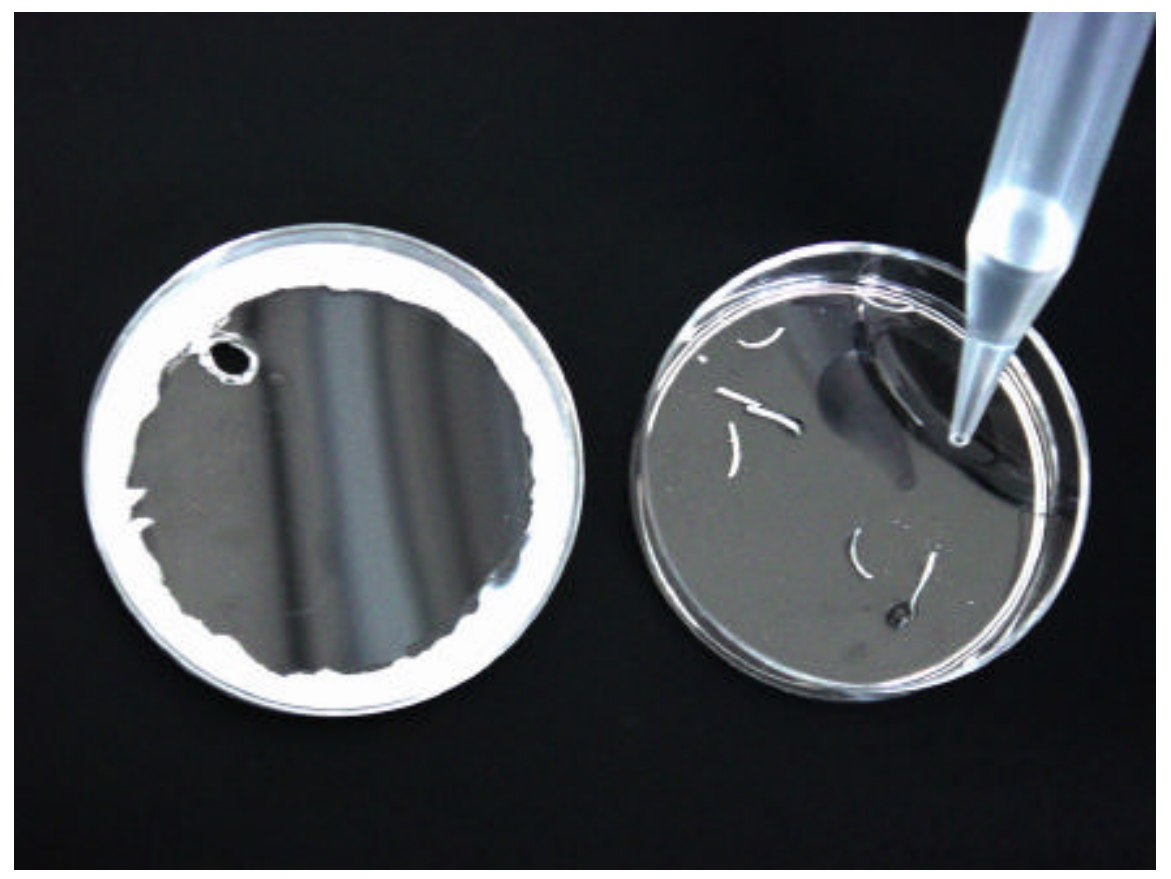

Figura 2. Placa de Petri vaselinada. Adição das amostras de unhas com 2 $\mathrm{mL}$ de água deionizada

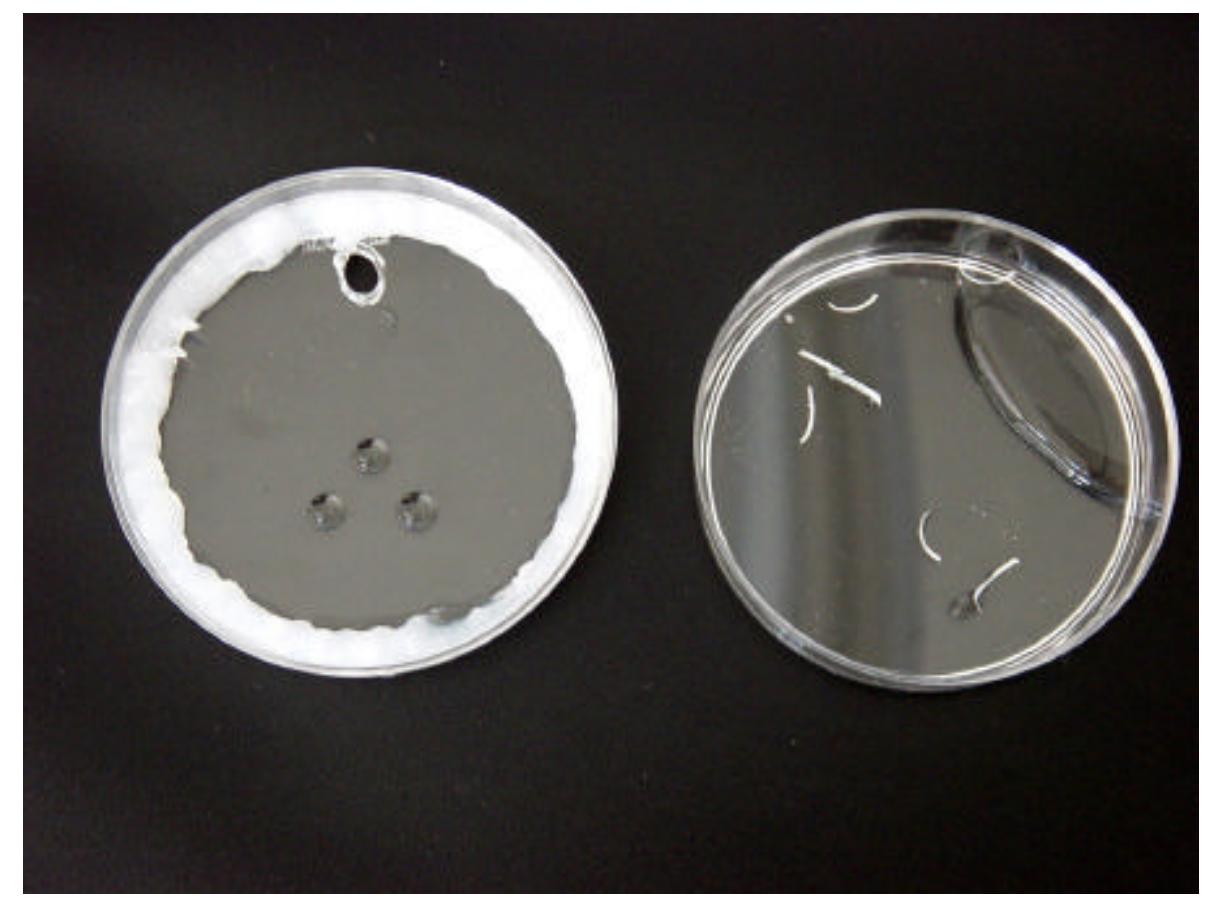

Figura 3. Adição de $50 \mu \mathrm{L}$ de $\mathrm{NaOH} 0,05 \mathrm{M}$ na tampa da placa de Petri distribuídos em 3 gotas 


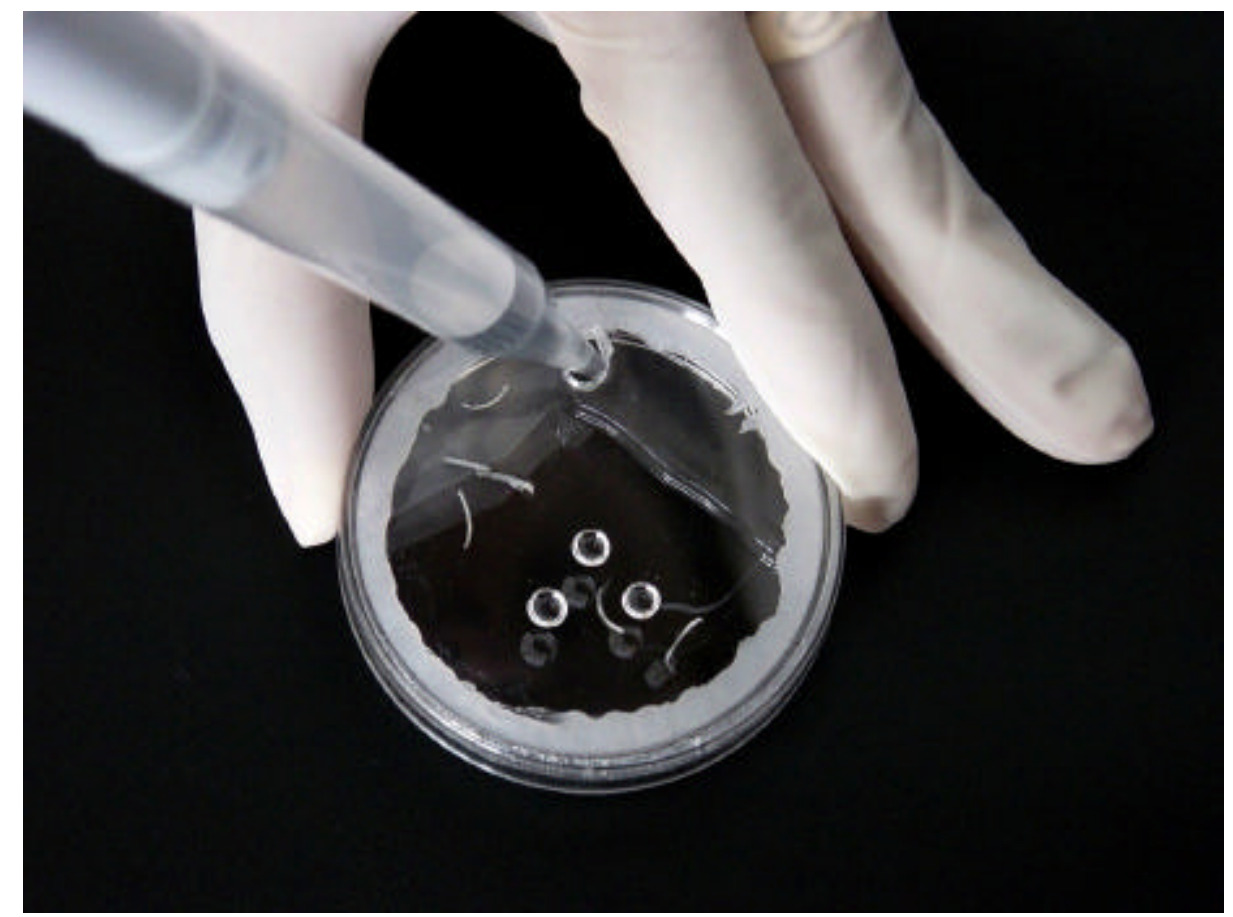

Figura 4. Fechamento das placas e adição de $2 \mathrm{~mL}$ HMDS

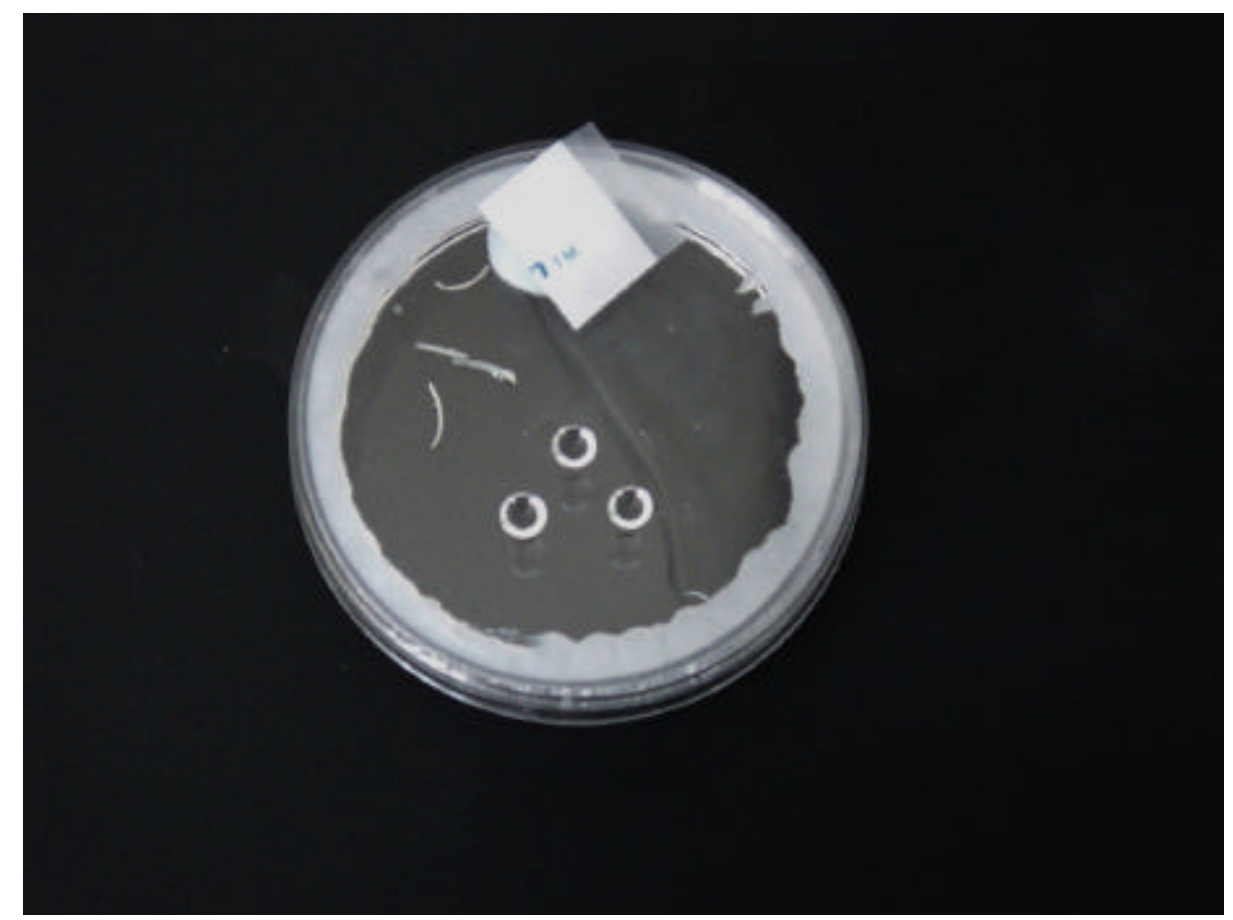

Figura 5. Vedamento imediato do orifício com vaselina e parafilme 


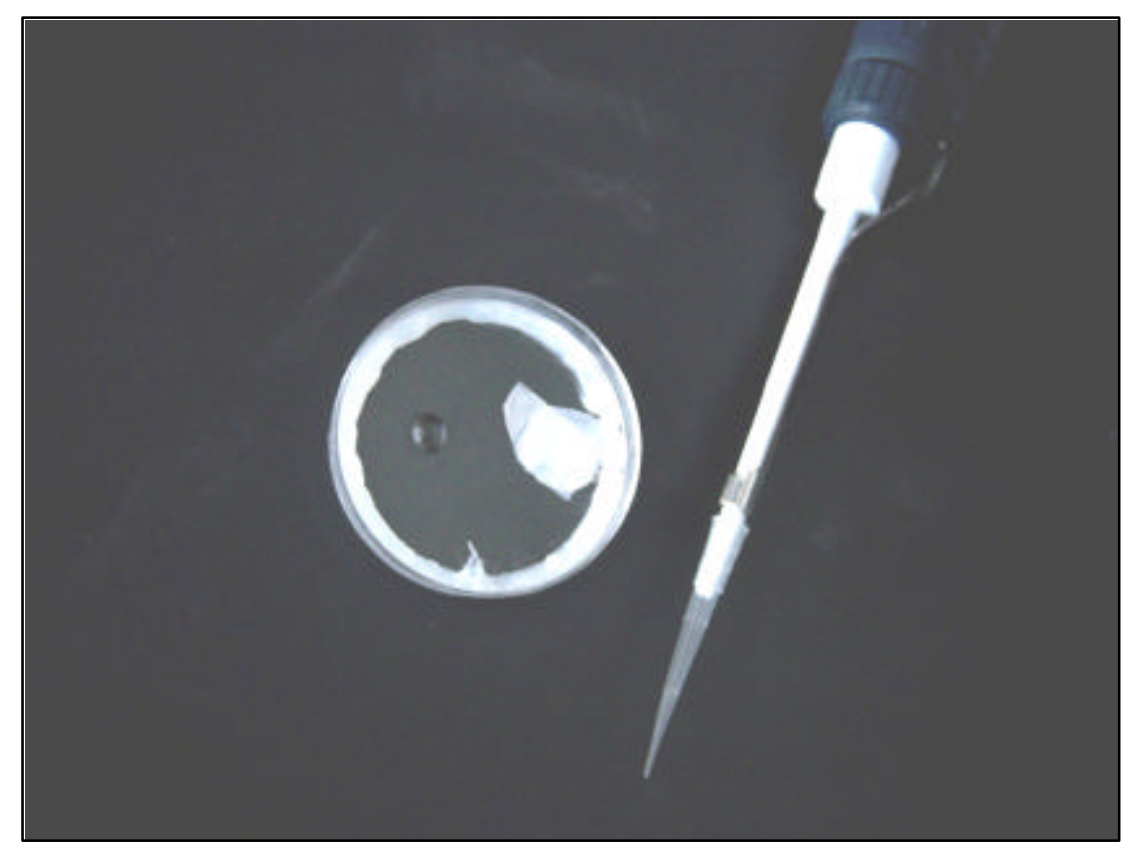

Figura 6. As gotas de $\mathrm{NaOH}$ foram combinadas numa única gota, tamponada com $25 \mu \mathrm{L}$ de ácido acético e o volume total foi ajustado para $75 \mu \mathrm{L}$ com água deionizada

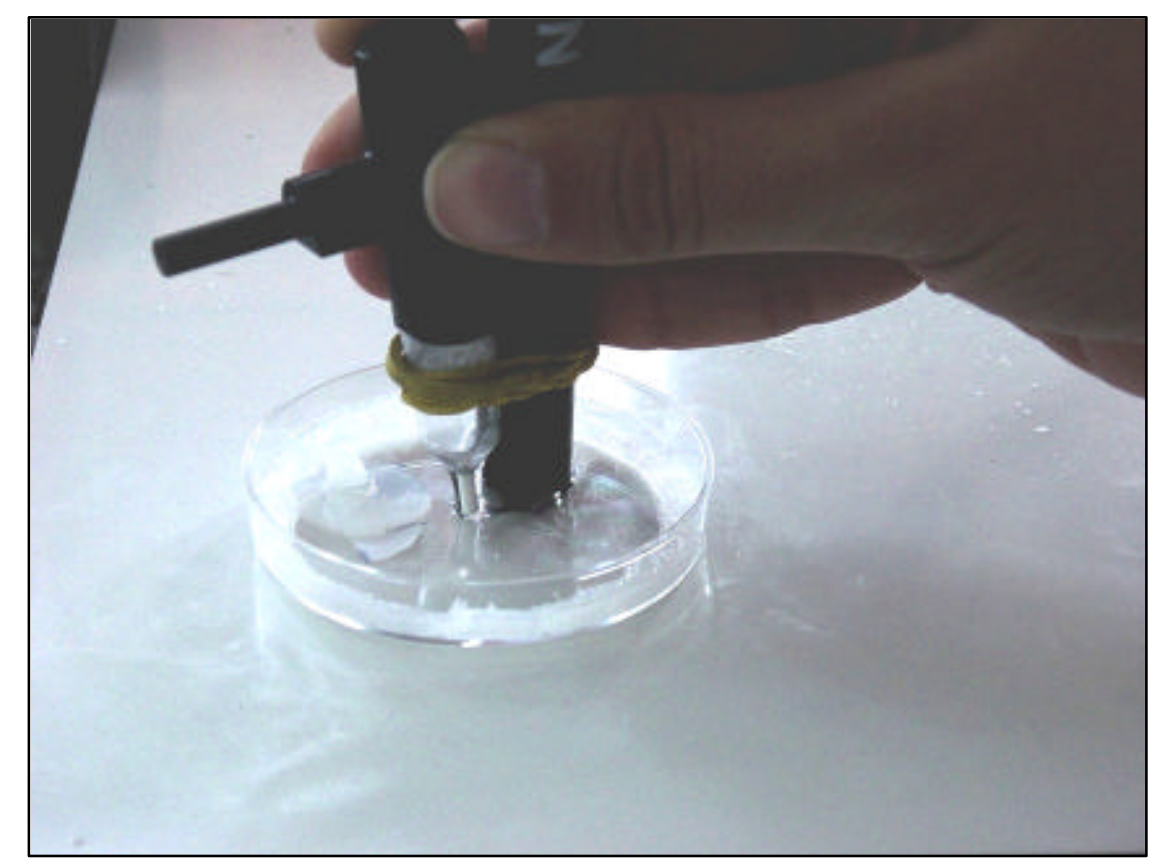

Figura 7. A leitura foi feita com eletrodo Orion 9409 e um micro eletrodo calomelano de referência 
RESULTADOS 


\section{5 - Resultados}

As Tabelas 3 e 4 mostram os valores médios e os respectivos desvios- padrão das concentrações de F encontradas nas unhas das mãos e dos pés, respectivamente, das crianças de 2-3 anos. As médias e os desvios-padrão foram efetuados para cada voluntário como também para cada dia da coleta das amostras, separadas em: unhas das mãos e unhas dos pés. A concentração de $F$ nas unhas variou de 1,258 a 17,417 $\mu \mathrm{g} / \mathrm{g}$. 
Tabela 3. Concentração média de $\mathrm{F}(\mu \mathrm{g} / \mathrm{g})$ nas amostras de unhas das mãos por data e voluntários.

\begin{tabular}{|c|c|c|c|c|c|c|c|c|c|c|c|c|}
\hline \multirow{2}{*}{ Data } & \multicolumn{10}{|c|}{ Voluntários } & \multirow{2}{*}{ Média } & \multirow{2}{*}{$( \pm D P)$} \\
\hline & 1 & 2 & 3 & 4 & 5 & 6 & 7 & 8 & 9 & 10 & & \\
\hline $29 / 11$ & * & 3,030 & 2,709 & 3,061 & 2,805 & 2,768 & 5,055 & 4,466 & * & 1,566 & 3,148 & 1,026 \\
\hline $13 / 12$ & 2,335 & 3,109 & 2,572 & * & 3,582 & 2,606 & 2,861 & 3,559 & 3,028 & 2,182 & 2,870 & 0,498 \\
\hline $27 / 12$ & 4,321 & 2,232 & 2,879 & 2,345 & 1,962 & 3,337 & 1,934 & 2,736 & 4,241 & 2,104 & 2,809 & 0,892 \\
\hline $10 / 01$ & 6,169 & 3,578 & 5,476 & 3,993 & 1,403 & 3,427 & 3,756 & 3,175 & 4,773 & 1,943 & 3,769 & 1,459 \\
\hline $24 / 01$ & 16,989 & 3,331 & 3,096 & 2,670 & 10,439 & 3,105 & 3,263 & 2,836 & 14,793 & 11,997 & 7,252 & 5,682 \\
\hline $07 / 02$ & 3,920 & 3,403 & * & 3,883 & 5,380 & 4,348 & 5,487 & 3,843 & 3,122 & 2,885 & 4,030 & 0,911 \\
\hline $21 / 02$ & 5,184 & 6,067 & 3,947 & 4,288 & * & 5,460 & 6,385 & 3,855 & 3,881 & 5,532 & 4,955 & 0,984 \\
\hline $07 / 03$ & 5,014 & 4,497 & 2,749 & 3,238 & 8,546 & 9,402 & 4,145 & 3,028 & * & 2,198 & 4,757 & 2,557 \\
\hline $21 / 03$ & 3,740 & 4,140 & 3,031 & 2,972 & 6,237 & 5,222 & 3,773 & 3,109 & 2,627 & 2,073 & 3,692 & 1,251 \\
\hline $04 / 04$ & 2,585 & 2,382 & 5,214 & 2,816 & * & 5,505 & 3,503 & 3,510 & 2,674 & 1,671 & 3,318 & 1,287 \\
\hline $18 / 04$ & 8,849 & 8,961 & 7,374 & 6,226 & * & 10,364 & 11,113 & 13,873 & 16,426 & 7,274 & 10,051 & 3,328 \\
\hline 02/05 & 6,858 & 6,474 & 3,042 & 4,556 & * & 8,308 & 5,112 & 5,183 & 4,347 & 4,110 & 5,332 & 1,615 \\
\hline $16 / 05$ & 5,270 & 3,229 & 3,638 & 3,574 & * & 4,940 & 5,302 & 5,998 & 4,770 & 2,989 & 4,412 & 1,071 \\
\hline $30 / 05$ & * & * & 2,294 & 4,704 & 4,722 & 2,738 & 4,433 & * & 1,966 & 1,953 & 3,259 & 1,303 \\
\hline $13 / 06$ & 2,127 & 3,031 & 3,058 & 1,554 & 2,732 & 1,947 & 5,786 & 3,824 & 2,561 & 2,268 & 2,889 & 1,206 \\
\hline $27 / 06$ & 1,890 & 2,314 & 2,281 & 1,905 & * & 3,084 & 4,045 & * & 2,251 & 2,075 & 2,481 & 0,734 \\
\hline $11 / 07$ & 1,362 & 1,637 & 1,574 & 1,389 & 2,707 & 1,785 & 3,672 & 5,764 & 2,459 & * & 2,483 & 1,445 \\
\hline $25 / 07$ & 1,724 & 1,697 & 1,689 & 1,557 & 4,729 & 2,157 & 2,009 & 2,722 & 2,863 & 1,305 & 2,245 & 1,004 \\
\hline Média & 4,896 & 3,712 & 3,331 & 3,219 & 5,423 & 4,472 & 4,535 & 4,468 & 4,799 & 3,301 & & \\
\hline (\#DP) & 3,841 & 1,897 & 1,473 & 1,305 & 3,940 & 2,556 & 2,048 & 2,711 & 3,741 & 2,723 & & \\
\hline
\end{tabular}

${ }^{*}$ Amostras perdidas 
Tabela 4. Concentração média de $\mathrm{F}(\mu \mathrm{g} / \mathrm{g})$ nas amostras das unhas dos pés por data e voluntários.

\begin{tabular}{|c|c|c|c|c|c|c|c|c|c|c|c|c|}
\hline \multirow{2}{*}{ Data } & \multicolumn{10}{|c|}{ Voluntários } & \multirow{2}{*}{ Média } & \multirow{2}{*}{$( \pm \mathrm{DP})$} \\
\hline & 1 & 2 & 3 & 4 & 5 & 6 & 7 & 8 & 9 & 10 & & \\
\hline $29 / 11$ & 1,413 & 2,599 & 3,265 & 1,461 & 1,765 & * & * & 5,481 & 2,254 & 1,394 & 2,454 & 1,391 \\
\hline $13 / 12$ & 2,650 & 2,421 & 4,783 & * & 2,009 & 1,900 & 2,688 & 2,226 & 3,802 & 1,366 & 2,649 & 1,045 \\
\hline $27 / 12$ & 3,453 & * & 2,577 & * & 2,951 & 2,753 & 2,918 & 2,511 & 2,879 & 1,726 & 2,721 & 0,494 \\
\hline $10 / 01$ & 7,639 & 5,359 & 4,865 & 4,322 & 3,029 & 3,751 & 2,469 & 1,903 & 4,544 & * & 4,209 & 1,717 \\
\hline $24 / 01$ & 4,677 & * & 4,323 & 3,213 & 3,441 & 2,845 & 2,177 & 2,526 & 13,744 & 13,563 & 5,612 & 4,628 \\
\hline 07/02 & 8,893 & 4,963 & 4,840 & 3,376 & 3,665 & 3,093 & 4,652 & 3,735 & 3,452 & 3,287 & 4,396 & 1,720 \\
\hline $21 / 02$ & 4,080 & 9,237 & 6,240 & 3,552 & 2,300 & 2,720 & 6,998 & 5,265 & 7,189 & 3,827 & 5,141 & 2,235 \\
\hline $07 / 03$ & 4,855 & 3,101 & 2,623 & 1,905 & * & 2,790 & 3,656 & 2,714 & * & 1,258 & 2,863 & 1,084 \\
\hline $21 / 03$ & 5,036 & 4,183 & 4,093 & 1,936 & 1,695 & 2,115 & 1,950 & 3,617 & 2,630 & 1,370 & 2,863 & 1,267 \\
\hline $04 / 04$ & 3,624 & 3,416 & 3,922 & 1,715 & * & 4,005 & 1,568 & 2,382 & 3,952 & 2,678 & 3,029 & 0,969 \\
\hline $18 / 04$ & 8,573 & 17,417 & 10,060 & 6,512 & 5,744 & 5,795 & 12,015 & * & 10,551 & 6,011 & 9,186 & 3,862 \\
\hline 02/05 & 8,958 & 12,954 & 5,859 & 7,506 & 3,264 & 3,817 & 5,436 & 6,523 & 7,890 & 3,054 & 6,526 & 3,013 \\
\hline $16 / 05$ & 5,936 & 6,373 & 4,758 & 4,734 & 3,068 & 3,335 & 5,440 & 5,264 & 5,657 & 3,438 & 4,800 & 1,161 \\
\hline $30 / 05$ & * & * & 2,217 & 4,217 & 4,786 & 1,750 & 2,447 & 3,283 & 6,551 & 2,352 & 3,450 & 1,632 \\
\hline $13 / 06$ & 1,748 & 2,060 & 3,393 & 2,349 & 4,829 & 1,457 & 1,745 & 1,637 & 5,147 & 1,524 & 2,589 & 1,386 \\
\hline $27 / 06$ & 1,733 & 2,099 & 3,107 & 5,365 & * & 1,623 & 2,152 & 1,764 & 6,757 & 1,771 & 2,930 & 1,862 \\
\hline $11 / 07$ & 2,264 & 2,165 & 3,240 & 3,156 & 5,660 & 1,461 & 2,484 & * & 2,901 & * & 2,916 & 1,253 \\
\hline $25 / 07$ & 2,100 & 2,102 & 3,132 & 2,889 & 2,493 & 1,631 & 2,827 & 1,818 & 4,006 & * & 2,555 & 0,745 \\
\hline Média & 4,567 & 5,363 & 4,294 & 3,638 & 3,380 & 2,755 & 3,742 & 3,291 & 5,524 & 4,063 & & \\
\hline (\#DP) & 2,610 & 4,537 & 1,824 & 1,737 & 1,327 & 1,158 & 2,623 & 1,549 & 3,061 & 3,134 & & \\
\hline
\end{tabular}

${ }^{*}$ Amostras perdidas 
A Figura 8 ilustra a concentração média de $F$ nas unhas das mãos e dos pés das crianças, ao longo do tempo sendo que de 29/11 a 27/12 utilizourse dentifrício placebo, de 28/12 a 24/01 dentifrício fluoretado, de 25/01 a 21/02 novamente dentifrício placebo e desta data em diante os voluntários voltaram a sua condição normal. Podemos observar um aumento na concentração média de $\mathrm{F}$ nas unhas na $5^{\underline{a}}$ coleta, quando foram encontrados valores de 7,251 \pm 5,682 e 5,612 \pm 4,628 para unhas das mãos e dos pés, respectivamente, e o pico na concentração de $\mathrm{F}$ ocorreu na $11^{\mathrm{a}}$ coleta quando se encontraram valores de 10,051 $\pm 3,328$ e 9,186 $\pm 3,862$, para as mãos e pés, respectivamente. 


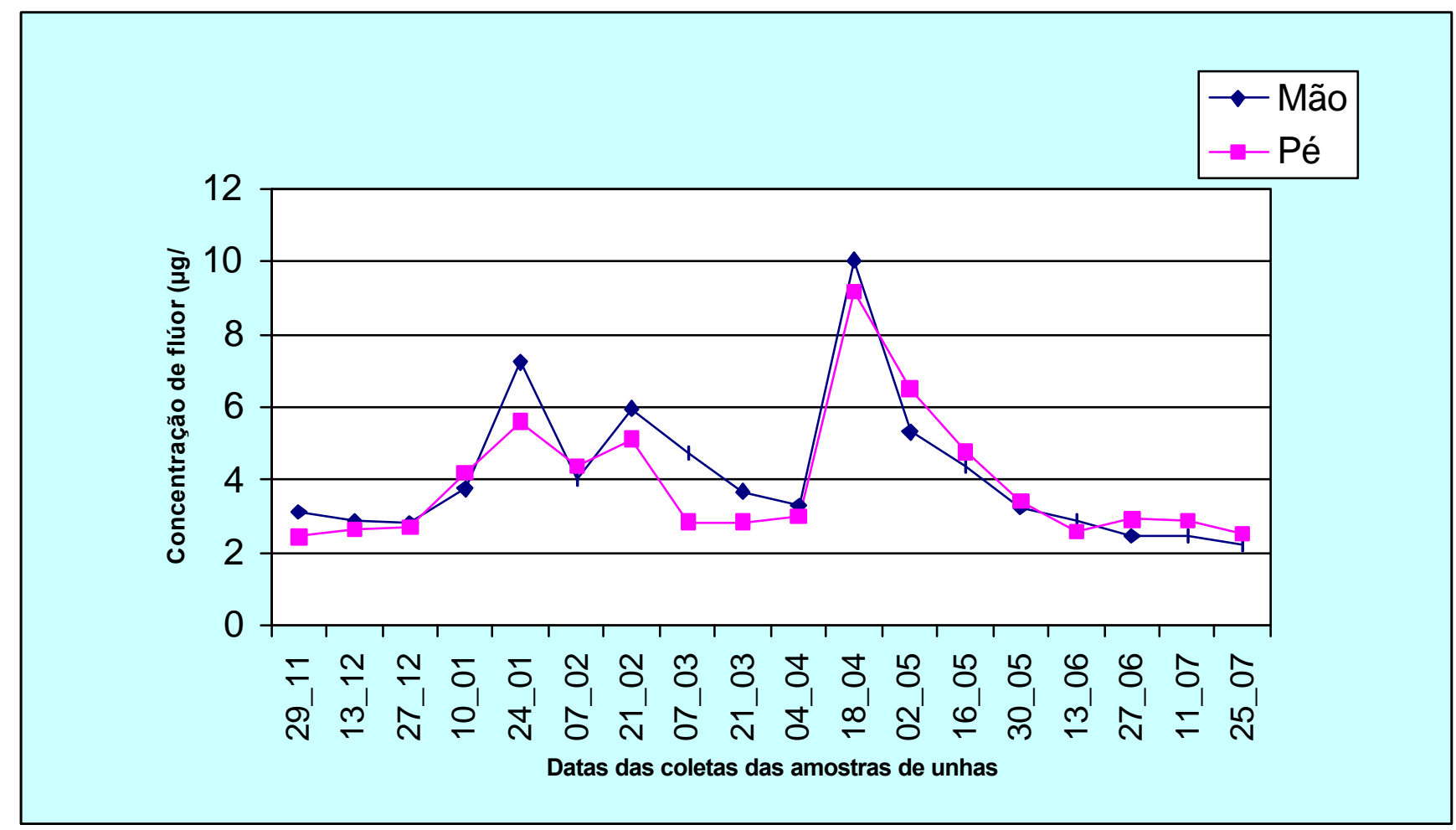

Figura 8. Concentração de F nas unhas das mãos e dos pés ao longo do tempo. Foi usado dentifrício placebo entre 29/11 e 27/12, dentifrício fluoretado (1500 ppm F) entre 28/12 e 24/01 e dentifrício placebo entre 25/01 e 21/02, quando as crianças retornaram ao seu dentifrício habitual. 
A Tabela 5 mostra as coletas das unhas realizadas, nas respectivas datas, bem como as médias e os desvios-padrão. Apesar da concentração média de $\mathrm{F}$ nas unhas das mãos ser ligeiramente maior que a dos pés, esta diferença não foi estatisticamente significante $(F=0,36922, p=0,558446)$. No entanto, a Análise de Variância revelou uma diferença significante entre os tempos de coleta $(F=14,50786, \quad p<0,0000001)$. Nesta tabela também podemos observar o teste de Tukey realizado para comparações individuais entre as diferentes coletas $(p<0,05)$. O pico encontrado na $11^{\text {a }}$ coleta foi significantemente maior quando comparado com todas as outras coletas $(p<0,05)$. O pico mais discreto, encontrado na $5^{\text {a }}$ coleta, só não foi significantemente diferente dos valores encontrados nas coletas 6, 7, 12 e $13(p>0,05)$. 
Tabela 5. Concentração média $( \pm \mathrm{DP})$ de $\mathrm{F}(\mu \mathrm{g} F / \mathrm{g})$ nas amostras de unhas das mãos e dos pés, nas diferentes coletas

\begin{tabular}{clrl}
\hline Coletas & Datas & Unhas das mãos & Unhas dos pés \\
\hline 1 & $29 / 11 / 01^{\mathrm{a}}$ & $3,148( \pm 1,026)$ & $2,454( \pm 1,391)$ \\
2 & $13 / 12 / 01^{\mathrm{a}}$ & $2,870( \pm 0,497)$ & $2,649( \pm 1,044)$ \\
3 & $27 / 12 / 01^{\mathrm{a}}$ & $2,809( \pm 0,891)$ & $2,721( \pm 0,494)$ \\
4 & $10 / 01 / 02^{\mathrm{abc}}$ & $3,769( \pm 1,459)$ & $4,209( \pm 1,717)$ \\
5 & $24 / 01 / 02^{\mathrm{d}}$ & $7,251( \pm 5,682)$ & $5,612( \pm 4,627)$ \\
6 & $07 / 02 / 02^{\mathrm{abcd}}$ & $4,030( \pm 0,911)$ & $4,395( \pm 1,720)$ \\
7 & $21 / 02 / 02^{\mathrm{bcd}}$ & $4,955( \pm 0,984)$ & $5,140( \pm 2,234)$ \\
8 & $07 / 03 / 02^{\mathrm{abc}}$ & $4,757( \pm 2,557)$ & $2,862( \pm 1,084)$ \\
9 & $21 / 03 / 02^{\mathrm{ab}}$ & $3,692( \pm 1,250)$ & $2,862( \pm 1,266)$ \\
10 & $04 / 04 / 02^{\mathrm{a}}$ & $3,317( \pm 1,286)$ & $3,029( \pm 0,968)$ \\
11 & $18 / 04 / 02^{\mathrm{e}}$ & $10,051( \pm 3,328)$ & $9,186( \pm 3,862)$ \\
12 & $02 / 05 / 02^{\mathrm{cd}}$ & $5,332( \pm 1,615)$ & $6,526( \pm 3,013)$ \\
13 & $16 / 05 / 02^{\mathrm{abcd}}$ & $4,412( \pm 1,071)$ & $4,800( \pm 1,161)$ \\
14 & $30 / 05 / 02^{\mathrm{ab}}$ & $3,258( \pm 1,302)$ & $3,450( \pm 1,631)$ \\
15 & $13 / 06 / 02^{\mathrm{a}}$ & $2,888( \pm 1,205)$ & $2,588( \pm 1,385)$ \\
16 & $27 / 06 / 02^{\mathrm{a}}$ & $2,480( \pm 0,734)$ & $2,930( \pm 1,862)$ \\
17 & $11 / 07 / 02^{\mathrm{a}}$ & $2,483( \pm 1,445)$ & $2,916( \pm 1,252)$ \\
18 & $25 / 07 / 02^{\mathrm{a}}$ & $2,245( \pm 1,004)$ & $2,555( \pm 0,744)$ \\
\hline
\end{tabular}

Datas com letras iguais não foram significativamente diferentes com relação à concentração de $F$ $(p>0,05)$ 
Na Tabela 6 temos os valores da concentração de $\mathrm{F}$ (ppm) na água das residências dos voluntários nos diferentes dias das coletas de unhas. A concentração média de $F$ variou entre 0,217 e 1,147 ppm $(n=35)$. O teste Kruskall-Wallis encontrou uma diferença significante entre a água coletada nas diferentes residências $(\mathrm{KW}=15,873, \mathrm{p}=0,032)$. $\mathrm{O}$ teste de Dunn demonstrou que a concentração de $\mathrm{F}$ na água coletada na casa dos voluntários 4, 5, 6 foi significantemente mais alto do que a água coletada nas residências dos voluntários 7-8, 9, $10(p<0,05)$. A figura 9 ilustra os dados desta tabela.

Tabela 6. Concentração de $F$ (ppm) na água de abastecimento das residências dos voluntários.

\begin{tabular}{|c|c|c|c|c|c|c|c|}
\hline \multirow[b]{2}{*}{ Datas } & \multicolumn{6}{|c|}{ Voluntários } & \multirow[b]{2}{*}{ ( $\pm D P)$} \\
\hline & $1,2,3^{*}$ & $4,5,6^{*}$ & $7,8^{\star *}$ & 9 & 10 & Média & \\
\hline $29 / 11$ & 0,854 & 0,908 & 0,302 & 0,854 & 0,685 & 0,721 & 0,694 \\
\hline $13 / 12$ & 1,04 & 0,997 & 0,857 & 0,777 & 0,743 & 0,883 & 0,131 \\
\hline 27/12 & 0,975 & 0,993 & 0,928 & 0,813 & 0,813 & 0,904 & 0,087 \\
\hline $10 / 01$ & 0,869 & 0,975 & 0,904 & 0,526 & 1,01 & 0,857 & 0,193 \\
\hline $24 / 01$ & 0,921 & 0,971 & 0,881 & 0,217 & 0,691 & 0,736 & 0,309 \\
\hline 07/02 & 0,749 & 1,081 & 0,332 & 0,558 & 0,524 & 0,649 & 0,283 \\
\hline $21 / 02$ & 0,885 & 1,147 & 0,58 & 0,956 & 0,802 & 0,874 & 0,208 \\
\hline Média & $0,899^{a b}$ & $1,010^{a}$ & $0,683^{b}$ & $0,672^{b}$ & $0,753^{b}$ & & \\
\hline ( $\pm D P)$ & 0,093 & 0,079 & 0,276 & 0,254 & 0,149 & & \\
\hline
\end{tabular}

*Voluntários: trigêmeos

** Voluntários: gêmeos

*** Médias na mesma linha seguidas por letras iguais não são estatisticamente diferentes $(P>0,05)$. 


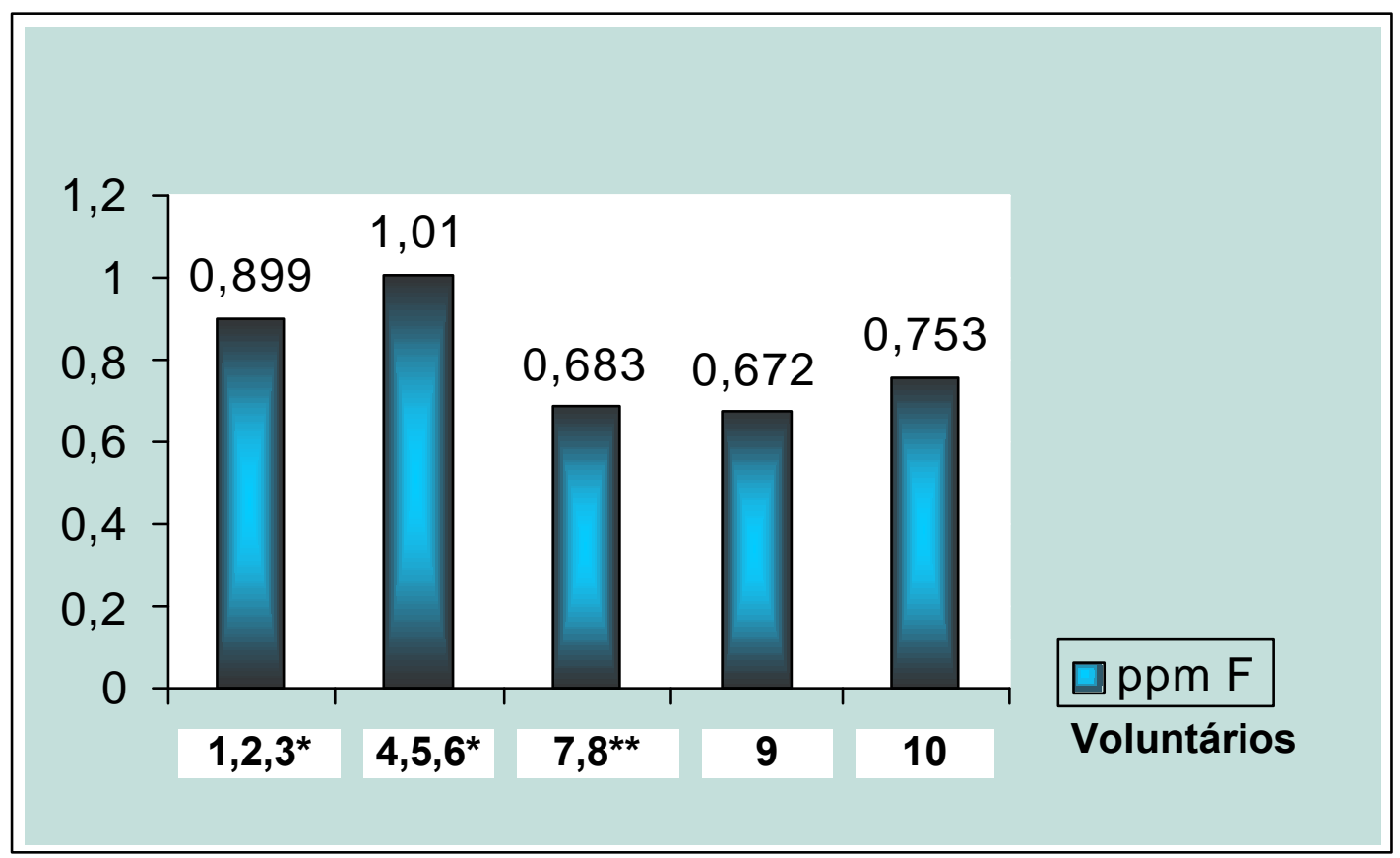

*Voluntários: trigêmeos

** Voluntários: gêmeos

FIGURA 9. Concentração média de $F$ (ppm) na água de abastecimento das residências dos voluntários. 
Na Tabela 7 têm-se os dados dos hábitos de escovação das crianças antes do início de experimento. Esta tabela demonstra o tipo de dentifrício (fluoretado ou placebo - sem F) e a freqüência de escovação. Observa-se que três crianças realizavam a escovação antes do experimento com dentifrício placebo - sem $\mathrm{F}$ e as outras utilizavam dentifrício fluoretado (1100 - 1500 ppm), ficando a média da freqüência da escovação em 2,4 escovações ao dia.

Tabela 7. Hábitos de escovação das crianças antes do experimento.

\begin{tabular}{ccc}
\hline Voluntários & Dentifrício & Freqüência \\
\hline $\mathbf{1 , 2 , 3 ^ { * }}$ & placebo & 3x/dia \\
$\mathbf{4 , 5 , 6 ^ { * }}$ & Tandy $(1100 \mathrm{ppm}, \mathrm{NaF})$ & 2x/dia \\
$\mathbf{7 , 8 ^ { * * }}$ & Tandy $(1100 \mathrm{ppm}, \mathrm{NaF})$ & $3 x /$ dia \\
$\mathbf{9}$ & Tandy (1100 ppm, NaF) & 2x/dia \\
$\mathbf{1 0}$ & Sorriso (1500ppm, MFP) & 2x/dia \\
\hline${ }^{*}$ Voluntários: trigêmeos & \\
${ }^{*}$ Voluntários: gêmeos &
\end{tabular}


A Figura 10 mostra a correlação positiva $(r=0,571)$ e altamente significante $(p=0,0000001)$ da concentração de $F$ presente nas unhas das mãos e dos pés, obtida através do coeficiente de correlação de Pearson.

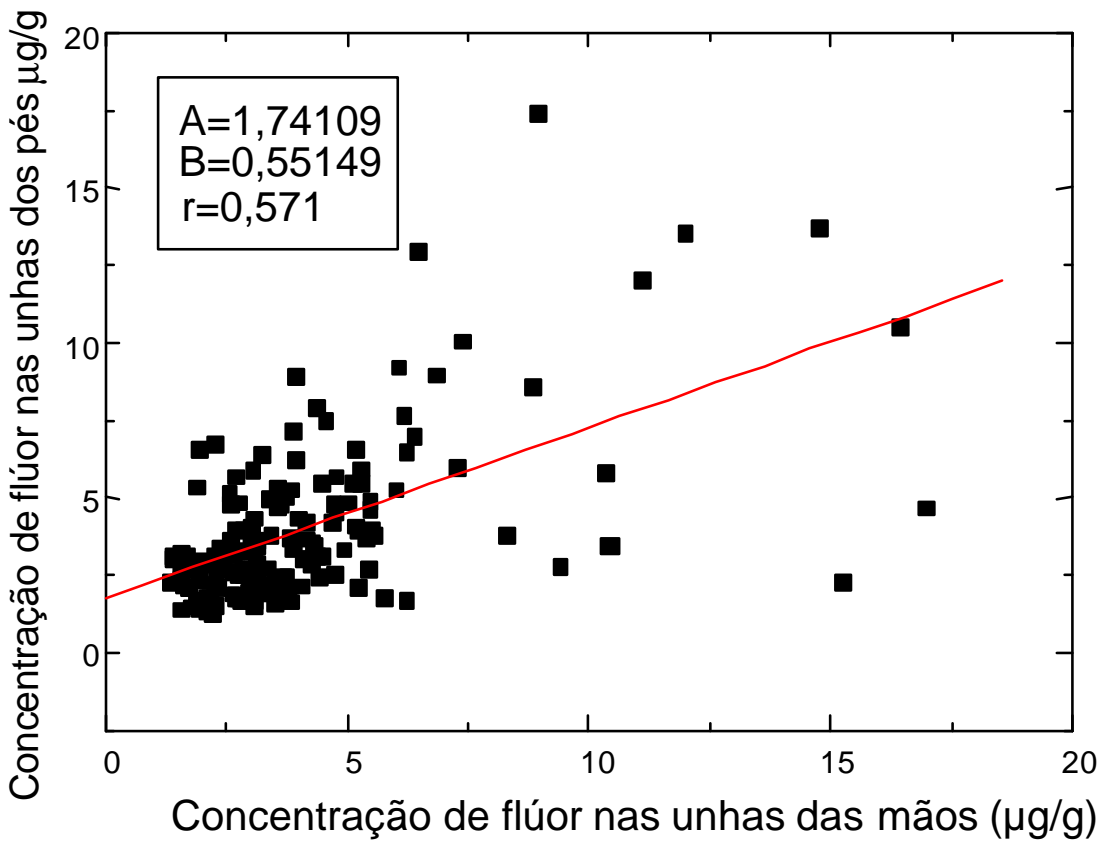

FIGURA 10. Correlação entre a concentração de $F(\mu \mathrm{g} / \mathrm{g})$ nas unhas das mãos e dos pés. 
DISCUSSÃO 


\section{6- Discussão}

Há na literatura vários trabalhos enfocando o uso da unha como biomarcador de exposição ao $\mathrm{F}$ em animais (BUZALAF et al. ${ }^{15}$, 2002) e humanos (SCHAMSCHULA et al. ${ }^{86}, 1985$; MACHOY ${ }^{58}, 1989$; CZARNOWSKI; KRECHNIAK ${ }^{26}$, 1990; SCHMIDT; LEUSCHKE ${ }^{87}, 1990$; SPATE et al. ${ }^{89}, 1994$; CZARNOWSKI et al. ${ }^{27}, 1996$; WHITFORD et al. ${ }^{103}$, 1999). No entanto, este é o primeiro relato do uso da unha como biomarcador de exposição subcrônica ao $\mathrm{F}$ a partir do dentifrício fluoretado em crianças em idade de risco para fluorose dentária.

No presente estudo, o pico na concentração de F nas unhas ocorreu na 112 dias depois de iniciado o uso do dentifrício fluoretado. Este achado está de acordo com WHITFORD et al. ${ }^{103}$ (1999), que administraram $3 \mathrm{mg}$ adicionais de $\mathrm{F}$ por dia, durante 1 mês para um voluntário, e observaram que demorou 108 dias, após o início da administração de $F$, para que um aumento na sua concentração fosse detectado nas unhas. Isto fez os autores hipotetizarem que o $\mathrm{F}$ seria incorporado à unha a partir da extremidade de crescimento, e não a partir do leito. Visto que o trabalho de WHITFORD et al. ${ }^{103}$ foi baseado em amostras de unhas coletadas de um adulto, um tempo mais curto poderia ser esperado para o presente estudo, pois o comprimento das unhas das crianças é menor. De qualquer modo, o trabalho de WHITFORD et al. ${ }^{103}$ foi baseado em dados provenientes de um único voluntário adulto. Além do mais, a velocidade de crescimento das 
unhas e as alterações metabólicas que podem ocorrer em função da idade podem dificultar a comparação entre os dois estudos. Foi estimado por McDONNELL; O’MULLANE ${ }^{65}$ (2001) que o crescimento médio das unhas dos polegares de crianças de 2-3 anos de idade é $0,7 \mathrm{~mm} /$ semana (variação $0,5-0,9)$. Os autores relataram ainda que o comprimento das unhas dos polegares até o ponto onde elas poderiam ser cortadas e analisadas para o conteúdo de $F$ foi $7,5 \mathrm{~mm}$ (variação $6,4-9,2$ ). Se for considerado que pode haver alguma extensão de unha abaixo da cutícula, que possa já estar recebendo $F$ da circulação sistêmica, então o tempo de aproximadamente 112 dias encontrado neste estudo para que as unhas possam crescer deste ponto até as pontas, as quais poderiam ser cortadas e analisadas para o $\mathrm{F}$, parece ser bastante razoável.

Nosso estudo demonstrou um aumento pequeno, mas estatisticamente significante na concentração de $F$ nas unhas na 28 dias depois de iniciado o uso de dentifrício fluoretado. Embora este aumento não tenha ocorrido para todas as crianças estudadas, o resultado mostra alguns aspectos diferentes dos relatados na literatura, quando se usa unhas como biomarcadores de exposição subcrônica ao F. Este aumento não era esperado, já que WHITFORD et al. ${ }^{103}$ (1999), em seu estudo baseado em coletas de amostras de unhas de um único indivíduo adulto, sugerem que o F entra nas unhas das mãos pela matriz (extremidade de crescimento). Este pequeno aumento na concentração de $\mathrm{F}$ do presente estudo sugere que o $\mathrm{F}$ entra também através do leito da unha. Além disso, as concentrações de F 
nas unhas das crianças na $6^{\underline{a}}$ e $7^{\text {a }}$ coletas, ainda estavam aumentadas, e não diferiram estatisticamente da concentração de $F$ encontrada no pico menor, indicando um aumento na concentração de $F$ nas unhas por todo o período em que houve uso do dentifrício fluoretado. As crianças que participaram deste estudo tinham idade de 2-3 anos. É possível que o leito das unhas de crianças mais jovens seja imaturo e permita a passagem de F para as unhas. Sendo assim, essa informação seria útil para trabalhos envolvendo exposições subcrônicas e provavelmente agudas ao F. Nestes casos, o tempo entre a administração do $\mathrm{F}$ e sua detecção nas unhas seria provavelmente menor do que previamente esperado para crianças jovens.

A maioria das crianças neste estudo utilizava dentifrício fluoretado (1100 ppm) antes do início do experimento. Somente três crianças usavam dentifrício sem F. Assim, a redução na concentração de $F$ nas unhas poderia ser esperada quando o dentifrício placebo foi usado pelas crianças que previamente utilizavam dentifrício fluoretado. De qualquer modo, esta redução não foi observada. Isto pode ter ocorrido devido ao fato de que as crianças usavam pouca quantidade de dentifrício fluoretado ou escovavam seus dentes poucas vezes ao dia antes do início do experimento. Em adição, existe uma distribuição de estado estacionário ("steady-state") para o F entre o fluido extracelular e a camada de hidratação dos cristalitos ósseos (WHITFORD $\left.^{102}, 1996\right)$. Isto pode ajudar a explicar a ausência de redução na concentração de $F$ nas unhas quando o dentifrício placebo foi usado. A camada de hidratação dos cristalitos é contínua, ou pelo menos disponível, 
aos fluidos extracelulares. Presumivelmente, o F neste "pool" é rapidamente passível de trocas, podendo, deste modo, sofrer migração em qualquer uma das direções, dependendo das concentrações relativas no fluido extracelular e na camada de hidratação (WHITFORD ${ }^{102}$, 1996). Quando os níveis plasmáticos caem, um fluxo de $\mathrm{F}$ da camada de hidratação para o fluido extracelular, e daí para o plasma, ocorre. Uma vez que as crianças estavam habituadas a uma exposição crônica ao $\mathrm{F}$ pela dieta e dentifrício antes de iniciado o estudo, a queda transitória nos níveis de $\mathrm{F}$ plasmáticos que poderia ter ocorrido quando o dentifrício placebo foi usado pode ter sido compensada por este mecanismo. Já que os níveis de plasma devem ter permanecido relativamente estáveis, por conta deste mecanismo, a concentração de $\mathrm{F}$ nas unhas não mudou. Também este mecanismo pode ter sido provavelmente o responsável pelo fato de $\operatorname{ARSATI}^{3}$ (2003) não ter encontrado uma redução na concentração de $F$ nas unhas de crianças que usavam dentifrício fluoretado e passaram a usar dentifrício placebo. A autora analisou as unhas de crianças brasileiras, residentes em Piracicaba-SP, com idade entre 20 e 30 meses, que receberam por três meses $F$ proveniente da dieta mais dentifrício fluoretado (fase A), e num segundo momento, também por três meses, apenas da dieta fluoretada (fase B). A concentração de F nas unhas das mãos das crianças $($ DP, intervalo de $95 \%$ de confiança, unidade $\mu \mathrm{g} / \mathrm{g})$ foi: $2,80 \pm 0,94(2,42$ a 3,19) e 2,64 $\pm 0,91(2,27$ a 3,02) para as fases $A$ e $B$, respectivamente, sem diferença significante entre ambas. 
Em virtude destes dados, existe uma dificuldade em se usar a unha como biomarcador de exposição crônica ao F a partir do dentifrício, na mesma população, quando a exposição ao dentifrício é eliminada. O caminho inverso parece ser possível. Além do mais, pode-se especular que a unha possa ser usada para diferenciar crianças com histórias variadas de exposição ao $\mathrm{F}$ pelo dentifrício, à semelhança do que vem sendo relatado para a água de abastecimento (WHITFORD ${ }^{103}, 1999 ;$ ARSATP $^{3}$ 2003).

No presente estudo, as mães foram orientadas a colocar, na escova, uma porção de dentifrício (contendo 1500 ppm F) do tamanho de uma ervilha. Uma limitação do estudo foi não ter sido realizada estimativa de ingestão de $\mathrm{F}$ das crianças a partir da dieta e do dentifrício. No entanto, tem sido relatado que crianças na faixa etária entre 2 e 3 anos ingerem cerca de $50 \%$ da quantidade de dentifrício aplicada à escova (RICHARDS; BANTING ${ }^{80}, 1996$; LIMA; CURY57, 2001). Desta maneira, pode-se estimar que a quantidade média de $\mathrm{F}$ ingerida diariamente pela escovação, quando se usou dentifrício fluoretado tenha sido em torno de 1,125 mg de F (considerando-se o uso de $1,5 \mathrm{~g}$ de dentifrício por dia, e uma ingestão de $50 \%$ do mesmo).

Também, neste estudo, não foi realizada estimativa de ingestão diária de F a partir da dieta. Há alguns relatos na literatura para crianças na faixa etária de 2-3 anos, que poderiam permitir especulações. LIMA; CURY 57 (2001) e ROJAS-SANCHES ${ }^{85}$ (1999) relataram ingestões diárias de F a partir da dieta para crianças brasileiras e americanas, respectivamente em 
torno de $0,04 \mathrm{mg} / \mathrm{kg}$ peso corporal, o que corrigido pelo peso, corresponderia a uma quantidade de $\mathrm{F}$ ingerido em torno de 0,54 $\mathrm{mg}$ (considerando-se 0 peso corporal médio de 13,5 kg). Assim, estima-se que a quantidade de $\mathrm{F}$ ingerida pelas crianças do presente estudo a partir do dentifrício fluoretado, no período experimental, tenha sido superior à ingerida a partir da dieta. Quando o dentifrício fluoretado era usado habitualmente (antes do período experimental e após ele), a ingestão de $\mathrm{F}$ a partir dele deve ter sido semelhante àquela da dieta, como relata a literatura (RICHARDS; BANTING ${ }^{80}$, 1996; LIMA; CURY57 ${ }^{57}$ 2001), pois a maioria das crianças usava dentifrício contendo 1100 ppm F e provavelmente quantidades menores do que a empregada no estudo.

Quando se fala em ingestão de F, qualquer que seja a fonte, deve-se sempre ter em mente a sua biodisponibilidade, pois o fato de uma dose de F ser ingerida não implica que 100\% dela será absorvida. Deste modo, os cálculos de ingestão de $\mathrm{F}$ feitos devem estar superestimados.

SPAK; EKSTRAND; ZYLBERSTEIN ${ }^{88}$ (1982) administraram 3 soluções diferentes (500 mL de uma solução aquosa contendo 10 ppm de $\mathrm{F}$, $500 \mathrm{~mL}$ de leite contendo 10 ppm $\mathrm{F}$ e $500 \mathrm{~mL}$ de uma fórmula infantil preparada com uma solução de $10 \mathrm{ppm}$ F) contendo $5 \mathrm{mg}$ F para 4 voluntários, em 3 ocasiões separadas e monitoraram os níveis de F urinários e plasmáticos por 15 horas. Foi observada uma absorção de $72 \%$ do F presente no leite e $65 \%$ do F presente na fórmula infantil. Foi relatado que os alimentos poderiam atuar como uma barreira física, impedindo o acesso do 
F à mucosa do trato gastro-intestinal. Os autores enfatizaram que a ingestão diária total de $\mathrm{F}$ por crianças pode estar sendo superestimada.

Num estudo de protocolo semelhante, TRAUTNER; SIEBERT ${ }^{95}$ (1986) analisaram a biodisponibilidade de produtos à base de carne, frango e peixe, além de chá e leite, comparados com solução de $\mathrm{NaF}$ e suplementos de $\mathrm{NaF}$. Os autores observaram que o tempo médio para se atingir o pico na concentração plasmática de $\mathrm{F}$ quando se usou solução de $\mathrm{NaF}$ foi de $26 \pm 8,2$ minutos, enquanto que quando se administraram suplementos, foi de $41 \pm 9,3$ minutos, mostrando claramente o tempo necessário para a dissolução dos suplementos no trato gastro-intestinal. A curva da concentração de $\mathrm{F}$ no plasma ao longo do tempo após sua ingestão foi similar para o chá e a solução de NaF. Entretanto, após a ingestão de produtos à base de carne, frango e peixe, o aumento na concentração de $\mathrm{F}$ plasmática foi mais demorado, não sendo observado um pico definido, provavelmente devido à alta concentração de cálcio nestes alimentos. Também a adição de leite à solução de $\mathrm{NaF}$ e de sacarose ao chá reduziu a disponibilidade do $\mathrm{F}$, enquanto que a adição de sacarose à solução de $\mathrm{NaF}$ não alterou sua curva plasmática. Acredita-se isto ocorreu porque a ingestão concomitante de alimentos afeta a absorção de $F$, apesar de este mecanismo não estar ainda completamente esclarecido.

A literatura tem se mostrado contraditória no que diz respeito à biodisponibilidade do F a partir do NaF e do MFP. 
O F presente no MFP $\left(\mathrm{Na}_{2} \mathrm{PO}_{3} \mathrm{~F}\right)$ não é iônico, e sim covalentemente ligado ao fósforo. Segundo WHITFORD ${ }^{100}$ (1990) a absorção do $\mathrm{F}$ presente no MFP ocorre principalmente, após hidrólise enzimática da molécula por fosfatases. Após a administração oral, a absorção do MFP ocorre mais lentamente que a do $\mathrm{NaF}$ e de outros compostos solúveis e iônicos, o que resulta em picos plasmáticos menores e tardios. Isto tem sido atribuído à relativa perda de atividade da fosfatase ácida na mucosa gástrica (ERICSSON $\left.{ }^{33}, 1983\right)$.

Contraditoriamente, RIGALLI et al. ${ }^{82}$ (1994) relataram que, em ratos, o MFP é absorvido no estômago sem hidrólise. Este fenômeno, juntamente com o fato de que o MFP se liga a globulinas plasmáticas, formando o complexo MFP- $\alpha-2$ macroglobulina, causa um aumento imediato na concentração de MFP ligado a proteínas, significantemente maior que o aumento na concentração plasmática de $\mathrm{F}$ ultrafiltrável. O metabolismo do complexo MFP- $\alpha-2$-macroglubulina envolve a ligação a receptores, incorporação pelas células, degradação lisossomal e retorno do $\mathrm{F}$ ligado a moléculas de baixo peso molecular $(2200 \pm 600 \mathrm{Da})$ para o espaço extracelular. Segundo ESTEBAN; RIGALLI; PUCHE ${ }^{35}$ (1997) o F inorgânico seria o produto final da hidrólise lisossomal dos complexos. Por outro lado, no lúmen intestinal o MFP é hidrolisado numa proporção 3 vezes maior que a absorção de F. Após o preenchimento do "loop" duodenal com MFP, o F ultrafiltrável contribui para o aumento da concentração plasmática de $F$, sem evidência de MFP ligado a proteínas (RIGALLI et al. ${ }^{82}$, 1994). RIGALLI et 
al..$^{81}$ (1996) relataram que, em humanos, após a administração oral de NaF, todo o F plasmático é difusível. Por outro lado, após a ingestão de MFP, o plasma contém $\mathrm{F}$ difusível e ligado a proteínas durante 6-8 horas após a administração. A área sob a curva do F plasmático total para o MFP (1540 $\pm 117 \mu \mathrm{mol} . \mathrm{min} / \mathrm{L})$ foi o dobro daquela do $\mathrm{NaF} \quad(812 \pm 52 \mu \mathrm{mol} . \mathrm{min} / \mathrm{L})$ $(\mathrm{p}<0,001)$. Baseado nisto, os autores concluíram que a biodisponibilidade do F a partir do MFP é o dobro daquela do NaF, embora nem todo o $F$ do MFP esteja disponível para ultrafiltração.

Já o trabalho de TRAUTNER; EINWAG ${ }^{94}$ (1989) relatou uma biodisponibilidade semelhante para o $\mathrm{F}$ presente no MFP ou no $\mathrm{NaF}$ em humanos. Os autores testaram algumas variáveis, observando que o pico da concentração plasmática de $\mathrm{F}$ foi diminuído quando os compostos eram administrados concomitantemente com alimentos. Do mesmo modo, a administração conjunta de leite, reduziu a biodisponibilidade em $30 \%$ aproximadamente. Entretanto, quando o leite era ingerido juntamente com outros alimentos, a biodisponibilidade não era alterada. Isto levou os autores a hipotetizarem que a formação de sais de cálcio e o aprisionamento do $\mathrm{F}$ nos produtos de coagulação do leite são importantes fatores que levam à redução na biodisponibilidade. No entanto, o aumento na permanência do quimo após a ingestão concomitante de alimentos permite que, pelo processo digestivo, o F seja liberado dos compostos e produtos de coagulação aos quais se encontrava ligado. 
Apesar destas contradições, há uma tendência a se considerar biodisponibilidades semelhantes para o $\mathrm{F}$ ingerido na forma de $\mathrm{NaF}$ e de MFP (WHITFORD $\left.{ }^{102}, 1996\right)$.

No presente trabalho, apesar de a concentração média de $\mathrm{F}$ nas unhas das mãos ser ligeiramente maior que a encontrada nas unhas dos pés, na maioria dos períodos experimentais, esta diferença não foi estatisticamente significante. Estes dados vão ao encontro aos relatados por MACHOY ${ }^{58}$ (1989) que comparou a concentração de $F$ nas unhas das mãos com as dos pés de um único indivíduo de 10-12 anos de idade, mas contrariam os achados de WHITFORD et al. ${ }^{103}$ (1999), que encontraram valores para as unhas das mãos aproximadamente o dobro dos encontrados para as dos pés. Esta heterogeneidade dos resultados relatados na literatura pode ser devida às características da amostra estudada, como tamanho e idade dos voluntários. Um estudo comparando diferentes faixas etárias talvez possa ajudar a esclarecer o fato.

Os resultados deste trabalho indicam que a unha pode ser usada como biomarcador de exposição subcrônica ao $\mathrm{F}$ a partir do dentifrício fluoretado. Entretanto, um estudo com protocolo similar, mas no qual seja feita uma estimativa o mais precisa possível da ingestão diária de $\mathrm{F}$ das crianças a partir da dieta e dentifrício poderia contribuir para uma melhor elucidação desta questão. Da mesma maneira, seria importante verificar se as unhas poderiam ser usadas como biomarcadores de ingestão crônica de F a partir do dentifrício, em populações infantis submetidas a diferentes 
níveis de exposição ao mesmo, particularmente no presente momento, quando existe uma tendência a se indicar o uso de dentifrícios com concentração reduzida de F. 
CONCLUSÕES 


\section{7 - Conclusões}

Com base neste estudo cruzado longitudinal realizado com crianças de risco para fluorose dentária, em incisivos superiores (2 a 3 anos de idade), que utilizaram dentifrício fluoretado, pôde-se concluir que:

$\checkmark$ As unhas, tanto das mãos quanto dos pés podem ser usadas como biomarcadores de exposição subcrônica ao $\mathrm{F}$ a partir do dentifrício fluoretado em crianças de 2-3 anos de idade.

$\checkmark$ Após o início da utilização do dentifrício fluoretado, observou-se um aumento na concentração deste elemento nas unhas das crianças de 2-3 anos depois de 4 semanas, que poderia ser atribuído à incorporação de $\mathrm{F} \mathrm{a}$ partir do leito das unhas.

$\checkmark$ Um pico mais pronunciado na concentração de $F$ nas unhas ocorreu 112 dias após o início do uso do dentifrício fluoretado, podendo ser atribuído à somatória da incorporação de $\mathrm{F}$ a partir do leito e da extremidade de crescimento das unhas.

$\checkmark$ Apesar da concentração de $F$ nas unhas das mãos ser ligeiramente maior que a dos pés, na maioria dos períodos analisados, esta diferença não foi estatisticamente significante. 
ANEXOS 
ANEXO 1. Instruções para coleta das amostras de unha e água e realização da escovação

\section{UNHAS}

- As unhas deverão ser cortadas nas datas estipuladas que são: 29/11/01, 13/12/01, 27/12/01.

- Deverão ser armazenadas nos potinhos devidamente rotulados com o nome da criança, data da coleta e tipo de amostra (por exemplo: unhas das mãos ou unhas dos pés).

- Lembre-se, para cada data existem dois potinhos: um para unhas das mãos e outro pra unhas dos pés.

- Os potinhos deverão ser armazenados à temperatura ambiente até o último dia da coleta desta etapa (27/12/01).

\section{ÁGUA}

- A água da torneira deverá ser coletada nas mesmas datas da coleta das unhas $(29 / 11,13 / 13$ e $27 / 12)$.

- Colocar a água da torneira nos potinhos devidamente datados.

- Após a coleta congelar imediatamente.

\section{REALIZAÇÃO DA ESCOVAÇÃO}

- Utilizar a pasta de dente fornecida.

- A quantidade de pasta deverá ser o correspondente ao tamanho de uma ervilha.

- A escovação deverá ser realizada: após o café da manhã, após o almoço e antes de dormir.

Observação: No dia 27/12 iremos recolher as amostras juntamente com o restante da pasta utilizada. E iniciaremos a segunda etapa com outra pasta que também será fornecida.

Qualquer dúvida entrar em contato com: Maria Heloísa: 2272883 ou 97119863.

Prof $^{\mathrm{a}}$ Dr $^{\mathrm{a}}$ Marília: 2271486 
ANEXO 2. Carta de informação ao paciente

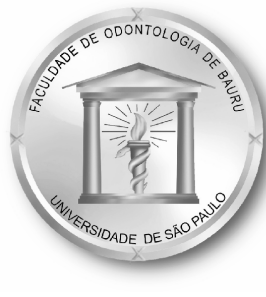

UNIVERSIDADE DE SÃo PAULO

\section{FACULDADE DE ODONTOLOGIA DE BAURU}

Al. Dr. Octávio Pinheiro Brisolla, 9-75 - Bauru -SP - CEP 17012-

$$
901-\text { C.P. } 73
$$

PABX (0XX14)235-8000 - FAX (0XX14)223-4679

Departamento de Ciencias Biológicas

e-mail: dep-cibi@fob.usp.br - Fone: (0xx14) 235-8282

\section{Universidade de São Paulo}

\section{Faculdade de Odontologia de Bauru \\ Comitê de Ética em Pesquisa \\ Carta de Informação ao Paciente}

Nome do paciente:

As informações contidas nesta carta serão fornecidas pela aluna de mestrado Maria Heloísa Corrêa Rodrigues, sob a orientação de Prof $\underline{a}$ Dr $\underline{a}$ Marília Afonso Rabelo Buzalaf, com o intuito de informar o paciente e seu responsável sobre a natureza dos procedimentos a que se submeterá ao participar da pesquisa, com a capacidade de livre arbítrio e sem qualquer coação.

\section{1 - Título do trabalho experimental}

"Influência de dentifrício fluoretado na concentração de flúor presente nas unhas de crianças de 2 a3 anos."

\section{2 - Objetivo}

O objetivo deste estudo é avaliar a concentração de flúor presente nas unhas das mãos de crianças de 2 a 3 anos que estarão utilizando dentifrício fluoretado. 


\section{3 - Procedimentos da Fase Experimental}

O experimento contará de três etapas distintas. Na primeira etapa, as crianças escovarão os dentes 3 vezes ao dia com dentifrício placebo (sem flúor) durante 30 dias. Na segunda etapa, as crianças usarão dentifrício Sorriso (com flúor) durante o mesmo período. A terceira e última etapa será idêntica a primeira. As pastas e as escovas infantis serão fornecidas pelos pesquisadores. Serão colhidas amostras das unhas das mãos das crianças no início do experimento e a cada 2 semanas até o término do mesmo e por mais 5 meses adicionais. A cada 2 semanas também serão colhidas amostras de água de torneira das casas das crianças.

\section{4 - Benefícios do Experimento}

Essa pesquisa fornecerá dados importantes com relação à ingestão de flúor pelas crianças na faixa etária de 2 a 3 anos.

\section{5 - Informações}

Os pais/ou responsáveis terão a garantia de receber esclarecimento de qualquer dúvida acerca dos procedimentos, riscos, benefícios e outros assuntos relacionados com a pesquisa. Qualquer dúvida ou problema, por favor, entrar em contato com um dos pesquisadores no telefone 235-8246 (Departamento de Bioquímica)

Por estarem entendidos e de acordo com a presente carta de informação.

Nome do pai/mãe ou responsável

Assinatura do pai/mãe ou responsável 
ANEXO 3. Termo de Consentimento Livre e Esclarecido

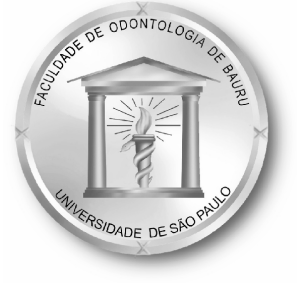

UNIVERSIDADE DE SÃo PAULO

FACULDADE DE ODONTOLOGIA DE BAURU

Al. Dr. Octávio Pinheiro Brisolla, 9-75 - Bauru-SP - CEP 17012-901 C.P. 73

PABX (0XX14)235-8000 - FAX (0XX14)223-4679

\section{TERMO DE CONSENTIMENTO LIVRE E ESCLARECIDO}

(a)

Pelo presente instrumento que atende às exigências legais, o Sr. portador da cédula de identidade_, após leitura minuciosa da CARTA DE INFORMAÇÃO AO PACIENTE, devidamente explicada pelos profissionais em seus mínimos detalhes, ciente dos serviços e procedimentos aos quais será submetido, não restando quaisquer dúvidas a respeito do lido e explicado, firma seu CONSENTIMENTO LIVRE E ESCLARECIDO concordando em participar de pesquisa proposta.

Fica claro que o paciente ou seu representante legal, pode a qualquer momento retirar seu CONSENTIMENTO LIVRE E ESCLARECIDO e deixar de participar desta pesquisa e ciente de que todas as informações prestadas tornaram-se confidenciais e guardadas por força de sigilo profissional (Art. 9 - do Código de Ética Odontológica).

Por estarem de acordo assinam o presente termo.

Bauru SP, de de 
ANEXO 4. Peso das unhas das mãos $(\mathrm{mg})$ dos voluntários nas datas das coletas.

\begin{tabular}{|c|c|c|c|c|c|c|c|c|c|c|}
\hline \multirow{2}{*}{ Data } & \multicolumn{10}{|c|}{ Voluntários } \\
\hline & 1 & 2 & 3 & 4 & 5 & 6 & 7 & 8 & 9 & 10 \\
\hline $29 / 11$ & * & 14,33 & 19,18 & 3,70 & 8,65 & 11,65 & 2,53 & 3,33 & * & 17,06 \\
\hline $13 / 12$ & 13,45 & 11,88 & 15,81 & * & 15,56 & 15,40 & 10,56 & 8,49 & 9,07 & 6,78 \\
\hline $27 / 12$ & 13,30 & 9,49 & 13,58 & 11,39 & 9,76 & 11,02 & 13,39 & 8,80 & 8,67 & 12,82 \\
\hline $10 / 01$ & 13,72 & 11,66 & 12,12 & 4,88 & 14,93 & 14,78 & 16,13 & 13,86 & 7,42 & 18,58 \\
\hline $24 / 01$ & 12,38 & 16,16 & 15,87 & 8,40 & 6,31 & 11,45 & 11,19 & 14,88 & 18,48 & 17,80 \\
\hline $07 / 02$ & 16,34 & 16,80 & * & 12,33 & 5,38 & 16,83 & 10,37 & 12,77 & 14,74 & 15,26 \\
\hline $21 / 01$ & 11,25 & 17,35 & 13,32 & 15,46 & 11,62 & 19,50 & 10,08 & 14,47 & 16,83 & 7,50 \\
\hline $07 / 03$ & 16,16 & 18,10 & 19,82 & $10,80 / 9,38^{\star *}$ & 11,25 & 12,52 & 11,32 & 11,82 & * & 16,59 \\
\hline $21 / 03$ & 13,71 & 11,02 & 17,40 & $10,18 / 10,12^{* *}$ & 11,82 & 13,55 & 5,81 & 11,30 & 14,22 & 14,66 \\
\hline $04 / 04$ & 14,85 & 15,89 & 16,13 & 19,08 & * & 12,44 & 18,68 & 17,58 & 16,70 & 17,44 \\
\hline $18 / 04$ & 11,56 & 11,55 & 19,45 & 19,88 & * & 12,76 & 12,04 & 11,49 & 5,52 & 19,35 \\
\hline $02 / 05$ & 17,77 & 17,28 & 19,05 & 19,67 & * & 19,64 & 11,47 & 10,84 & 13,28 & 19,03 \\
\hline $16 / 05$ & 7,84 & 11,79 & 18,98 & 18,80 & * & 16,27 & 17,92 & 9,44 & 14,59 & 17,80 \\
\hline $30 / 05$ & 16,41 & 10,84 & 18,69 & 19,63 & 4,15 & 13,10 & 13,99 & 15,41 & 18,92 & 15,68 \\
\hline $13 / 06$ & * & * & 3,89 & 19,07 & 13,34 & 16,44 & 4,32 & * & 17,29 & 9,68 \\
\hline $27 / 06$ & 15,20 & 13,74 & 18,45 & 18,21 & * & 17,12 & 7,86 & 2,96 & 19,71 & 10,87 \\
\hline $11 / 07$ & 13,13 & 15,03 & 11,20 & 19,52 & 7,75 & 11,09 & 8,70 & 6,50 & 17,96 & * \\
\hline $25 / 07$ & 10,53 & 13,55 & 13,68 & 14,21 & 2,57 & 14,81 & 15,08 & 13,37 & 13,87 & 17,03 \\
\hline
\end{tabular}

* Amostras perdidas

** Amostras analisadas em duplicata 
ANEXO 5. Peso (mg) das unhas dos pés dos voluntários nas datas das coletas.

\begin{tabular}{ccccccccccc}
\hline & \multicolumn{1}{c}{ Data } & \multicolumn{1}{c}{ Voluntários } & & & \\
\cline { 2 - 11 } & 1 & 2 & 3 & 4 & 5 & 6 & 7 & 8 & 9 & 10 \\
\hline $\mathbf{2 9 / 1 1}$ & 11,73 & 7,50 & 12,08 & 14,95 & 12,27 & $*$ & $*$ & 3,39 & 19,94 & 9,68 \\
$\mathbf{1 3 / 1 2}$ & 10,86 & 3,34 & 9,61 & $*$ & 8,36 & 10,67 & 8,52 & 7,94 & 17,31 & 16,06 \\
$\mathbf{2 7 / 1 2}$ & 13,14 & $*$ & 13,90 & $*$ & 16,13 & 11,56 & 4,76 & 4,53 & 5,05 & 12,28 \\
$\mathbf{1 0 / 0 1}$ & 8,59 & 4,17 & 4,90 & 9,69 & 9,34 & 8,65 & 11,59 & 9,56 & 6,98 & $*$ \\
$\mathbf{2 4 / 0 1}$ & 7,18 & $*$ & 5,13 & 8,10 & 6,72 & 7,42 & 11,64 & 7,04 & 13,60 & $11,05 / 11,77^{* *}$ \\
$\mathbf{0 7 / 0 2}$ & 3,47 & 6,63 & 12,29 & 11,30 & 15,07 & 8,69 & 4,91 & 7,34 & 10,73 & 13,93 \\
$\mathbf{2 1 / 0 1}$ & 4,71 & 2,91 & 3,45 & 11,51 & 17,09 & 18,40 & 8,09 & 5,69 & 11,29 & 16,01 \\
$\mathbf{0 7 / 0 3}$ & 5,73 & 7,69 & 12,37 & 9,64 & 10,36 & 7,43 & 3,09 & 5,56 & & 18,86 \\
$\mathbf{2 1 / 0 3}$ & 6,15 & 5,70 & 11,20 & 8,84 & 15,16 & 12,55 & 4,63 & 3,08 & 14,73 & 13,03 \\
$\mathbf{0 4 / 0 4}$ & 4,79 & 6,27 & 8,75 & 8,13 & $*$ & 2,68 & 14,58 & 16,73 & $*$ & 14,20 \\
$\mathbf{1 8 / 0 4}$ & 14,05 & 4,76 & 10,09 & 14,42 & 18,66 & 14,76 & 6,82 & $*$ & 11,87 & 16,56 \\
$\mathbf{0 2 / 0 5}$ & 10,28 & 7,42 & 12,69 & 10,46 & 11,35 & 11,61 & 5,46 & 4,55 & 9,46 & 18,83 \\
$\mathbf{1 6 / 0 5}$ & 5,28 & 4,73 & 13,85 & 16,65 & 19,87 & 13,60 & 6,55 & 7,52 & 16,86 & 14,26 \\
$\mathbf{3 0 / 0 5}$ & $*$ & $*$ & 11,94 & 12,97 & 13,44 & 14 & 9,65 & 9,83 & 3,09 & 18,75 \\
$\mathbf{1 3 / 0 6}$ & 12,56 & 19,98 & 15,86 & 9,50 & 11,13 & 15,07 & 12,28 & 12,07 & 12,60 & 19,68 \\
$\mathbf{2 7 / 0 6}$ & 16,82 & 8,36 & 16,59 & 13,54 & $*$ & 14,24 & 6,92 & 9,34 & 10,75 & 13,76 \\
$\mathbf{1 1 / 0 7}$ & 9,09 & 7,61 & 14,87 & 13,46 & 19,26 & 11,01 & 7,78 & $*$ & 17,77 & $*$ \\
$\mathbf{2 5 / 0 7}$ & 9,66 & 8,93 & 18,04 & 9,054 & 14,74 & 13,90 & 6,42 & 12,35 & 8,13 & $*$ \\
\hline *Amostras perdidas & & & & & & & & \\
** Amostras analisadas & em duplicata & & & & & &
\end{tabular}


ANEXO 6. Exemplo de planilha (Excel) utilizada para calcular a concentração de $\mathrm{F}$ nas unhas.

\section{1/07/02Análise de $F$ nas unhas de crianças 2-3 anos-Helo}

\begin{tabular}{|c|c|c|c|c|c|c|}
\hline $\mathrm{nm} F$ & $\mu \mathrm{g} \mathrm{F}$ & $\log F$ & $\mathrm{mV}$ & Log F. Calc. & $\mu \mathrm{g} F$ calc. & $\begin{array}{c}\% \\
\text { variação }\end{array}$ \\
\hline 1 & 0,019 & $-1,721246$ & 78,5 & $-1,7069969$ & 0,0196 & $-3,34$ \\
\hline 5 & 0,095 & $-1,022276$ & 38,2 & $-1,0407922$ & 0,0910 & 4,17 \\
\hline 10 & 0,19 & $-0,721246$ & 19,3 & $-0,7283538$ & 0,1869 & 1,62 \\
\hline 50 & 0,950 & $-0,022276$ & $-24,1$ & $-0,0109026$ & 0,9752 & $-2,65$ \\
\hline 1093029 & & inclinação & $-0,0165311$ & & Rquad. & 0,999512 \\
\hline
\end{tabular}

Amostra $\quad m V \quad$ Log F. Calc. $\mu g F$ calc. peso $(\mathrm{mg}) \quad F(p p m)$

10/01/02

Mão

$\begin{array}{rrrr}40-1,0705483 & 0,085 & 13,72 & 6,196 \\ 58,7-1,3796805 & 0,042 & 11,66 & 3,578 \\ 46,5-1,1780006 & 0,066 & 12,12 & 5,476 \\ 78,7-1,7103031 & 0,019 & 4,88 & 3,993 \\ 76,8-1,6788940 & 0,021 & 14,93 & 1,403 \\ 53,6-1,2953717 & 0,051 & 14,78 & 3,427 \\ 48,9-1,2176754 & 0,061 & 16,13 & 3,756 \\ 57,3-1,3565369 & 0,044 & 13,86 & 3,175 \\ 63-1,4507643 & 0,035 & 7,42 & 4,773 \\ 62,5-1,4424988 & 0,036 & 18,58 & 1,943\end{array}$

Pé

$46,8-1,1829600 \quad 0,066$

$8,597,639$

$75,1-1,6507910 \quad 0,022$

$4,17 \quad 5,359$

$73,4-1,6226881 \quad 0,024$

$4,9 \quad 4,865$

$58,6-1,3780273 \quad 0,042$

$9,694,322$

$68,9-1,5482980 \quad 0,028$

$9,34 \quad 3,029$

65,3-1,4887859 0,032

$8,65 \quad 3,751$

$68,6-1,5433387 \quad 0,029$

$11,592,469$

$80,5-1,7400592 \quad 0,018$

$9,56 \quad 1,903$

$65,9-1,4987046 \quad 0,032$

$6,98 \quad 4,544$ 

REFERÊNCIAS BIBLIOGRÁFICAS 


\section{REFERÊNCIAS BIBLIOGRÁFICAS*}

1. ALLEN, C.D.; ASHLEY, F.D.; NAYLOR, M.N. Caries experience in 11years-old schoolchildren between 1962 and 1981. Brit. dent. J., v. 154, n. 6 , p. 167-70, Mar. 1983.

2. ANDLAW, R.J.; BURCHELL, C.K.; TUCKER, G. Comparison of dental health in 11- years-old children in 1970 and 1979, and of 14- years-old children in 1973-1979, studies in Bristol, England. Caries Res., v. 16, n. 3, p. 257-64, 1982.

3. ARSATI, Y. B .de O .L. A unha como indicador biológico de exposição a fluoreto para prever risco de fluorose dental. Piracicaba, 2003. 75p. Tese (Doutorado) - Faculdade de Odontologia de Piracicaba, Universidade de Campinas.

4. BAELUM, V. et al. Daily dose of fluoride and dental fluorosis. Tandlaegebladet, v. 91, n. 10, p. 452-6, June 1987.

5. BASTOS, J.R. de M. et al. Concentração de flúor em água mineral engarrafada e de fontes naturais das cidades de Lindóia, Águas de Lindóia e Serra Negra, Brasil. Rev. Univ. Fed. Passo Fundo, v. 6, n. 1, p. 15-19, jan./jun. 2001.

\footnotetext{
* Normas recomendadas para uso no âmbito da Universidade de São Paulo, com base no documento "Referências Bibliográficas: exemplos", emanado do Conselho Supervisor do Sistema Integrado de Bibliotecas da USP, em reunião de 20 de setembro de 1990.
} 
6. BIESWANGER, B.B.; STOOKEY, G.K. The comparative clinical cariostatic efficacy of sodium fluoride and sodium monofluoropfosphate dentifrice: a review of trials. ASDC J. dent Chil., v. 57, n. 5, p. 337-47, Sept. /Oct. 1989.

7. BRASIL. Ministério da Saúde. Secretaria Nacional de Vigilância Sanitária. Lei $n$ @6050, de 24 de maio de 1974. Disponível na Internet. www.saude.gov.br/sp./areastecnicas/bucal/dados/fluor/lei6050.htm

8. BRASIL. Ministério da saúde. Secretaria Nacional de Vigilância Sanitária. Portaria $\mathrm{n}^{0 .} 22$ de dezembro de 20 de dezembro de 1989. Disponível na Internet.

www.saude.gov.br/sps/areastecnicas/bucal/dados/fluor/port22vig.htm.

9. BURT, B.A. The changing patterns of systemic fluoride intake. J. dent. Res., v. 71, n. 5, p. 1228-37, May 1992.

10. BUZALAF, M.A.R.; CURY, J.A.; WHITFORD, G.M.; fluoride exposures and dental fluorosis: a literature review. Rev. Fac. Odont. Bauru, v. 9, n. 1/2, p. 1-10, jan. /jun. 2001.

11. BUZALAF, M.A.R. et al. Fluoride content of infant formulas prepared whith deionized, bottled mineral and fluoridated drinking water. ASDC J. dent. Child., v. 68, n. 1, p.37-41, Jan. /Feb. 2001.

12. BUZALAF, M.A.R. et al. Fluoride content of several brands of teas and juices found in Brasil and risk of dental fluorosis. Rev. Fac. Odont. Bauru, v. 10, n. 4, p. 263-7, out. /dez. 2002. 
13. BUZALAF, M.A.R. et al. Fluoride content of infant foods in Brasil and risk of dental fluorosis. ASDC J. Dent. Child., v. 69, n. 2, p. 196-200, May/Aug 2002.

14. BUZALAF, M.A.R. et al. Fluctuations in public water fluoride level in Bauru, Brazil. J. Publ. HIth. Dent., v. 62, n. 3, p. 173-6, Summer 2002.

15. BUZALAF, M.A.R. et al. Correlation between plasma and nail fluoride concentrations in rats given different levels of fluoride in water. Fluoride, v. 35, n. 3, p. 185-192, Aug. 2002.

16. BUZALAF, M.A.R. et al. Association between the early use of toothpaste and other variables with dental fluorosis: a transversal retrospective study. Rev. Fac. Odont. Bauru, v. 10, n. 3, p. 196-200, jul/set. 2002.

17. BUZALAF, M.A.R. et al. Fluoride content of several brands of chocolate bars and chocolate cookies found in Brazil. Pesq. Odont. Bras., 2003. /no prelo/

18. CAMPOS, S.V. Amostra de unha indicam presença de cocaína. Referência obtida via base de dados: USP, 2002. disponível na Internet. www.usp.br/agenciausp./bols/2002/rede1055.htm

19. CARMO, do M.D. et al. Localidades com diferentes concentrações de flúor nas águas de consumo e sua relação com a prevalência de fluorose. Odont. mod., v. 22, n. 4, p. 18-21, out. /dez. 1995. 
20. CLARK, D.C. Trends in prevalence of dental fluorosis in North America. Community Dent. oral Epidem., v. 22, p. 148-52, 1994.

21. CLARKSON, J. J. International collaborative research on fluoride. J. dent. Res., v. 79, n. 4, p. 893-904, Apr. 2000.

22. CLOVIS, J.; HARGREAVES, J.A. Fluoride intake from beverage comsumption. Community Dent. oral Epidem., v. 16,n. 1, p. 11-5, Feb. 1988.

23. COMMITTEE ON BIOLOGICAL MARKERS OF THE NATIONAL RESEARCH COUNCIL. Biological markers in environmental health research. Environ. Health Perspec., v. 74, p. 3-9, 1987.

24. CULLEN, M.R.; REDLICH, C.A. Significance of individual sensitivity to chemicals: elucidation of host susceptibility by use of biomarkers in environmental health research. Clin. Chem., v. 12, p. 1809-13, Dec. 1995.

25. CURY, J.A. Concentração de fluoreto em chás brasileiros e seu significado na prevenção de cárie. Rev. gaúcha Odont., v. 29, n. 2, p. 136-8, abr./jun. 1981.

26. CZARNOWSKI, W.; KRECHNIAK, J. Fluoride in urine, hair and nails of phosphate fertilizer workers. Brit. J. Ind. Med., v. 47, n.5, p. 329-51, 1990. 
27. CZARNOWSKI, W. et al. Fluoride in drinking water and human urine in morthern and central Poland. Sci. Total Environ., v. 191, n. 1 /2, p. 177-84, Nov. 1996.

28. DEAN, H.T. et al. Studies on mass control of dental caries though fluoridation of the public water supply. Publ. Hlth. Rep., v. 65, p. 1403-8, 1950.

29. DeCAPRIO, A.P. Biomarkers: coming age for environmental health and risk assessment. Environ. Science Tech., v. 31, p. 1837-48, 1997.

30. DENBESTEN, P.K. Dental Fluorosis: its use as biomarker. Advanc. dent. Res., v. 8, n. 1, p. 105-110, June 1994.

31. DENBESTEN, P.K. Biological mechanisms of dental fluorosis relevant to the use of fluoride supplements. Community. Dent. oral Epidem., v. 27, n. 1, p. 41-7, Feb. 1999.

32. EAGER, J.M. Denti di Chiaie. Publ. Hlth. Rep., v. 91, n. 3, p. 284-5, May /June, 1976.

33. ERICSSON, Y. Monofluorphosphate physiology: general considerations. Caries Res., v. 17, p. 46-55, 1983. Supplement 1.

34. ERICSSON, Y.; FORSMAN, B. Fluoride retained from mouthrinses and dentifrices in preschool children. Caries Res., v. 3, n. 3, p. 290-9, 1969. 
35. ESTEBAN, L.; RIGALLI, A.; PUCHE, R.C. Metabolism of the complex monofluorophosphate-alpha-2-macroglubulin in the rat. Medicina (Buenos Aires), v. 59, n. 2, p. 151-6.

36. EVANS, R.W.; STAMM, J.W. Dental fluorosis following downward adjustment of fluoride in drinking water. J. Publ. HIth. Dent., v. 51, n. 2, p .91-8, Spring 1991.

37. EVANS, R.W.; DARVELL, B.W. Refining the estimate of the critical period for susceptibility to enamel fluorosis in human maxillary central incisors. J. Publ. HIth. Dent., v. 55, n. 4, p. 238-49, Fall 1995.

38. FEJERSKOV, O.; BAELUM, V.; RICHARDS, A. Dose-response and dental fluorosis. In: Fejerskov, O.; Ekstrand, J.; Burt, B.A. Fluoride in Dentistry.2.ed. Copenhagen, Munksgaard, 1996. p. 153-66.

39. FOMON, S.J.; EKSTRAND, J. Fluoride intake by infants. J. Publ. HIth. Dent., v. 59, n. 4, p. 229-34, Fall 1999.

40. FOMON, S.J.; EKSTRAND, J.; ZIEGLER, E.E. Fluoride intake and prevalence of dental fluorosis: trends in fluoride intake with special attention to infants. J. Publ. Hlth. Dent., v. 60, n. 3, p. 131-9, Summer 2000.

41. FORSMAN, B. Early supply of fluoride and enamel fluorosis. Scand. J. dent. Res., v. 85, n. 1, p. 22-30, Jan. 1977. 
42. GRANDJEAN, P. Biomarkers in Epidemiology. Clin. Chem., v. 41, n.12, p. 1800-3, Dec. 1995.

43. GREC, R.H.C. et al. Consumo de água mineral em Bauru. In: JORNADA ODONTOLÓGICA DE BAURU, 16, Bauru, 2003. /no prelo/

44. GUHA-CHOWDHURY, N.; DRUMMOND, B. K.; SMILLIE, A.C. Total fluoride intake in children aged 3 to 4 years - a longitudinal study. J. dent. Res., v. 75, n. 7, p. 1451-7, July 1996.

45. HARGREAVES, J.A.; INGRAM, G.S.; WAGG, B.J. A gravimetric study of the ingestion of toothpaste by children. Caries Res., v. 6, n. 3, p. 237-43, 1972.

46. HEILMAN, J.R. et al. Fluoride concentration of infant foods. J. Amer. dent. Ass., v. 128, n. 7, p. 857-63, July 1997.

47. HEILMAN, J.R. et al. Assessing fluoride levels of carbonated soft drinks. J. Amer. dent. Ass., v. 130, n. 11, p. 1593-9, Nov. 1999.

48. HEINTZE, S.D.; BASTOS, J.R.de M. Avaliação do teor de flúor e pH em bebidas no mercado nacional. Rev. Ass. paul. cirurg. Dent., v. 50, n. 4, p. 339-45, jul./ago. 1996.

49. HOLT, R.D. et al. Enamel opacities and dental caries in children who used a low fluoride toothpaste between 2 and 5 years of age. Int. Dent. J., v. 44, n. 4, p. 331-41, Aug. 1994. 
50. HULKA, B.S. Epidemiological studies using biological markers: issues for epidemiologists. Cancer Epidem. Biomarkers Prev., v. 1, n. 1, p. 139, Nov. / Dec. 1991.

51. ISHII, T.; SUCKLING, G. The severity of dental fluorosis in children exposed to water with a high fluoride content for various periods of time. J. dent. Res., v. 70, n. 6, p. 952-6, June 1991.

52. JACKSON, R.D. et al. Dental fluorosis in children residing in communities with different water fluoride levels: 33-month follow-up. Pediat. Dent., v. 21, n. 4, p. 248-54, July/Dec. 1999.

53. LALUMANDER, J.A. The prevalence and risk factors of fluorosis among children in a padiatric practice in Asheville, North Carolina (abs.). J. Publ. HIth. Dent., v. 52, n. 3, p. 188-9, Spring 1992.

54. LEAKE, J. et al. Has the level of dental fluorosis among Toronto children changed? J. Canad. dent. Ass., v. 68, n. 1, p. 21-5, Jan. 2002.

55. LEVERETT, D.H. Prevalence of dental fluorosis in fluoridated and in non-fluoridated communities-a preliminary investigation. J. Publ. HIth. Dent., v. 46, n. 4, p. 184-7, Fall 1986.

56. LEVY, S.M.; KIRITSY, M.C.; WARREN, J.J. Sources of fluoride intake in children. J. Publ. HIth. Dent., v. 55, n. 1, p. 39-52, Winter 1995.

57. LIMA, Y.B.O.; CURY, J.A. Ingestão de flúor por crianças através da água e dentifrício. Rev. Saúde Publ., v. 35, n. 6, p. 576-81, dez. 2001. 
58. MACHOY, Z. Effects of environment upon fluoride content in nails in children. Fluoride, v. 22, n. 4, p. 169-73, Oct. 1989.

59. MALTZ, M.; FARIAS, C. Fluorose dentária em escolares de quarto cidades brasileiras com e sem água artificialmente fluoretada. Rev. Fac. Odont. Porto Alegre, v. 39, n. 2, p. 18-21, dez. 1998.

60. MANSBRIDGE, J.N.; BROWN, M.D. Changes in dental caries prevalence in Edinburgh children over three decades. Community. dent. HIth., v. 2, n. 1, p. 3-13, Mar. 1985.

61. MASCARENHAS, A.K. Risk factors for dental fluorosis: A review of the recent literature. Pediat. Dent., v. 22, n. 4, p. 269-77, July/ Aug. 2000.

62. MASCARENHAS, A.K.; BURT, B.A. Fluorosis risk from early exposure to fluoride toothpaste. Community Dent. oral Epidem., v. 26, n. 4, p. 241-8, Aug. 1998.

63. MCCLURE, F.J. Water fluoridation. The search and the victory. Washington, DC, Us Government Printing Office, 1970.

64. McDOGNAGH, M. et al. Systematic review of water fluoridation. Brit. med. J., v.321, p.855-9, n.7265, Oct. 2000.

65. MCDONNELL, S.T.; O'MULLANE, D. Fingernails, a fluoride biomarker relevance of growth rate and length. J. dent. Res., v. 80, n. 4, p. 1145, 2001. /Abstract n.29/ 
66. McKAY, F.S. Mottled enamel: The prevetion of its further production though a chance of water supply at Oakley, IDA. J. Amer. Dent. Ass., v. 20, n.7, p. 1137-49, July 1933.

67. MELLBERG, J.R.; RIPA, L.W. Self-applied topical fluoride Fluoride in preventive dentistry: theory and clinical implications. Chicago, Quintessence Publishing Co., p. 243-77, 1983.

68. MUHLER, J.C. et al. The effect of a stannous fluoride-containing dentifrice on caries reduction in children. J. dent. Res., v. 33, n.5, p. 606-12, Oct.1954.

69. OPHAUG, R.H.; SINGER, L.; HARLAND, B.F. Estimated fluoride intake of 6-month-old infants in four dietary regions of the United States. Amer. J. clin. Nut., v. 33, n. 2, p. 324-7, Feb. 1980.

70. O’RAHILLY, R. Cútis, pelos e unhas. In: GARDNER, E.; GRAY, D.J.; O'RAHILLY, R. Anatomia estudo regional do corpo humano. 2.ed. Rio de Janeiro, Guanabara Koogan, 1964. Cap.8, p. 66-74.

71. PANG, D.T.Y.; PHILIPPS, C.L.; BAWDEN, J.W. Fluride intake from beverage comsumption in a sample of North Carolina children. J. dent. Res., v. 71, n.7, p. 1382-8, July 1992.

72. PENDRYS, D.G.; KATZ, R.V. Risk of enamel fluorosis associated with fluoride supplementation, infant formula, and fluoride dentifrice use. Amer. J. Epidemiol., v. 130, n. 6, p. 1199-208, Dec. 1989. 
73. PENDRYS, D.G.; KATZ, R.V. Risk factors for enamel fluorosis in optimally fluoridated children born after the US manufacturer's decision to reduce the fluoride concentration of infant formula. Amer. J. Epidemiol., v. 148, n.10, p.967-74, Nov. 1998.

74. PENDRYS, D.G.; STAMM, J.W. Relationship of total fluoride intake to beneficial effects and enamal fluorosis. J. dent. Res., v. 69, (Spec.Issue), p. 529-38, Feb. 1990.

75. PENDRYS, D.G.; MORSE, D.E. Use of fluoride supplementation by children living in fluoridated communities. ASDC J. Dent. Child., v. 57, n. 5, p. 343-7 Sept. / Oct. 1990.

76. PENDRYS, D.G.; MORSE, D.E. Fluoride supplement use by children in fluoridated communities. J. Publ. HIth. Dent., v. 55, n. 3, p. 160-4, Summer 1995.

77. PENDRYS, D.G.; KATZ, R.V.; MORSE, D.E. Risk factors for enamel fluorosis in a nomfluoridated population. Amer. J. Epidemiol., v. 143, n. 8, p. 808-15, Apr. 1996.

78. PEREIRA, A.C. et al. Dental caries and fluorosis prevalence study in a nonfluoridated Brazilian community: trend analysis and toothpaste association. ASDC J. Dent. Child., v. 67, n. 2, p. 132-5, Mar. / Apr. 2000. 
79. PESSAN, J.P.; SILVA, S.M.B.; BUZALAF, M.A.R. Evaluation of the total fluoride intake of 4-7-years-old children from diet and dentifrice. J. Appl. Oral Sci., 2003. /no prelo/

80. RICHARDS, A; BANTING, D.W. Fluoride toothpastes. In: Fejerskov, O.; Ekstrand, J.; Burt, B.A. Fluoride in dentistry. 2.ed. Copenhagen, Munksgaard, 1996, p. 328-46.

81. RIGALLI, A.; MOROSANO, M.; PUCHE, R.C. Bioavailability of fluoride administered as sodium fluoride or sodium monofluorophosphate to human volunteers. Arzneimittelforschung, v. 46, n. 5, p. 531-3, May 1996.

82. RIGALLI, A. et al. Gastric and intestinal absorption of monofluorophosphate and fluoride in the rat. Arzneimittelforschung, v. 44 , n. 5 , p. $651-5$, May 1994.

83. RIORDAN, P.J. Dental fluorosis decline after changes to supplement and toothpaste regimens. Community Dent. oral Epidem., v. 30, n. 3, p. 233-40, June 2002.

84. RIORDAN, P.J.; BANKS, J.A. Dental fluorosis and fluoride exposure in Western Australia. J. dent. Res., v. 70, n. 7, p. 1022-8,July 1991.

85. ROJAS-SANCHEZ, F. et al. Fluoride intake from foods, beverages and dentifrice by young children in communities with negligible and 
optimally fluoridated water: a pilot study. Community Dent. oral Epidem., v. 27, n. 4, p.288-97, 1999

86. SCHAMSCHULA, R.G. et al Physiological indicators of fluoride exposure and utilization: an epidemiological study. Community Dent. oral Epidem., v. 13, n. 2, p. 104-7, Apr. 1985.

87. SCHMIDT, C.W.; LEUSCHKE, W. Fluoride content in fingernails of individuals with and without chronic fluoride exposure. Fluoride, v. 23, n. 2, p. 79-82, Apr. 1990.

88. SPAK, C.K.; EKSTRAND, J.; ZYLBERSTEIN, D. Bioavailability of fluoride added by baby formula and milk. Caries Res., v. 16, n. 3, p. 249-56, 1982.

89. SPATE, V.L. et al. Determination of fluoride in human nails via cyclic instrumental neutron activation. J. Radioanalyt. Nucl. Chem., v. 170, p. 27-33, 1994.

90. SZPUNAR, S.M.; BURT, B.A. Dental caries, dental fluorosis, and fluoride exposure in Michigan schoolchildren. J. dent. Res., v. 67, n. 5, p. 802-6, May 1988.

91. TABARI, E.D. et al. Dental fluorosis in permanent incisor teeth in relation to water fluoridation, social deprivation and toothpaste use in infancy. Brit. dent. J., v. 189, n. 4, p. 216-20, Aug. 2000. 
92. TAVES, D.R. Separation of fluoride by rapid diffusion using hexamethyldisiloxane. Talanta, v. 15, p. 969-74, 1968.

93. TAVES, D.R. Dietary fluoride intake of fluoride ashed (total fluoride) unashed (inorganic fluoride) analysis of individual foods. Brit. J. Nutr., v. 49, n. 3, p. 295-301, May 1983.

94. TRAUTNER, K.; EINWAG, J. Influence of milk and food on fluoride bioavailability from $\mathrm{NaF}$ and $\mathrm{Na}_{2} \mathrm{FPO}_{3}$ in man. J. dent. Res., v. 68, $\mathrm{n}$. 1, p. 72-7, Jan. 1989.

95. TRAUTNER, K.; SIEBERT, G. An experimental study of bioavailability of fluoride from dietary source in man. Arch. oral Biol., v. 31, n. 4, p. 223-8, 1986.

96. TSUTSUI, A.; YAGI, M.; HOROWITZ, A.M. The prevalence of dental caries and fluorosis in japanese communities with up to $1.4 \mathrm{ppm}$ of naturally occurring fluoride. J. Publ HIth. Dent., v. 60, n. 3, p. 14753, Summer 2000.

97. VIEGAS, A.R. et al. Fluoretação da água de abastecimento público.

Rev. Ass. paul. cirurg. Dent., v. 41, n. 4, p. 202-4, jul./ago. 1987.

98. VILLENA, R.S.; BORGES, D.G.; CURY, J.A. Avaliação da concentração de flúor em águas minerais comercializadas no Brasil. Rev. Saúde Publ., v. 30, n. 6, p. 512-8, dez. 1996. 
99. WARREN, J.J.; LEVY, S.M.A. A review of fluoride dentifrice related to fluorosis. Pediat. Dent., v. 21, n. 4, p. 265-71, July /Aug. 1999.

100. WHITFORD, G.M. The physiological and toxicological characteristics of fluoride. J. dent. Res., v. 69, p. 539-49, Feb. 1990. Special issue.

101. WHITFORD, G.M. Intake and metabolism of fluoride. Advanc. dent. Res., v. 8, n. 1, p.5-14, June 1994.

102. WHITFORD, G. M. The metabolism and toxicity of fluoride. 2.ed. Basel, Karger, 1996.

103. WHITFORD, G. M. et al. Fingernail fluoride: a method for monitoring fluoride exposure. Caries Res., v. 33, n. 6, p. 462-7, Nov./ Dec. 1999.

104. ZACHERL, W.A.; LONG, D.M. Reduction in caries attack rate - nonfluoridated community. J. Dent. Res., v. 58, p. 227, 1979. /Abstract n. $535 /$ 

ABSTRACT 


\section{ABSTRACT}

The purpose of this study was to evaluate the use of fingernails and toenails as biomarkers of exposure to fluoride $(F)$ from fluoridated dentifrice in 2-3 year-old children. Ten 2-3 year-old children used a placebo dentifrice (without F) for 28 days, fluoride dentifrice (1,570 ppm F as MFP) for the following 28 days, and then placebo dentifrice for additional 28 days, when returned to their usual dentifrices. They were instructed to brush their teeth 3 times a day with a pea-size amount of the specified dentifrice. Fingernails and toenails were clipped every 2 weeks, during the experimental period and for additional 22 weeks. Fingernail and toenail $\mathrm{F}$ concentrations were analyzed with the ion specific electrode (Orion 9409) following HMDS-facilitated diffusion. Data were analyzed by 2-way ANOVA and Tukey's test $(p<0.05)$. Nail F concentrations ranged from 1.258 to $17.417 \mu \mathrm{g} / \mathrm{g}$. There were not significant differences between fingernails and toenails $\mathrm{F}$ concentrations. Mean $F$ concentrations $( \pm S D, n=10)$ at the 4 first weeks and the 6 last weeks were $2.709 \pm 0.971$ and $2.696 \pm 1.167 \mu \mathrm{g} / \mathrm{g}$, for fingernails and toenails, respectively. Mean peak $\mathrm{F}$ concentrations, which occurred 112 days after starting the use of fluoride dentifrice were $10.051 \pm 3.328$ and $9.186 \pm 3.862$ $\mu \mathrm{g} / \mathrm{g}$ for fingernails and toenails, respectively. This indicates that $\mathrm{F}$ enters nails via the growth end. In addition, smaller, but statistically significant increases in nail $\mathrm{F}$ concentrations were seen 28 days after starting the use of the fluoride dentifrice $(7.251 \pm 5.682$ and $5.612 \pm 4.627 \mu \mathrm{g} / \mathrm{g}$, for fingernails and toenails, respectively), which suggests that $\mathrm{F}$ also enters through the nail 
bed. Results indicate that there are no differences between fingernails and toenails $\mathrm{F}$ concentrations and that they are suitable biomarkers of exposure to $\mathrm{F}$ from fluoride dentifrice in small children. 
APÊNDICE 


\section{Universidade de São Paulo Faculdade de Odontologia de Bauru \\ Al. Dr. Octávio Pinheiro Brisolla, 9-75 - Bauru-SP - CEP 17012-901 - C.P. 73 \\ PABX (0XX14)235-8000 - FAX (0XX14)223-4679 \\ Comilê de Ética em Pesquisa}

Bauru, 9de novembro de 2001

Senhora Professora,

O projeto de pesquisa encaminhado a este Comitê de Ética

denominado "Influência de dentifrício fluoretado na concentração de flúor presente nas unhas de crianças de 2 a 3 anos.", a ser desenvolvido pela CD.Maria Heloisa Corrêa Rodrigues sob sua orientaçã foi enviado ao relator para avaliaçăo.

Após o envio da documentação solicitada, o projeto foi aprovado por este comitê.

Informamos que após o envio do trabalho concluido, este comitê enviará o parecer final, que será utilizado para publicação do trabalho.

Atenciosamente,

Prof ${ }^{n}$. Dr ${ }^{2}$. Ana Lúcia A .Capelozza

Coordenadora

Il ma. Senhora

Prof Dra Marilia Afonso Rabelo Buzalaf 


\section{Universidade de São Paulo Faculdade de Odontologia de Bauru}

Al. Dr. Octávio Pinheiro Brisolla, 9-75 - Bauru-SP - CEP 17012-901 - C.P. 73 PABX (0XX14)235-8000 - FAX (0XX14)223-4679

Comite de Éfica em Pesquisa

Of: $n^{\circ}$ CEP/16 2003/FOB

Bauru, 25 de abril de 2003

Senhora Professora,

Informamos que após anàlise por este Comitẽ de Ética em Pesquisa em Seres Humanos, seu pedido de alteraçăo do titulo do projeto de pesquisa intitulado "Influência de dentifricio fluoretado na concentraçāo de flúor presente nas unhas de crianças de 2-3 anos" de autoria da CD. Maria Heloisa Corrêa Rodrigues, sob a sua orientação, para "Unha como biomarcador de exposição subcrônica ao flúor a partir do dentifrício fluoretado em crianças de 2-3 anos", foi aprovado considerando que sua metodologia nảo sofreu modificaçôes.

Lembramos que após o envio do trabalho concluído, este Comitē enviará o parecer final, que será utilizado para a publicaçăo do trabalho.

Atenciosamente,

Prof $^{u} \mathrm{Dr}^{\mathrm{a}}$ Ana Lúcia Alvares Capelozza

Coordenadora do Comite de Ética em Pesquisa em Seres Humanos 
APÊNDICE 3. Manuscrito enviado para publicação, Caries Research

Fingernails and Toenails as Biomarkers of Subchronic Exposure to Fluoride from Dentifrice in 2-3 year-old Children

Maria Heloísa Corrêa Rodrigues ${ }^{a}$

José Roberto de Magalhães Bastos ${ }^{a}$

Marília Afonso Rabelo Buzalaf ${ }^{\text {b }}$

aDepartment of Pedodontics, Orthodontics and Public Health, Bauru Dental School, University of São Paulo, Brazil.

bDepartment of Biological Sciences, Bauru Dental School, University of São Paulo, Brazil.

Short title: Nails as biomarkers of fluoride exposure

Corresponding author:

Marília Afonso Rabelo Buzalaf

Al. Octávio Pinheiro Brisolla, 9-75

Bauru-SP 17012-901 Brazil

Tel. + 5514 2358246, Fax + 5514 2262076, e-mail:mbuzalaf@fob.usp.br 
Key words: Biomarker, Exposure, Fingernails, Toenails, Fluoride, Dentifrice, Children

\section{ABSTRACT}

This work evaluated the use of fingernails and toenails as biomarkers of subchronic exposure to fluoride $(F)$ from fluoride dentifrice $(F D)$ in 2-3 year-old children. Ten 2-3 year-old children used a placebo dentifrice (without $F$ ) for 28 days, FD (1,500 ppm F as MFP) for the following 28 days, and then placebo dentifrice for additional 28 days, when returned to their usual dentifrices. Fingernails and toenails were clipped every 2 weeks, during the experimental period and for additional 22 weeks. Nail F was analyzed with the electrode following HMDS-facilitated diffusion. There were not significant differences between fingernails and toenails $F$ concentrations. Mean peak $F$ concentrations occurred 16 weeks after starting the use of FD. Smaller, but significant increases in nail $F$ concentrations were seen 4 weeks after starting the use of FD. Results indicate that fingernails and toenails are suitable biomarkers of subchronic exposure to $F$ from FD in small children. A lag time of 4 weeks is enough for $\mathrm{F}$ detection in nails.

Introduced to the commercial market on the 1960's, fluoride dentifrice now accounts for nearly all dentifrice purchased in many countries. Since fluoride dentifrice was introduced in the market, the prevalence and severity of dental caries has declined while dental fluorosis prevalence has increased [Warren and Levy, 1999]. While the caries decline can be largely attributed to widespread fluoride dentifrice used, as well as many other sources of fluoride [Leverett, 1986; Jackson et al., 1999; Tabari et al., 2000], several recent studies have attributed much of the increase in fluorosis prevalence to early use of fluoride dentifrice [Evans, 1991; Mascarenhas and Burt, 1998; Warren and Levy, 1999; Pereira et al., 2000; Riordan, 2002; Buzalaf et al., 2002a].

Due to the increase in the prevalence of dental fluorosis, the search for biomarkers of exposure to fluoride that are easy to collect and analyze has been intensified [Clarkson, 2000]. Nail sampling is simple and non-invasive, and there are many reports suggesting the use of nails as biomarkers for fluoride exposure in animals [Buzalaf et al., 2002b] and humans [Schamschula et al., 1985; Machoy, 
1989; Czarnowski and Krechniak, 1990; Schmidt and Leuschke, 1990; Spate et al., 1994; Czarnowski et al., 1996; Whitford et al., 1999]. Both fingernails and toenails have been used for such purpose, but the literature is contradictory regarding the relationship between fingernails and toenails fluoride concentrations [Machoy, 1989; Whitford et al., 1999]. In addition, there are no longitudinal studies focusing on the use of nails as biomarkers of exposure to fluoride from dentifrice.

The aim of this longitudinal study was to evaluate the use of fingernails and toenails as biomarkers of subchronic fluoride exposure from fluoride dentifrice in 2-3 year-old children. In addition the fluoride concentrations of fingernail and toenail clippings were also compared.

\section{Materials and Methods}

\section{Volunteers}

Ten 2-3 year-old children took part in this longitudinal study, approved by the Ethical Committee of Bauru Dental School - University of São Paulo. All the children lived in a fluoridated area (Bauru, SP, Brazil, 0.6-0.8 ppm), had a good oral health and were not using medicines.

\section{Study Protocol}

The study had three different experimental periods. The children used a placebo dentifrice (without fluoride) for 28 days. Then a fluoride dentifrice (Sorriso, Kolynos, Brazil, containing 1,570 ppm fluoride, as dissodium monofluorphosphate) was used for the following 28 days and the placebo dentifrice was used again for additional 28 days, when the volunteers returned to their usual dentifrices. The parents were instructed to brush their children's teeth 3 times a day (after breakfast, after lunch and before sleep) as usual, with a pea-size (around $0.5 \mathrm{~g}$ ) amount of the dentifrice specific for each period.

\section{Nail sampling}

At the beginning of the study, when the placebo dentifrice started being used (November 29), fingernails and toenails were cut and stored separately. They were cut every two weeks, during the experimental period and for additional 22 weeks, totalizing 34 weeks. Thus, the last clipping was collected on July 25 . At the same 
days when the nail clippings were collected, samples from public water supply were obtained at the houses of each child. This was done because fluctuations in public water fluoride concentrations have been reported in Bauru [Buzalaf et al., 2002c]. The water samples, collected in $50 \mathrm{~mL}$ pastic vials, were frozen $\left(-20^{\circ} \mathrm{C}\right)$ until analysis.

\section{Analytical Procedure}

The nail clippings were pooled so that there were two analytical results (fingernails and toenails) for each child. Each nail clipping was cleaned briefly with deionized water using an interdental brush and then sonicated in deionized water for 10 minutes, dried at $60 \pm 5^{\circ} \mathrm{C}$ and weighed $( \pm 0.01 \mathrm{mg})$. The weights of the pooled samples ranged from 1.13 to $19.98 \mathrm{mg}$. Only in 3 cases, when the weight of the samples was higher than $10 \mathrm{mg}$, samples were analyzed in duplicate.

The fluoride concentrations of the nail clippings were determined after overnight, hexamethyldisiloxane (HMDS)-facilitated diffusion[Taves, 1968] as modified by Whitford [1996] using the ion-specific electrode (Orion Research, Cambridge, Mass., USA, model 9409) and a miniature calomel reference electrode (Accumet, \#13-620-79), both coupled to a potentiometer (Orion Research, model EA 940). During the diffusion process, which was conducted at room temperature, the solutions in the non-wettable Petri dishes (Falcon, No. 1007) were gently swirled on a rotatory shaker. Fluoride standards $(0.0095,0.019,0.095$ and $0.190 \mu \mathrm{g} F)$ were prepared by serial dilution of a stock-standard containing $0.1 \mathrm{M}$ of fluoride (Orion 940906) in triplicate and diffused in the same manner as the samples. In addition, nondiffused fluoride standards were prepared with the same solutions (0.05 M $\mathrm{NaOH}, 0.20 \mathrm{M}$ acetic acid, plus $\mathrm{NaF}$ ) that were used to prepare the diffused standards and samples. The nondiffused standards were made up to have exactly the same fluoride concentrations as the diffused standards. Comparison of the millivolt readings demonstrated that the fluoride in the diffused standards had been completely trapped and analyzed. The millivoltage potentials were converted to $\mu \mathrm{g} \mathrm{F}$ using a standard curve with a coefficient correlation of $r \geq 0.99$.

Fluoride in water samples was analyzed using the ion-specific electrode (Orion Research, Cambridge, MA, USA, model 9609), after sample buffering with an equal volume of TISAB II. A set of standards (containing 0.1, 0.2, 0.4, 0.8 and 1.6 ppm fluoride) was prepared, using serial dilution from a 100 ppm NaF stock solution 
(Orion). The millivoltage potentials were converted to ppm fluoride using a standard curve with a coefficient correlation of $r \geq 0.999$. The mean reproducibility of the readings, based on the duplicate samples, was 98 percent.

\section{Statistical Analysis}

The data are presented as mean $\pm S D$. Two-way analysis of variance (ANOVA) was used to detect significant differences between the means as Tukey's test was used as the post hoc test for the ANOVA. The criteria used were date and site (fingernail or toenail). A significance level of 0.05 was selected a priori as the indicator of statistical significance. The relation between the fluoride concentration of fingernails and toenails was checked by linear regression, using Pearson's coefficient of correlation.

The Kruskall-Wallis test was used to detect significant differences among the fluoride concentration in the water collected at the houses of the volunteers. Dunn's test was used as the post hoc test for the Kruskall-Wallis test. A significance level of 0.05 was selected a priori as the indicator of statistical significance.

\section{RESULTS}

Nail fluoride concentrations ranged between 1.258 and $17.417 \mu \mathrm{g} / \mathrm{g}$. Mean fluoride concentrations $( \pm S D, n=10$ ) at the 4 first weeks and the 6 last weeks were $2.709 \pm 0.971$ and $2.696 \pm 1.167 \mu \mathrm{g} / \mathrm{g}$, for fingernails and toenails, respectively. Table 1 and Figure 1show the time course of fluoride concentrations in fingernail and toenail clippings. A noticeable increase of fluoride concentrations in fingernail and toenail clippings was seen on February 21 (4 weeks after starting the use of fluoride dentifrice). Peak fluoride concentrations occurred on April 18 (16 weeks after starting the use of fluoride dentifrice).

Despite the fluoride concentrations in fingernail clippings were slightly higher than in toenail clippings in most of the dates (Figure 1), this difference was not statistically significant $(F=0.36922, p=0.558446)$, as showed by the two-way ANOVA. However, a significant difference among the dates was observed $(F=14.50786, \quad p<0.0000001)$. The clippings collected on January 24 were significantly higher than the ones collected from the beginning of the study up to 
January $10(p<0.05)$. The clippings collected on April 18 were significantly higher than all the others $(p<0.05)$. The nails collected on the subsequent clipping (May 2) were still significantly higher than the ones collected after this period $(p<0.05)$. These were not different from those collected prior to January 10 ( $p>0.05)$.

A significant correlation was found between the fluoride concentrations of fingernails and toenails $(r=0.57108, p<0.00000001)$.

Table 2 shows the fluoride concentration of the water collected at the houses of the volunteers. Fluoride concentration ranged between 0.217 and $1.147 \mu \mathrm{g} / \mathrm{mL}$. Mean fluoride concentration ranged between 0.672 and $1.010 \mu \mathrm{g} / \mathrm{mL}$. The KruskallWallis test found a significant difference among the water collected at the different houses ( $K W=15.873, p=0.032$ ). Dunn's test showed that the fluoride concentration of the water collected at the house of the volunteers 4-5-6 was statistically higher than the one collected at the houses of the volunteers $7-8,9$ and $10(p<0.05)$.

\section{Discussion}

There are some reports in the literature concerning the use of nails as biomarkers of fluoride exposure in animals [Buzalaf et al., 2002b] and humans [Schamschula et al., 1985; Machoy, 1989; Czarnowski and Krechniak, 1990; Schmidt and Leuschke, 1990; Spate et al., 1994; Czarnowski et al., 1996; Whitford et al., 1999]. However, this is the first report on the use of nails as biomarkers of subchronic exposure from fluoride dentifrice in children at the age of risk for dental fluorosis on the permanent central incisors. This is an important issue, since the early use of fluoride dentifrice has been implicated as an important risk factor for dental fluorosis [Evans, 1991; Mascarenhas and Burt, 1998; Warren and Levy, 1999; Pereira et al., 2000; Riordan, 2002; Buzalaf et al., 2002a].

In the present study, peak nail fluoride concentrations occurred 16 weeks after starting the use of fluoride dentifrice. This is in agreement with the findings of Whitford et al. [1999], who showed that when $3.0 \mathrm{mg}$ of fluoride were ingested each day for 30 days, a lag time of approximately 3.5 months occurred before the nail fluoride concentrations increased. The authors suggested that fluoride enters fingernails via the matrix (growth end) and not through the nail bed. Since the work of Whitford et al. [1999] was based on samples collected from an adult, a shorter lag time would be expected for the present work, because the length of children's nails is smaller. However, the work of Whitford et al. [1999] was based on data derived from an adult only. In addition, the velocity of nail growth and metabolic alterations 
that occur in function of the age make difficult the comparison between the two studies. It was estimated that the average rate of growth of thumbnails in children aged $2-3$ years is $0.7 \mathrm{~mm} /$ week (range $0.5-0.9 \mathrm{~mm}$ ). In addition, the length of thumbnails to the point at which they could be cut and analyzed for fluoride content was $7.5 \mathrm{~mm}$ (range 6.4 - $9.2 \mathrm{~mm}$ ) [McDonell and O'Mullane, 2001]. However, in this work, the authors made a reference point on the thumbnail at the margin of the lunula. If we consider that some extension of the nail below the cuticle may be already receiving fluoride from the systemic circulation, then a lag time of 100 days for the nail to grow from this point to the point at which it can be cut and analyzed for fluoride seems quite reasonable.

This work found a small, but significant increase in nail fluoride concentration 4 weeks after starting the use of fluoride dentifrice. This increase was not expected, since Whitford et al. [1999], based on samples collected from an adult volunteer, suggested that fluoride enters fingernails via the matrix (growth end). The early increase in nail fluoride concentration found in this study suggests that fluoride also enters nails through the nail bed. The children that participated in this study were 23 years old. It is possible that the nail bed of very young children is immature and permits the passage of fluoride into the nail. If so, this information will be very useful for future researches intending to use nails as biomarkers of subchronic and probably acute exposure to fluoride. In these cases, the lag time between fluoride administration and detection in nails will be probably smaller than previously expected for young children.

Most of the children in this study were using fluoride dentifrices $(1,100 \mathrm{ppm}$ fluoride) before the experimental period began. Only three children were using a fluoride-free dentifrice. Thus, a reduction in nail fluoride concentration would be expected when the placebo dentifrice was used for the children that used a fluoride dentifrice previously. However, this reduction was not observed. This may have been due to the fact that the children used a small amount of fluoride dentifrice or brushed their teeth few times a day prior to the beginning of the experiment. In addition, the steady-state distribution that exists between the extracellular fluid and the hydration shell of bone crystallites [Whitford, 1996] may help to explain the absence of reduction in nail fluoride concentrations when the placebo dentifrice was used. The ion-rich aqueous shells are continuous with, or at least available to, the extracellular fluids. Presumably, fluoride in this pool is rapidly exchangeable so that it can undergo net migration in either direction, depending on the relative 
concentrations in extracellular fluid and the hydration shells [Whitford, 1996]. When plasma levels fall, a net flux of fluoride from the hydration shell to the extracellular fluid occurs. Since children were used to a chronic exposure to fluoride from diet and dentifrice prior to the beginning of the study, the transient falls in plasma fluoride levels that could have occurred when the placebo dentifrice was used may have been compensated by this mechanism. In consequence, nail fluoride concentration did not change.

\section{REFERENCES}

Buzalaf MAR, Bastos JRM, Lauris JRP, Almeida BS, Aquilante AG: Association between the early use of toothpaste and other variables with dental fluorosis: a transversal retrospective study. Rev Fac Odontol Bauru 2002a;10:196-200.

Buzalaf MAR, Fukushima R, Granjeiro JM, Cury JA: Correlation between plasma and nail fluoride concentrations in rats given different levels of fluoride levels in water. Fluoride 2002b;35:185-192.

Buzalaf MAR, Granjeiro JM, Damante CA, Ornelas F: Fluctuations in public water fluoride level in Bauru, Brazil. J Publ Hlth Dent 2002c;62:173-176.

Clarkson J. Internacional collaborative research on fluoride: $\mathrm{J}$ Dent Res 2000;79:893-904.

Czarnowski W, Krechniak J: Fluoride in the urine, hair, and nails of phosphate fertilizer workers. Brit J Ind Med 1990;47: 349-51.

Czarnowski W, Stolarka K, Brzezinska B, Krechniak J: Fluoride in urine, hair and nails of phosphate fertilizer workers. Fluoride 1996;29: 163-5.

Evans DJ: A study of developmental defects in enamel in 10-year-old high social class residing in a non-fluoridated area. Comm Dent HIth 1991;8:31-38.

Jackson $\mathrm{RD}$ et al: Dental fluorosis in children residing in communities with different water fluoride levels: 33-month follow-up. Pediatr Dent 1999;21:248254.

Leverett DH: Prevalence of dental fluorosis in fluoridated and in non-fluoridated communities-a preliminary investigation. J Publ HIth Dent 1986; 46:184-187.

Machoy Z: Effects of environment upon fluoride content in nails of children. Fluoride 1989;22:169-173. 
Mascarenhas AK, Burt BA: Fluorosis risk from early exposure to fluoride toothpaste. Comm Dent Oral Epidemiol 1998; 26:241-248.

Pereira AC et al: Dental caries and fluorosis prevalence in a nonfluoridated Brazilian community: trend analysis and toothpaste association. ASDC J Dent Child 2000;67:132-135.

Mc Donell ST, O'Mullane DO: Fingernails, a fluoride biomarker - relevance of growth rate and length. J Dent Res 2001; 80(4):1145 (Abs 29).

Riordan PJ: Dental fluorosis decline after changes to supplement and dentifrice regimens. Comm Dent Oral Epidemiol 2002;30:233-240.

Schamschula RG, Sugar E, Un PSH, Toth K, Barmes DE, Adkins BL: Physiological indicators of fluoride exposure and utilization: An epidemiological study. Comm Dent Oral Epidemiol 1985;13:104-107.

Schmidt CW, Leuschke W: Fluoride content in finger nails of individuals with and without chronic fluoride exposure. Fluoride 1990;23:79-82.

Spate VL, Morris JS, Baskett CK, Mason MM, Reams CL, Hunter D et al.: Determination of fluoride in human nails via cyclic instrumental neutron activation analysis. J Radioanalyt Nucl Chem 1994;170:27-33.

Tabari ED et al.: Dental fluorosis in permanent incisor teeth in relation to water fluoridation, social deprivation and toothpaste use in infancy. Br Dent $\mathrm{J} 2000$; 189:216-20.

Warren JJ, Levy SM: A review of fluoride dentifrice related to dental fluorosis.

Pediatr Dent 1999;21:266-272.

Whitford GM: The metabolism and toxicity of fluoride. Basel, Karger, 1996.

Whitford GM, Sampaio FC, Arneberg P, von der Fehr FR: Fingernail fluoride: a method for monitoring fluoride exposure. Caries Res 1999;33:462-467. 
Table 1. Mean fluoride concentrations $( \pm S D$, unit $\mu \mathrm{g} / \mathrm{g})$ in fingernail and toenail clippings of 2-3 year-old children $(n=10)$ along the study.

\begin{tabular}{llll}
\hline Clipping & Date & Fingernail & Toenail \\
\hline 1 & $29-11-01^{\mathrm{a}}$ & $3.148 \pm 1.016$ & $2.454 \pm 1.391$ \\
2 & $13-12-01^{\mathrm{a}}$ & $2.870 \pm 0.497$ & $2.649 \pm 1.044$ \\
3 & $27-12-01^{\mathrm{a}}$ & $2.809 \pm 0.891$ & $2.721 \pm 0.494$ \\
4 & $10-01-02^{\mathrm{abc}}$ & $3.769 \pm 1.459$ & $4.209 \pm 1.717$ \\
5 & $24-01-02^{\mathrm{d}}$ & $7.251 \pm 5.682$ & $5.612 \pm 4.647$ \\
6 & $07-02-02^{\mathrm{abcd}}$ & $4.030 \pm 0.911$ & $4.395 \pm 1.720$ \\
7 & $21-02-02^{\mathrm{bcd}}$ & $5.985 \pm 3.387$ & $5.140 \pm 2.234$ \\
8 & $07-03-02^{\mathrm{abc}}$ & $4.757 \pm 2.557$ & $2.862 \pm 1.084$ \\
9 & $21-03-02^{\mathrm{ab}}$ & $3.692 \pm 1.250$ & $2.862 \pm 1.266$ \\
10 & $04-04-02^{\mathrm{a}}$ & $3.317 \pm 1.286$ & $3.029 \pm 0.968$ \\
11 & $18-04-02$ & $10.051 \pm 3.328$ & $9.186 \pm 3.862$ \\
12 & $02-05-02^{\mathrm{cd}}$ & $5.332 \pm 1.615$ & $6.526 \pm 3.013$ \\
13 & $16-05-02^{\mathrm{abcd}}$ & $4.412 \pm 1.071$ & $4.800 \pm 1.161$ \\
14 & $30-05-02^{\mathrm{ab}}$ & $3.258 \pm 1.302$ & $3.450 \pm 1.631$ \\
15 & $13-06-02^{\mathrm{a}}$ & $2.888 \pm 1.205$ & $2.588 \pm 1.385$ \\
16 & $27-06-02^{\mathrm{a}}$ & $2.480 \pm 0.734$ & $2.930 \pm 1.862$ \\
17 & $11-07-02^{\mathrm{a}}$ & $2.483 \pm 1.445$ & $2.916 \pm 1.252$ \\
18 & $25-07-02^{\mathrm{a}}$ & $2.245 \pm 1.004$ & $2.555 \pm 0.744$
\end{tabular}

Placebo dentifrice was used between 29-11-01 and 26-12-01. Fluoride dentifrice (1,570 ppm F) was used between 27-12-01 and 23-01-02. Placebo dentifrice was used again between 24-01-02 and 20-02-02, when the children returned to their usual dentifrices. The difference between fingernail and toenail clippings was not significant $(p>0.05)$. Thus, for significance among the different dates, the mean of fingernail and toenail clippings was considered. Dates with the same superscripts are not statistically different $(p>0.05)$. 


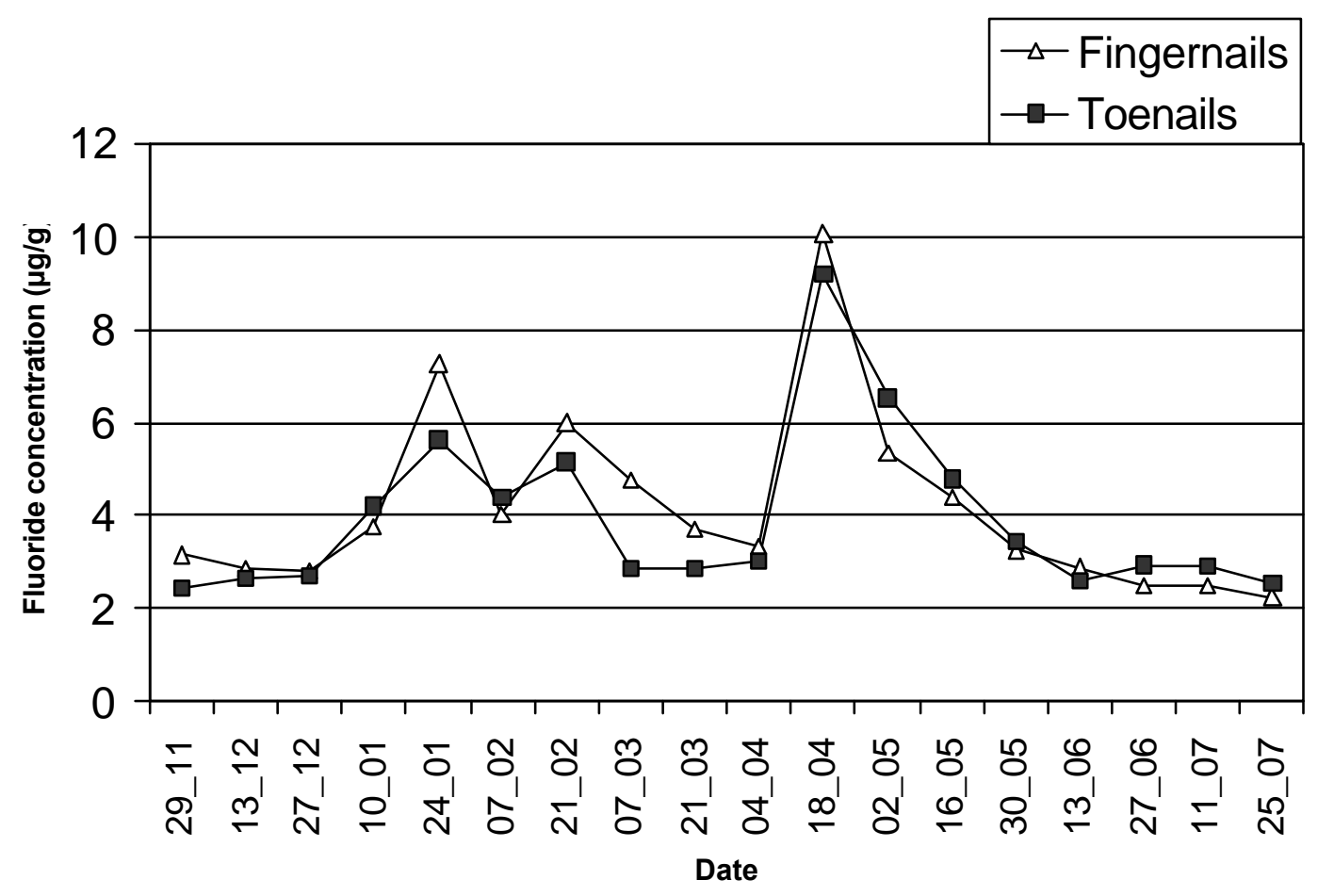

Figure 1. Time course of fluoride concentrations in fingernail and toenail clippings. Placebo dentifrice was used between 29-11-01 and 26-12-01. Fluoride dentifrice (1,570 ppm F) was used between 27-12-01 and 23-01-02. Placebo dentifrice was used again between 24-01-02 and 20-02-02, when the children returned to their usual dentifrices. 
Table 2. Fluoride concentration $(\mu \mathrm{g} / \mathrm{mL})$ of the water collected at the houses of the volunteers.

\begin{tabular}{lccccc}
\hline Dates & & \multicolumn{3}{c}{ Volunteers } \\
& $1-2-3^{*}$ & $4-5-6^{*}$ & $7-8^{\star *}$ & 9 & 10 \\
\hline $29-11-01$ & 0.854 & 0.908 & 0.302 & 0.854 & 0.685 \\
$13-12-01$ & 1.040 & 0.997 & 0.857 & 0.777 & 0.743 \\
$27-12-01$ & 0.975 & 0.993 & 0.928 & 0.813 & 0.813 \\
$10-01-02$ & 0.869 & 0.975 & 0.904 & 0.526 & 1.01 \\
$24-01-02$ & 0.921 & 0.971 & 0.881 & 0.217 & 0.691 \\
$07-02-02$ & 0.749 & 1.081 & 0.332 & 0.558 & 0.524 \\
$21-02-02$ & 0.885 & 1.147 & 0.58 & 0.956 & 0.802 \\
Mean & $0.899^{\mathrm{a}}$ & $1.010^{\mathrm{b}}$ & $0.683^{\mathrm{a}}$ & $0.672^{\mathrm{a}}$ & $0.753^{\mathrm{a}}$ \\
SD & 0.093 & 0.079 & 0.276 & 0.254 & 0.149 \\
\hline
\end{tabular}

*Triplets.

** Twins.

${ }^{* * *}$ Means followed by different letters are statistically different $(p<0.05)$. 